\title{
Analysis of Cost Reduction Potential of Vertical Bore Ground Heat Exchanger
}

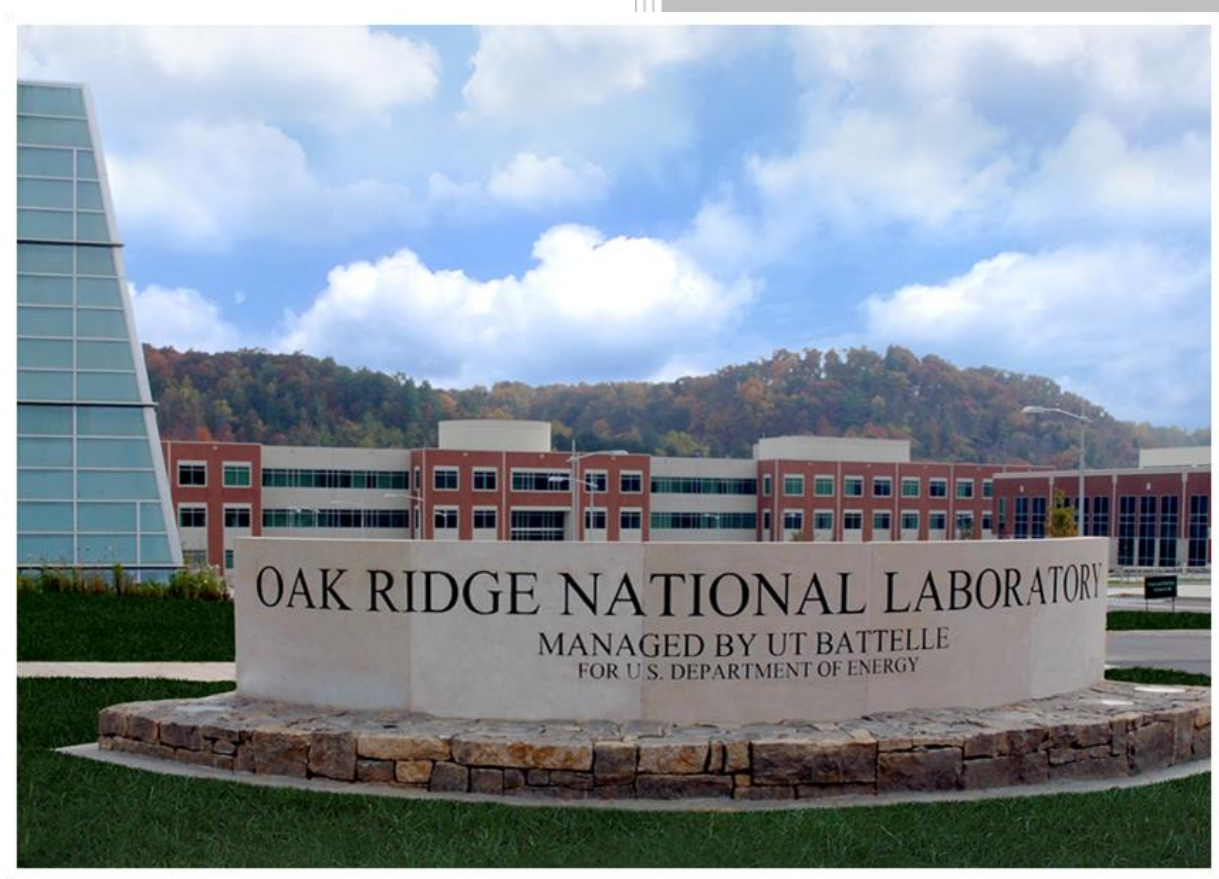

Approved for public release.

Distribution is unlimited

Xiaobing Liu

Yarom Polsky

Defeng Qian (University of

Alabama)

Josh Mcdonald (University of

Tennessee)

August 2018 


\title{
DOCUMENT AVAILABILITY
}

Reports produced after January 1, 1996, are generally available free via US Department of Energy (DOE) SciTech Connect.

Website http://www.osti.gov/scitech/

Reports produced before January 1, 1996, may be purchased by members of the public from the following source:

\author{
National Technical Information Service \\ 5285 Port Royal Road \\ Springfield, VA 22161 \\ Telephone 703-605-6000 (1-800-553-6847) \\ TDD 703-487-4639 \\ Fax 703-605-6900 \\ E-mail info@ntis.gov \\ Website http://classic.ntis.gov/
}

Reports are available to DOE employees, DOE contractors, Energy Technology Data Exchange representatives, and International Nuclear Information System representatives from the following source:

Office of Scientific and Technical Information

PO Box 62

Oak Ridge, TN 37831

Telephone 865-576-8401

Fax 865-576-5728

E-mail reports@osti.gov

Website http://www.osti.gov/contact.html

This report was prepared as an account of work sponsored by an agency of the United States Government. Neither the United States Government nor any agency thereof, nor any of their employees, makes any warranty, express or implied, or assumes any legal liability or responsibility for the accuracy, completeness, or usefulness of any information, apparatus, product, or process disclosed, or represents that its use would not infringe privately owned rights. Reference herein to any specific commercial product, process, or service by trade name, trademark, manufacturer, or otherwise, does not necessarily constitute or imply its endorsement, recommendation, or favoring by the United States Government or any agency thereof. The views and opinions of authors expressed herein do not necessarily state or reflect those of the United States Government or any agency thereof. 
Environment and Transportation Science Division

\title{
ANALYSIS OF COST REDUCTION POTENTIAL OF VERTICAL BORE GROUND HEAT EXCHANGER
}

\author{
Xiaobing Liu \\ Yarom Polsky \\ Defeng Qian (University of Alabama) \\ Josh Mcdonald (University of Tennessee)
}

Date Published: August 2018

\author{
Prepared by \\ OAK RIDGE NATIONAL LABORATORY \\ Oak Ridge, TN 37831-6283 \\ managed by \\ UT-BATTELLE, LLC \\ for the \\ US DEPARTMENT OF ENERGY \\ under contract DE-AC05-00OR22725
}





\section{CONTENTS}

List of Figures

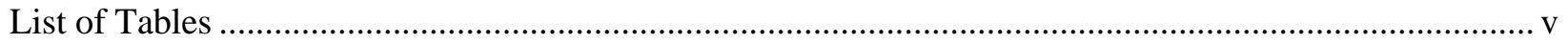

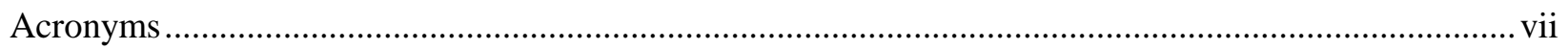

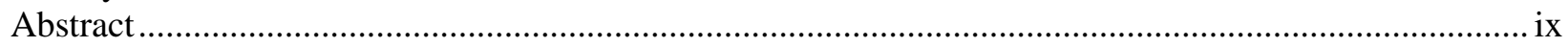

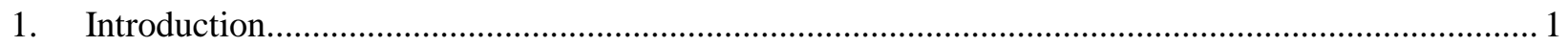

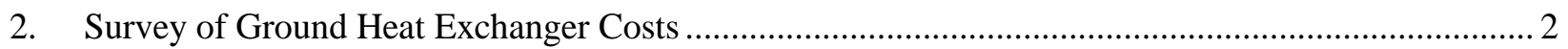

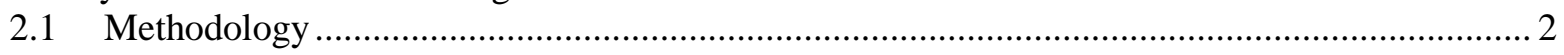

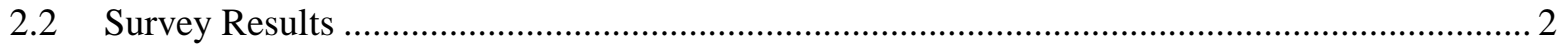

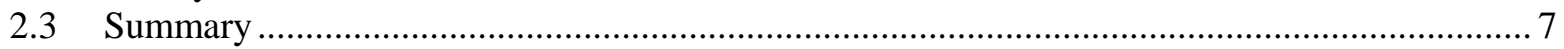

3. Cost Model of Vertical Bore Ground Heat Exchangers …...................................................... 7

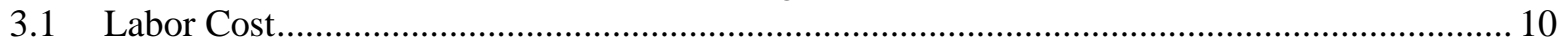

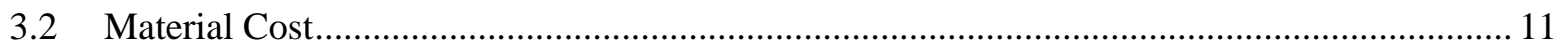

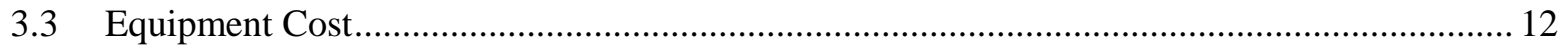

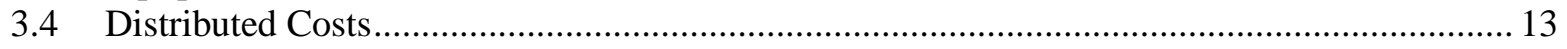

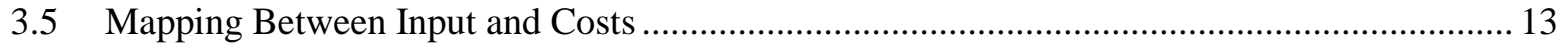

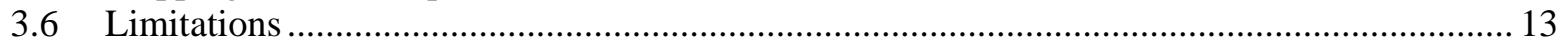

4. Cost Analysis of Typical Vertical Bore Ground Heat Exchangers................................................. 14

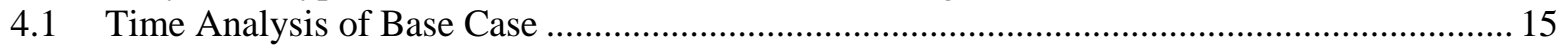

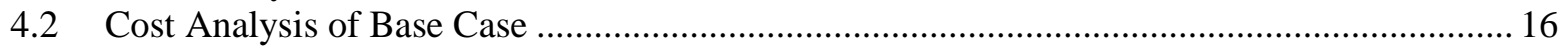

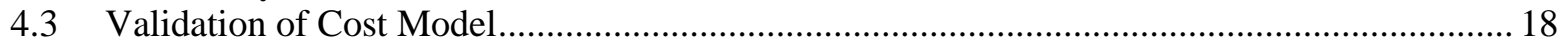

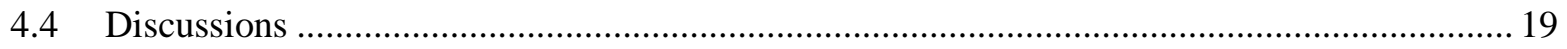

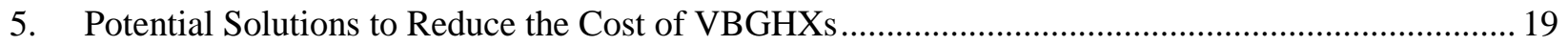

5.1 Improvements in Drilling Process.................................................................................. 19

5.1.1 Overview of Conventional Drilling Technologies for VBGHX Installation ............... 19

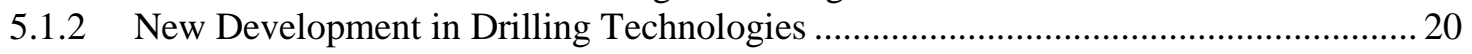

5.2 Improvements in Borehole Heat Transfer..................................................................... 21

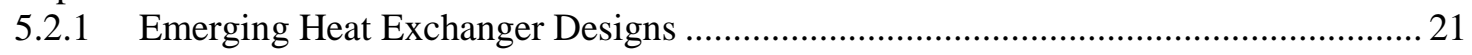

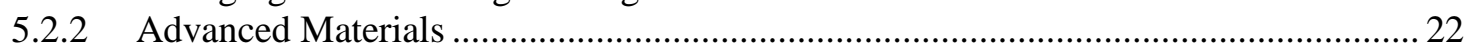

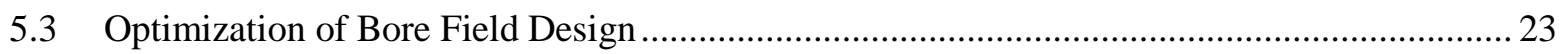

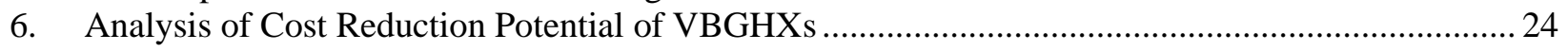

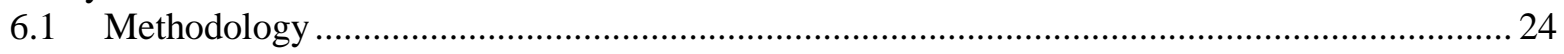

6.1.1 Reference Building and Baseline VBGHX Design ..............................................2 25

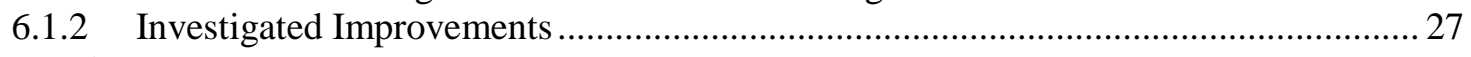

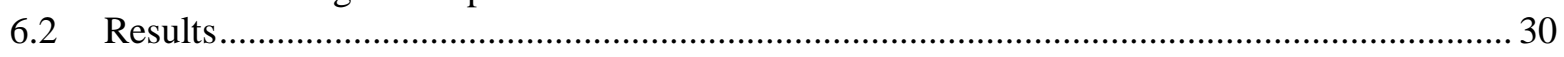

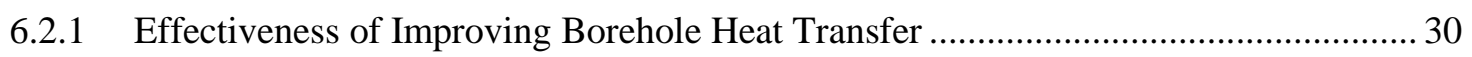

6.2.2 Effectiveness of Improving Bore Field Design.................................................... 33

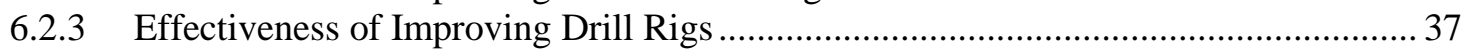

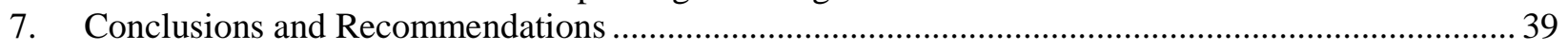

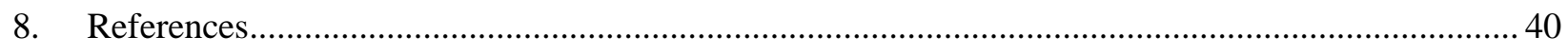

Appendix A. Survey Questionnaires........................................................................................ 1

Appendix B. A Brief Description of Major Tasks for Installing Ground Heat Exchangers ........................ 1

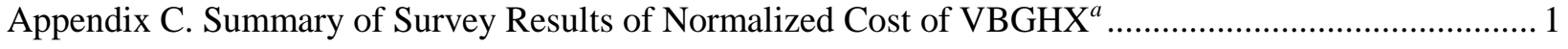





\section{LIST OF FIGURES}

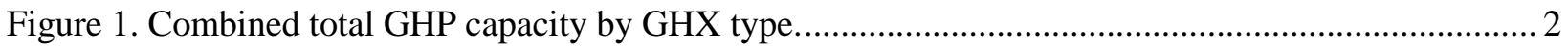

Figure 2. Combined total GHP capacity by heat exchanger loop.................................................... 3

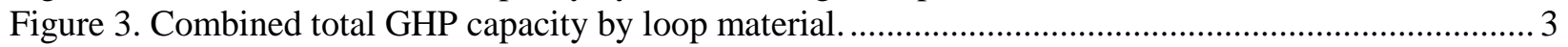

Figure 4. Survey results of vertical bore depth and horizontal trench length. ......................................... 4

Figure 5. Survey results of the normalized costs (dollars per cooling ton) of various GHX types.............. 4

Figure 6. Survey results of the normalized costs (dollars per linear foot) of vertical bores and

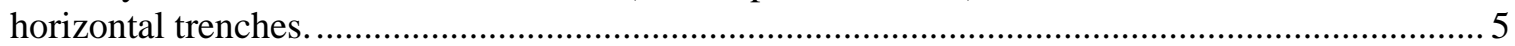

Figure 7. Survey results of vertical bore drilling costs at various ground formations. .............................. 5

Figure 8. Survey results of drilling rigs used for installing vertical bore GHXs. .................................... 6

Figure 9. Survey results of the ROP of typical drill rigs used for installing GHXs.................................. 6

Figure 10. Survey results of vertical bore drilling costs and ROP...................................................... 7

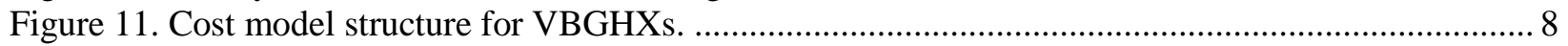

Figure 12. Costs of labor, material, and equipment associated with each task..................................... 17

Figure 13. Percentage of each task in the overall costs of labor, material, and equipment. ...................... 17

Figure 14. Task costs resulting from different ground formations. ...................................................... 18

Figure 15. A comparison of VBGHX costs at different ground formations: model predicted vs.

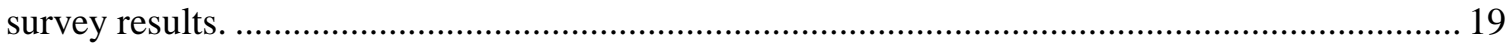

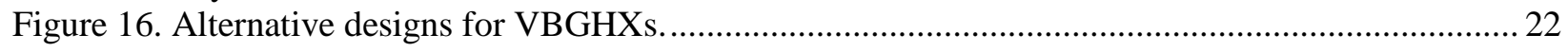

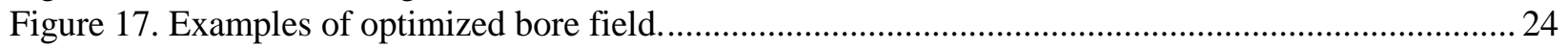

Figure 18. Procedure for evaluating cost reduction of improvements in VBGHXs. ............................... 25

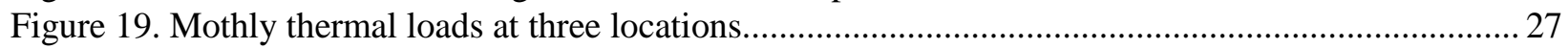

Figure 20. Bore field configuration with increased bore spacing within a fixed land area...................... 29

Figure 21. Percentages of total bore length reduction resulting from improvements in borehole

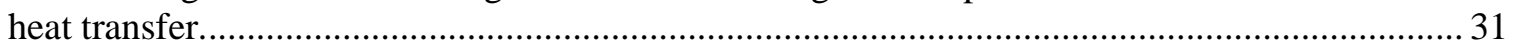

Figure 22. Changes of borehole heat exchanger cost resulting from improvements in borehole

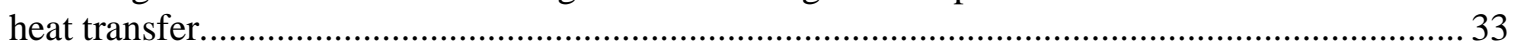

Figure 23. Changes in (a) total bore depth of a bore field and (b) depth of individual borehole resulting from increasing bore spacing (with high GTC $\left.-2 \mathrm{Btu} /\left[\mathrm{h}-\mathrm{ft}-{ }^{\circ} \mathrm{F}\right]\right)$.................................. 34

Figure 24. Changes in (a) total bore depth of a bore field and (b) depth of individual borehole

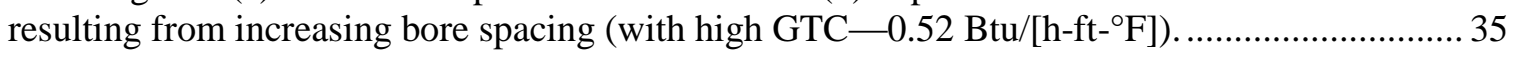

Figure 25. Changes in total bore field cost resulting from improving borehole heat transfer and

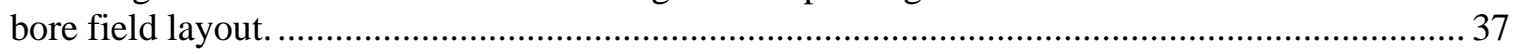

Figure 26. Reduction in normalized borehole heat exchanger cost resulting from increased rate of

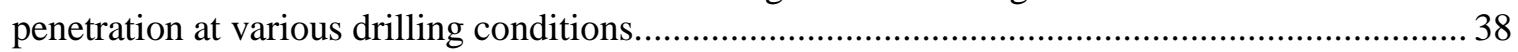

Figure 27. Reduction in normalized borehole heat exchanger cost redulting from a $25 \%$ increase in the rate of penetration at various drilling conditions under three price change scenarios. ......... 38

\section{LIST OF TABLES}

Table 1. Items for calculating the installed cost of individual VBGHXs ............................................. 9

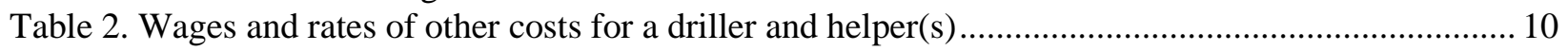

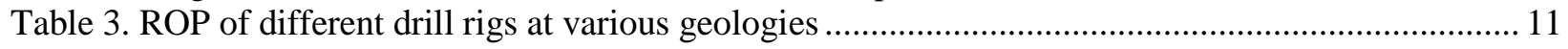

Table 4. Typical prices of materials used for implementing VBGHXs ................................................. 12

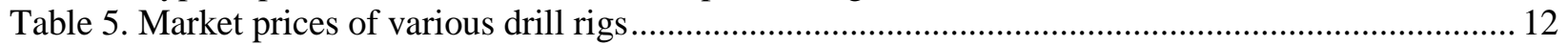

Table 6. Mapping between component costs and major input and parameters....................................... 14

Table 7. Time breakdown for each step of implementing an individual BHE.......................................... 15

Table 8. Cost breakdown for each step of implementing an individual BHE......................................... 16 
Table 9. Comparison of various drilling methods used for installing VBGHXs ....................................2 20

Table 10. Thermal conductivities of various grouting materials ......

Table 11. Thermal properties of four different ground formations....

Table 12. Borehole heat exchanger designs of baseline and improved cases ..........................................28

Table 13. Prices of improved materials and loops used for borehole heat exchangers 


\section{ACRONYMS}

$\begin{array}{ll}\text { BD } & \text { bore diameter } \\ \text { BHE } & \text { borehole heat exchanger } \\ \text { BTR } & \text { borehole thermal resistance } \\ \text { DOE } & \text { US Department of Energy } \\ \text { GHP } & \text { geothermal heat pump } \\ \text { GHX } & \text { ground heat exchanger } \\ \text { GSHP } & \text { ground source heat pump } \\ \text { GTC } & \text { ground thermal conductivity } \\ \text { HDPE } & \text { high-density polyethylene } \\ \text { HVAC } & \text { heating, ventilation, and air conditioning } \\ \text { IGSHPA } & \text { International Ground Source Heat Pump Association } \\ \text { PCM } & \text { phase change material } \\ \text { R\&D } & \text { research and development } \\ \text { ROP } & \text { rate of penetration } \\ \text { SCW } & \text { standing column wells } \\ \text { TE } & \text { thermally enhanced } \\ \text { VBGHX } & \text { vertical bore ground heat exchanger } \\ \text { WAHP } & \text { water-to-air heat pump }\end{array}$





\begin{abstract}
The geothermal heat pump (GHP), also referred to as a ground source heat pump, is a proven technology that can provide space conditioning and water heating with efficiencies higher than conventional heating, ventilation, and air-conditioning (HVAC) systems. This technology possesses great potential to become a mainstream technology for satisfying the thermal demands in the built environment. Analysis from the ongoing Geothermal Vision Study indicates that $100 \%$ retrofitting of commercial and residential markets with GHPs has the potential to save on the order of 6 quadrillion Btu per year (Liu et al. 2017). However, the current high installation costs and long payback periods limit the attractiveness of GHP installation in the United States. The cost of installing ground heat exchangers (GHXs) used for GHPs accounts for more than $30 \%$ of the total cost of a GHP system (NYSERDA 2017), and it is the biggest contributor to the cost premium of GHPs compared with conventional HVAC systems.
\end{abstract}

Information on the current practice for GHX design, installation, and associated costs was collected through a national survey. In addition, possible improvements in GHX design and borehole drilling were investigated through an extensive literature review, as well as discussions with industry professionals and technology providers. An existing cost model for the closed-loop vertical bore ground heat exchanger (VBGHX), which is the most commonly used GHX in the United States, was updated and expanded to account for various borehole heat exchanger (BHE) designs, geological conditions, and drilling technologies. This updated cost model can predict a detailed cost breakdown for each task of the installation processes.

This study systematically analyzed the installation processes and associated costs of the VBGHX to identify research and development $(R \& D)$ pathways that can significantly reduce installation costs and improve GHP market penetration in both the commercial and residential sectors. Emphasis was placed on the potential of novel methods to ease/improve subsurface component placement and minimize the required drilling by improving the heat transfer performance of BHE and optimizing the bore field design. Baseline specifications were first developed for typical installation scenarios that cover a large fraction of the residential and commercial market. These installation scenarios were then subjected to operational and cost analyses to identify the key technologies and economic drivers in the installation process. Coupled with a widely accepted VBGHX sizing program, a systematic study was conducted to assess the potential of various technology improvements in reducing the needed total drilling length and the associated cost under various geological and thermal loading conditions. Various improvements in borehole heat transfer, borehole field design, and drilling technologies were included in this assessment. Finally, recommendations were made for reducing the installed cost of VBGHX while retaining performance.

The main findings of this study are summarized in the following:

- Among the investigated individual BHE improvements, thermally enhanced grout and double Utube loop are the most effective measures in reducing the required bore length for satisfying a given thermal load.

- Ground thermal conductivity (GTC) value determines the achievable bore length reduction resulting from a given BHE improvement. At places with high GTC value, more than $60 \%$ reduction in bore length can be achieved by applying the thermally enhanced grout and the double U-tube loop.

- BHE improvement alone results in moderate (less than 30\%) reduction in the installed cost of VBGHX at places with a high GTC value (higher than $1.4 \mathrm{Btu} / \mathrm{h}-\mathrm{ft}-{ }^{\circ} \mathrm{F}$ ), but it might result in an increase of the installed cost at places with a low GTC value. 
- For VBGHXs that are composed of multiple BHEs, which is common in commercial GHP systems, increasing the spacing among vertical bores and the depth of each individual vertical bore can reduce the total number and length of the vertical bores. It can also significantly reduce the cost of the VBGHXs. Combining the BHE improvements and optimal borehole field design, the cost of VBGHXs can be reduced by $50 \%$.

- A higher rate of penetration (ROP) of drilling can shorten drilling time, which will reduce the associated labor and equipment cost for installing a VBGHX. Assuming the drill rig cost is unchanged, a $25 \%$ increase in ROP can result in 6\%-16\% reduction in the installed cost of VBGHX depending on the ground formation and whether casing is used. However, the cost reduction might become smaller if the higher ROP is achieved with more expensive drill rigs.

The following R\&D is recommended to reduce the cost of VBGHXs:

- Improve mobility and automation of drill rigs to reduce the time and labor needed for drilling vertical boreholes.

- Develop new BHE designs that require less drilling but offer the same performance.

- Expand the capabilities of VBGHX sizing programs to allow optimization of borehole field design to reduce the total length of boreholes while satisfying the thermal demands of a building. 


\section{INTRODUCTION}

The geothermal heat pump (GHP), also referred to as a ground source heat pump (GSHP), is a proven technology that can provide space conditioning and water heating with efficiencies higher than conventional heating, ventilation, and air-conditioning (HVAC) systems. This technology possesses great potential to become a mainstream technology for satisfying thermal demands in the built environment. A recent analysis (Liu et al. 2018) indicates that retrofitting the space heating and cooling systems of all existing commercial and residential buildings in the United States with GHPs has the potential to save 5.7 quadrillion Btu per year. However, the current high installation costs and long payback period limit the attractiveness of GHP installation in the United States. The cost for installing ground heat exchangers (GHXs) used for GHPs accounts for more than 30\% of the total cost of a GHP system (NYSERDA 2017), and it is the biggest contributor to the cost premium of GHPs compared with conventional HVAC systems.

The various types of GHXs used for GHPs are usually categorized based on the ground sources, fluid circulation (e.g., in a closed loop or open loop), and the heat exchanger designs (e.g., a single pipe, multiple pipes, coiled pipes, coaxial pipes, or other types of heat exchangers). Following the ASNI/CSA standard C448 (CSA 2016), the categorization of GHX is listed below:

- Ground-coupled closed-loop vertical bore ground heat exchanger (VBGHX)

- Ground-coupled closed-loop horizontal GHX

- Ground-coupled direct expansion

- Surface water with submerged exchangers

- Groundwater open-loop

- Groundwater standing column well

It was estimated that $46 \%$ of the existing GHP systems use closed-loop VBGHXs and $38 \%$ use closedloop horizontal GHXs. The remaining $16 \%$ use groundwater or surface water in an open-loop or closedloop configuration (Lund 2001).

Considering the market share of various GHXs, this study focuses on VBGHXs. The installation processes and associated costs of VBGHXs is systematically analyzed to identify research and development $(R \& D)$ pathways that can significantly reduce installation costs and improve GHP market penetration in both the commercial and residential sectors. Emphasis was placed on the potential for novel methods to ease/improve subsurface component placement and minimize the required drilling by improving the heat transfer performance of the borehole heat exchanger (BHE) and optimizing the bore field design.

The report describes the assessment basis, methodology, and findings. Section 2 introduces the results of a survey on the current practice of GHX installation and cost. Section 3 presents a detailed cost model for VBGHXs. Section 4 analyzes the time and cost breakdown of typical installation scenarios (base cases) that cover a large fraction of the residential and commercial market. Section 5 reviews possible solutions for reducing the cost of VBGHXs. Section 6 discusses the methodology, assumptions, and results of an assessment of cost reduction potential of VBGHXs resulting from improved BHE designs, optimized bore field layout, and advanced drilling rigs. Section 7 draws conclusions and recommends solutions and needed R\&D to reduce the cost of VBGHXs. 


\section{SURVEY OF GROUND HEAT EXCHANGER COSTS}

\subsection{METHODOLOGY}

A survey questionnaire was designed to collect information about the typical design and installation practices for various GHXs. The survey was organized into five sections: (1) general information about survey respondents, (2) specifications of GHXs, (3) specifications of drilling and grouting, (4) other nondrilling costs (e.g., site survey, site restoration), and (5) comments on possible solutions to reduce GHX cost. A complete survey questionnaire and a list of received comments is provided in Appendix A.

This survey was conducted through several channels, including an online forum of the International Ground Source Heat Pump Association (IGSHPA), the mailing list of IGSHPA-certified installers, and other social media, such as LinkedIn. Although only 8 responses were received, the collected information was still valuable since all the survey respondents had more than 10 years' experience in the GHP industry.

\subsection{SURVEY RESULTS}

Figures 1 through 3 show survey results of the combined total GHP capacity installed/designed by all the survey respondents. The combined total GHP capacity is categorized by GHX type (Figure 1), heat exchanger loop (Figure 2), and loop materials (Figure 3). These figures indicate that VBGHXs are most commonly used and that the most common design of VBGHXs use single U-tube heat exchanger loops made with high-density polyethylene (HDPE) pipes. In a single U-tube design, the heat transfer fluid flows down one leg of a U-shaped plastic tube and flows up through the other. The space between the Utube and the borehole wall is filled with grout to prevent water and contaminants from migrating along the vertical borehole. The double U-tube design uses two U-tubes, which are connected in parallel, in the vertical bore. The coaxial design contains an inner pipe and an outer pipe. Heat transfer fluid flows down through the annular between the two pipes and flows up through the inner pipe, or in a reversed direction. The annular between the outer pipe and the borehole wall is filled with grouting materials. Survey respondents used various brands of grouting materials, including both standard and thermally enhanced grouts.

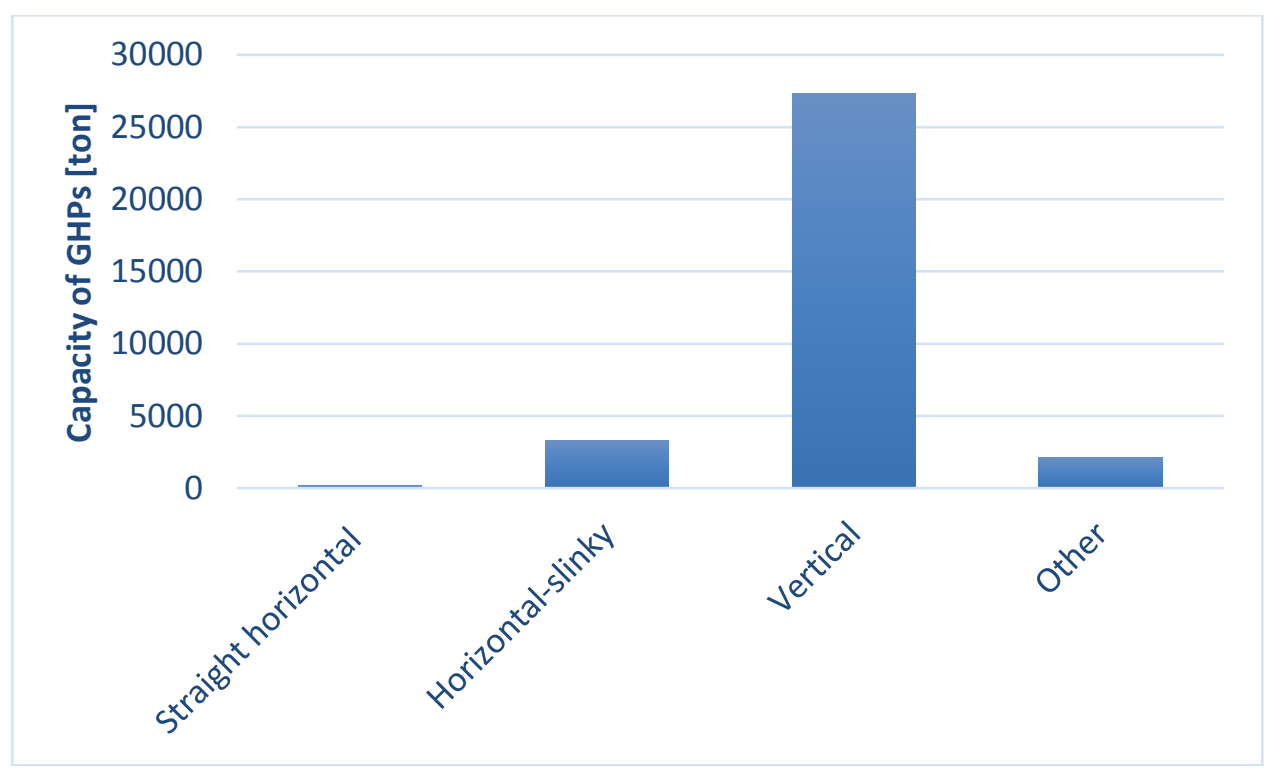

Figure 1. Combined total GHP capacity by GHX type. 


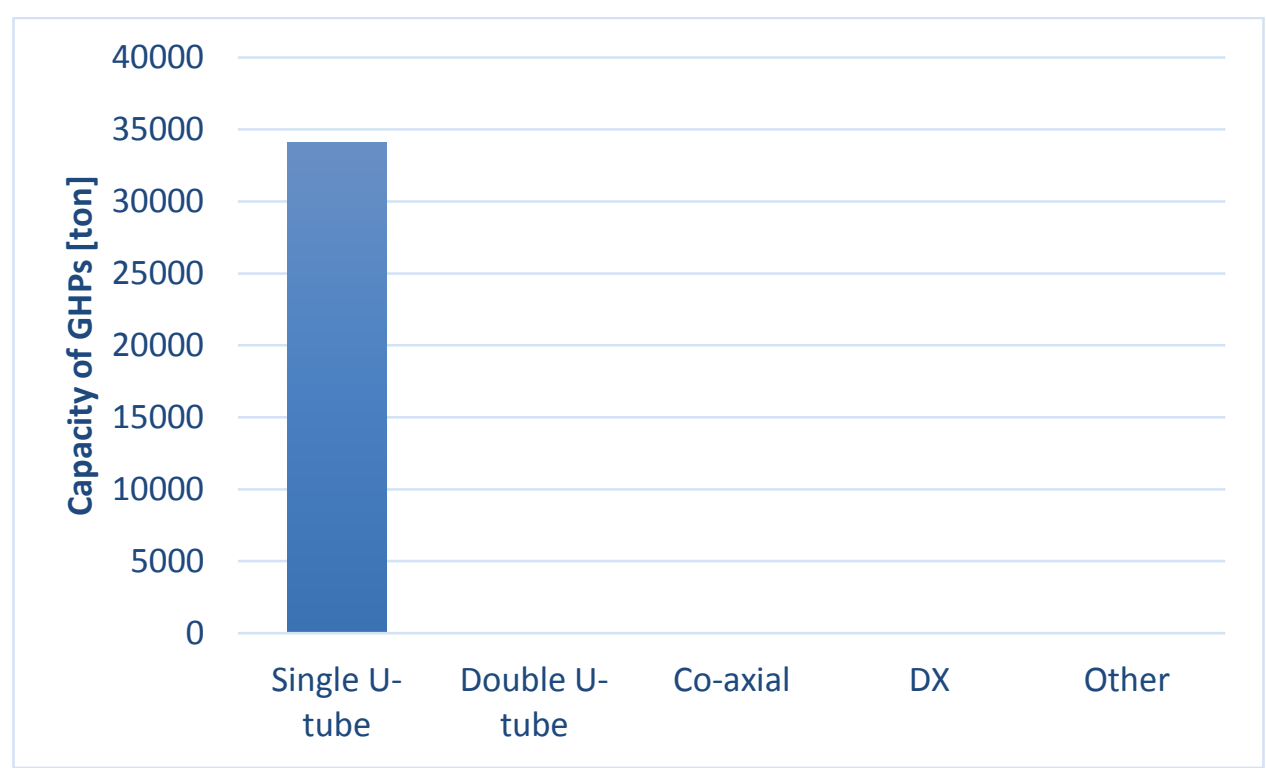

Figure 2. Combined total GHP capacity by heat exchanger loop.

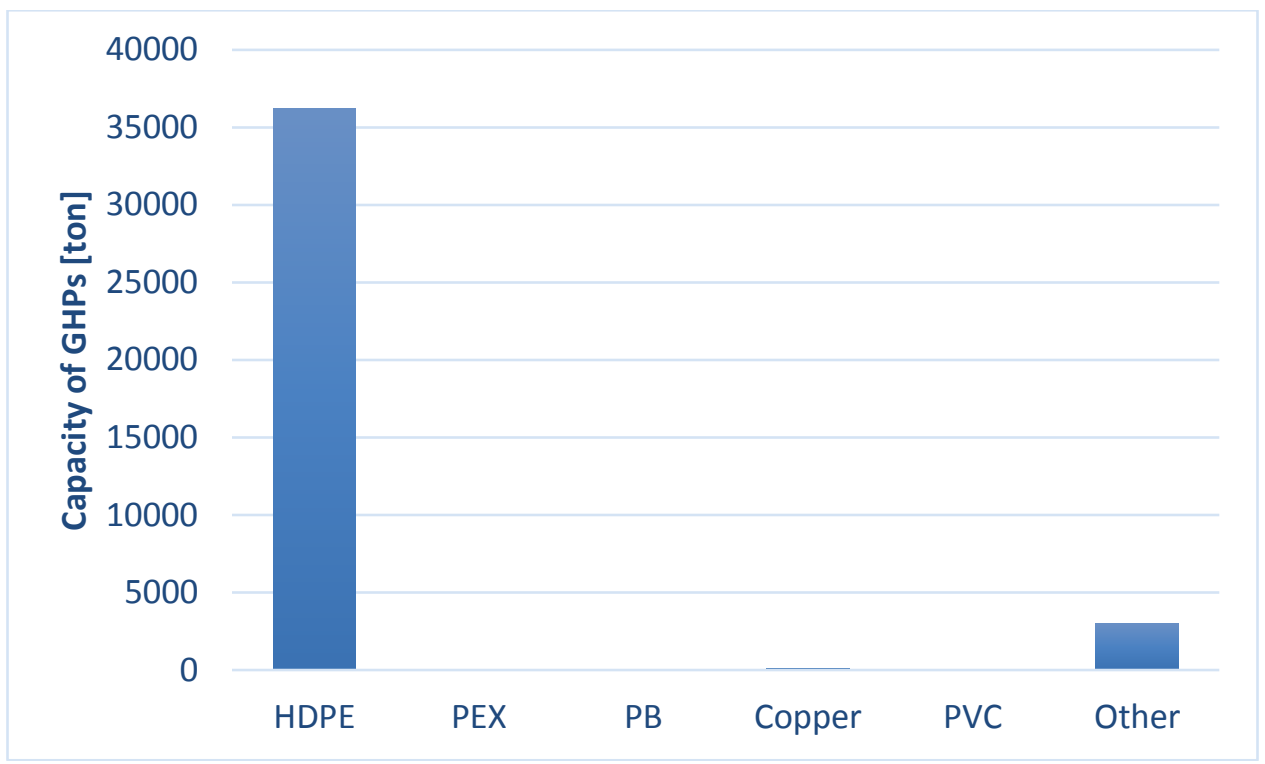

Figure 3. Combined total GHP capacity by loop material.

Figure 4 shows the survey results of the depth of vertical bores and the lengths of horizontal trenches with a box plot $^{1}$. The length of the horizontal trench varies from 60 to $500 \mathrm{ft}$ with an average of $275 \mathrm{ft}$, while the typical depth of the vertical bore is between 200 and $400 \mathrm{ft}$ with an average of $328 \mathrm{ft}$. Survey results indicate that the diameters of vertical bores vary from 4.25 to 6 in. (typically within $4.75-5.75$ in.).

\footnotetext{
${ }^{1}$ A box plot is a method for graphically depicting groups of numerical data through their quartiles. By default, the box is determined by the 25 th and 75 th percentiles. The band inside the box is always the second quartile (the median). The whiskers outside the box are determined by the 5th (lower) and 95th (upper) percentiles.
} 


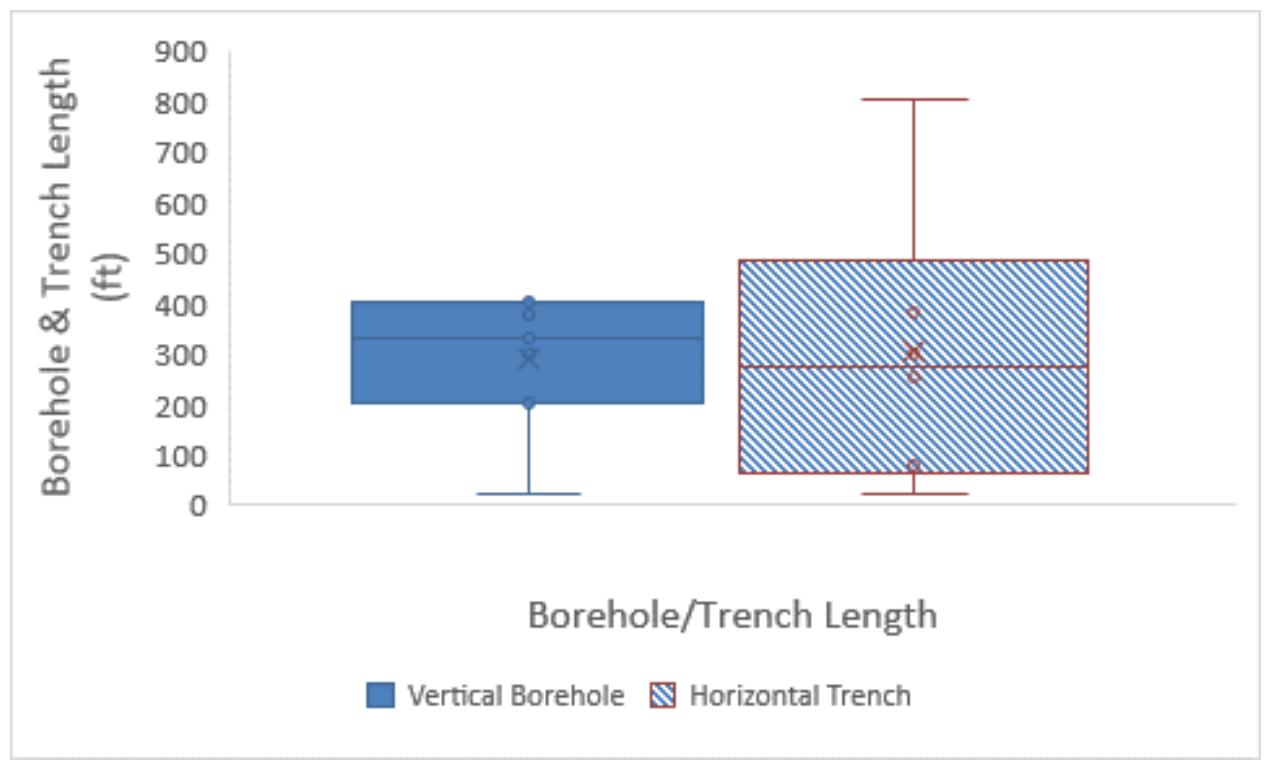

Figure 4. Survey results of vertical bore depth and horizontal trench length.

Figure 5 shows the survey results of the normalized costs (dollars per cooling ton) of various GHX types with a box plot. It indicates that VBGHXs are more expensive than other types of GHXs. The normalized costs of VBGHX vary from $\$ 1,600 /$ ton to $\$ 4,250 /$ ton, and the average is $\$ 2,350 /$ ton. The average normalized cost of the horizontal-slinky GHXs is just slightly higher than that of the straight horizontal GHXs. The "other" GHX is standing column wells (SCW), as indicated by the survey respondent. SCW is a semi-open loop system that uses groundwater to provide a heat sink and source for GHP systems.

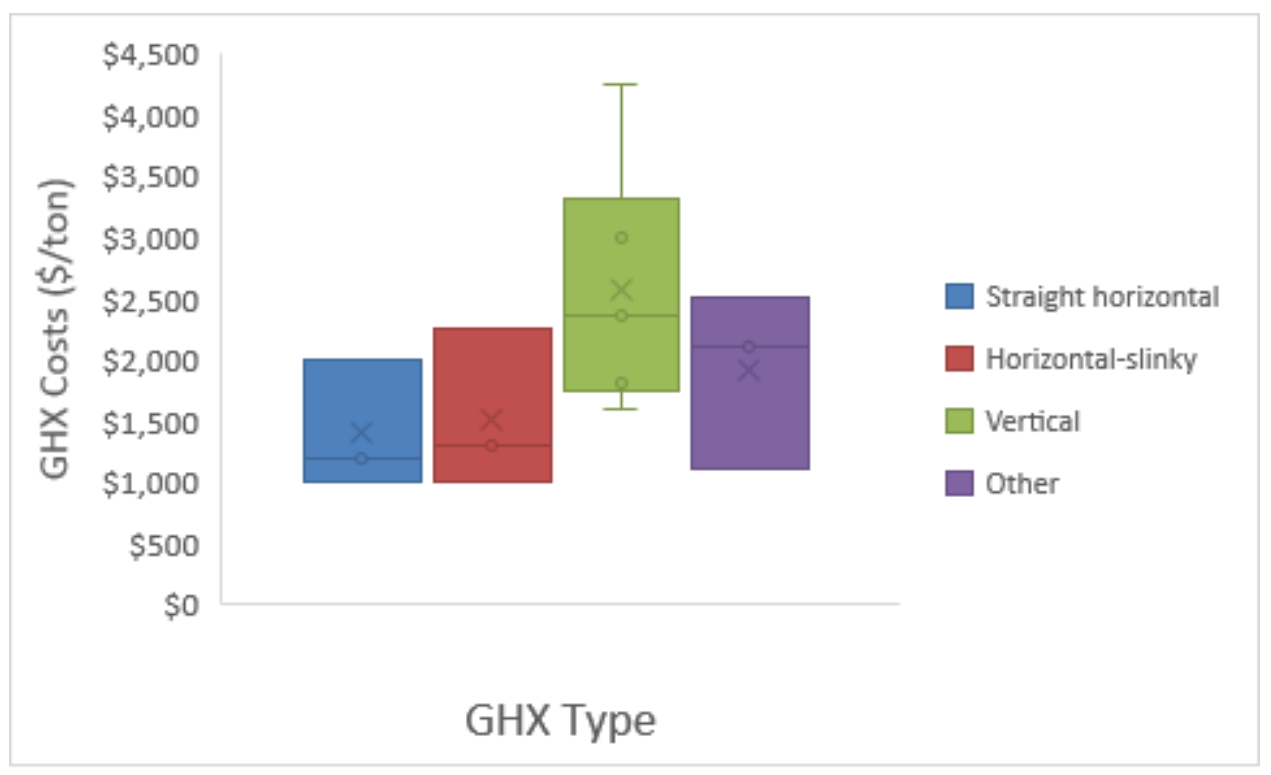

Figure 5. Survey results of the normalized costs (dollars per cooling ton) of various GHX types.

Figure 6 shows the survey results of the normalized costs of horizontal trenches (dollars per linear foot of horizontal trench) and vertical bores (dollars per linear foot of vertical bore). The cost of drilling vertical bores varies widely $(\$ 5.0-\$ 15.5 / \mathrm{ft})$ and is about twice the cost of digging horizontal trenches. 


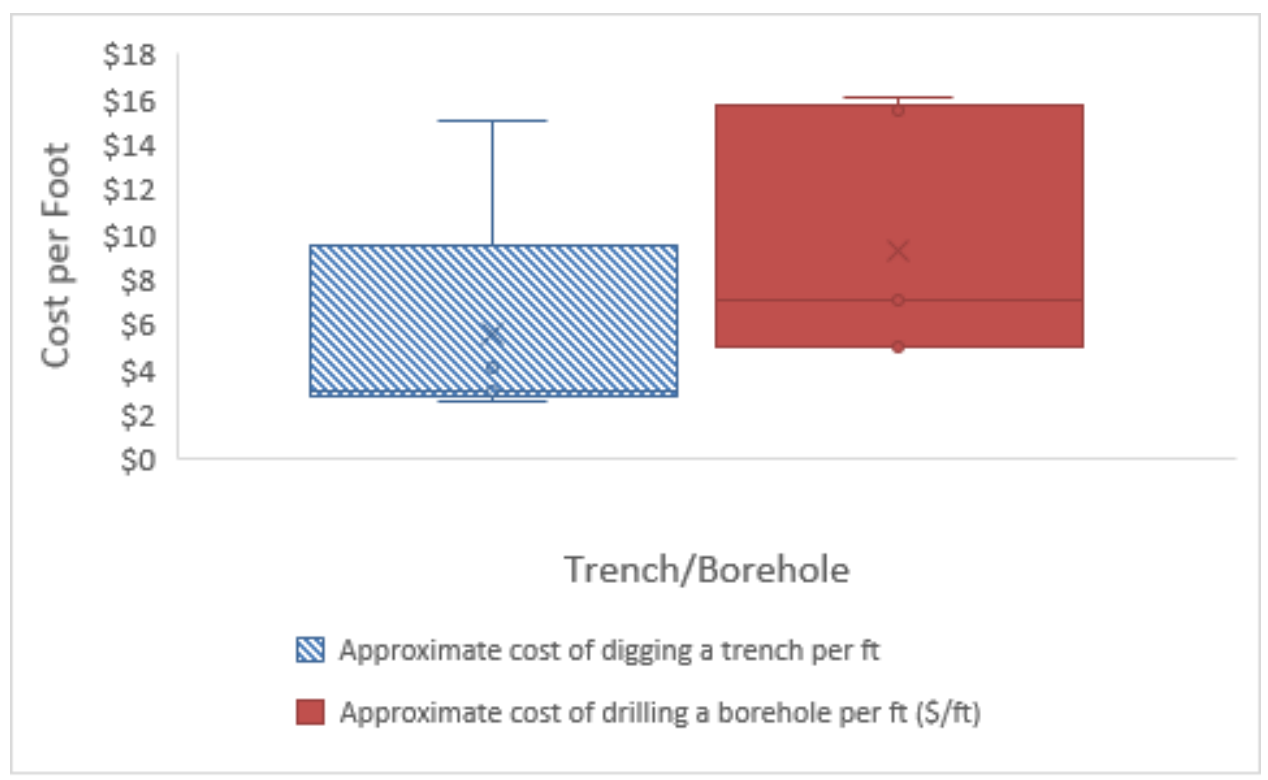

Figure 6. Survey results of the normalized costs (dollars per linear foot) of vertical bores and horizontal trenches.

Most survey respondents indicated that the cost of vertical bore drilling depends on the geological formations encountered during drilling. As can be seen in Figure 7, the normalized drilling cost is below $\$ 10 / \mathrm{ft}$ when drilling in drift, shale, sandstone, or limestone, but it could cost more than $\$ 15 / \mathrm{ft}$ when drilling in granite.

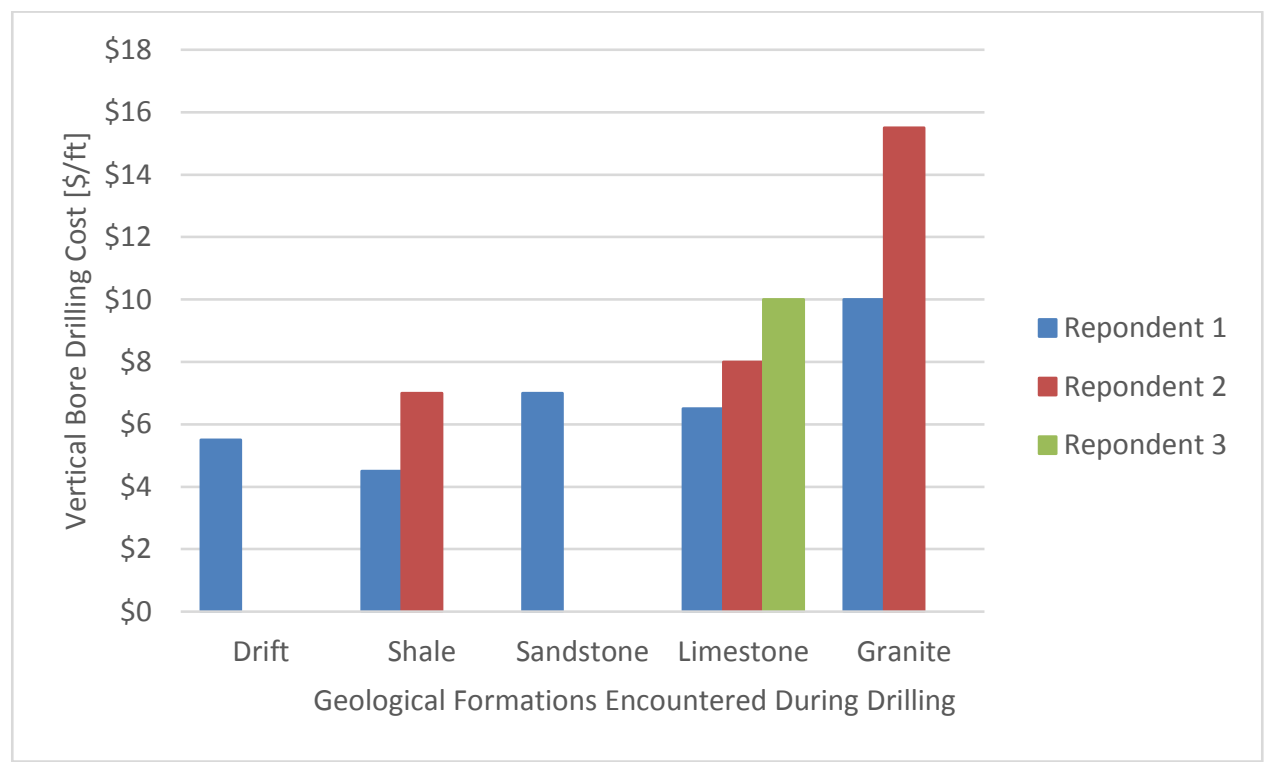

Figure 7. Survey results of vertical bore drilling costs at various ground formations.

Figure 8 shows the survey results of the drilling rigs used for installing VBGHXs. It indicates that air rotary, mud rotary, and downhole hammer are the most commonly used drilling rigs. Survey results also indicate that a driller might prefer (or is more familiar with) one type of drilling rig and use it more often than others. 


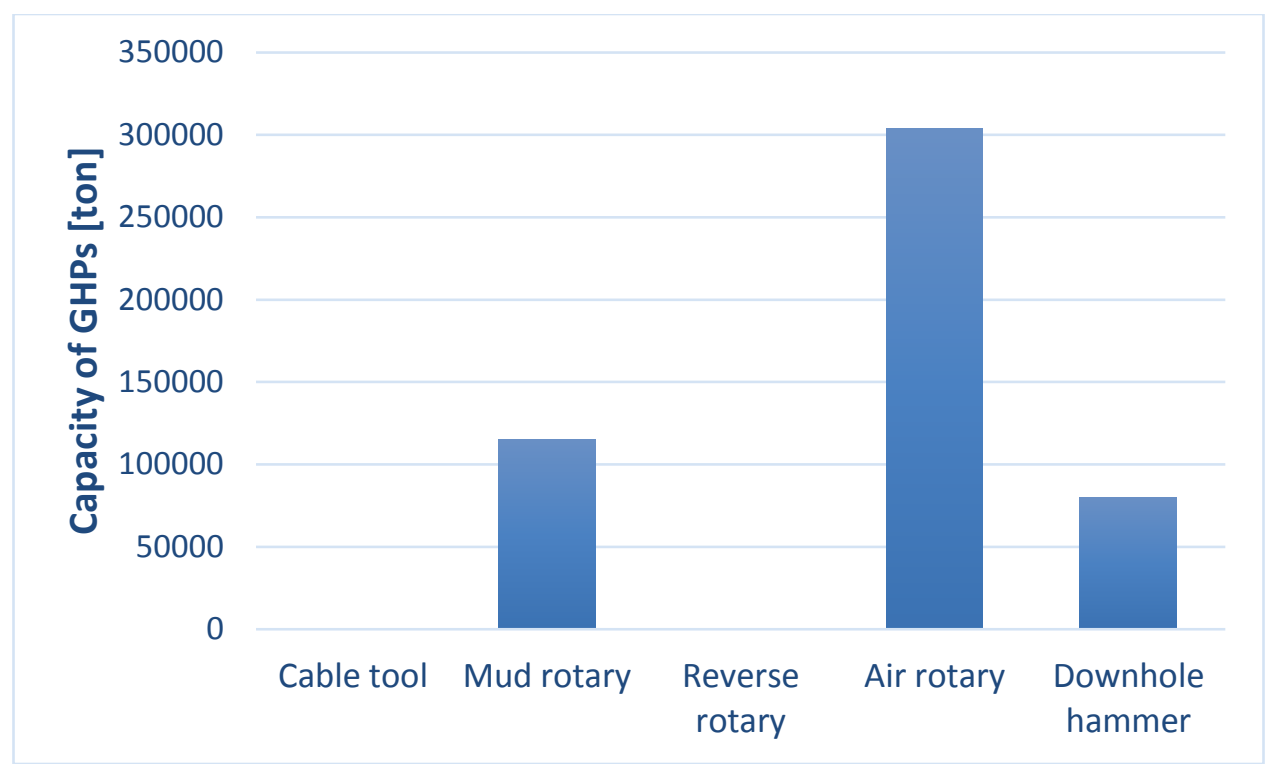

Figure 8. Survey results of drilling rigs used for installing vertical bore GHXs.

Figure 9 shows the survey results of the average rate of penetration (ROP) of the drilling process. As indicated by the box chart, ROP varies from 50 to $200 \mathrm{ft} / \mathrm{h}$ and the typical range (i.e., within the $25 \mathrm{th}$ and 75 th quartiles) is $60-150 \mathrm{ft} / \mathrm{h}$. Survey results indicate that the ROP is affected by the geological formations encountered during drilling. Previous studies (Kahraman 2003 and Kivade et al. 2015) found that ROP is affected by the mechanical characteristics of rock (e.g., modulus ratio and compressive strength). As discussed in Section 3, a correlation between ground formation and ROP was developed based on available information in the literature and it is used in a cost model to calculate the needed drilling time at a given ground formation.

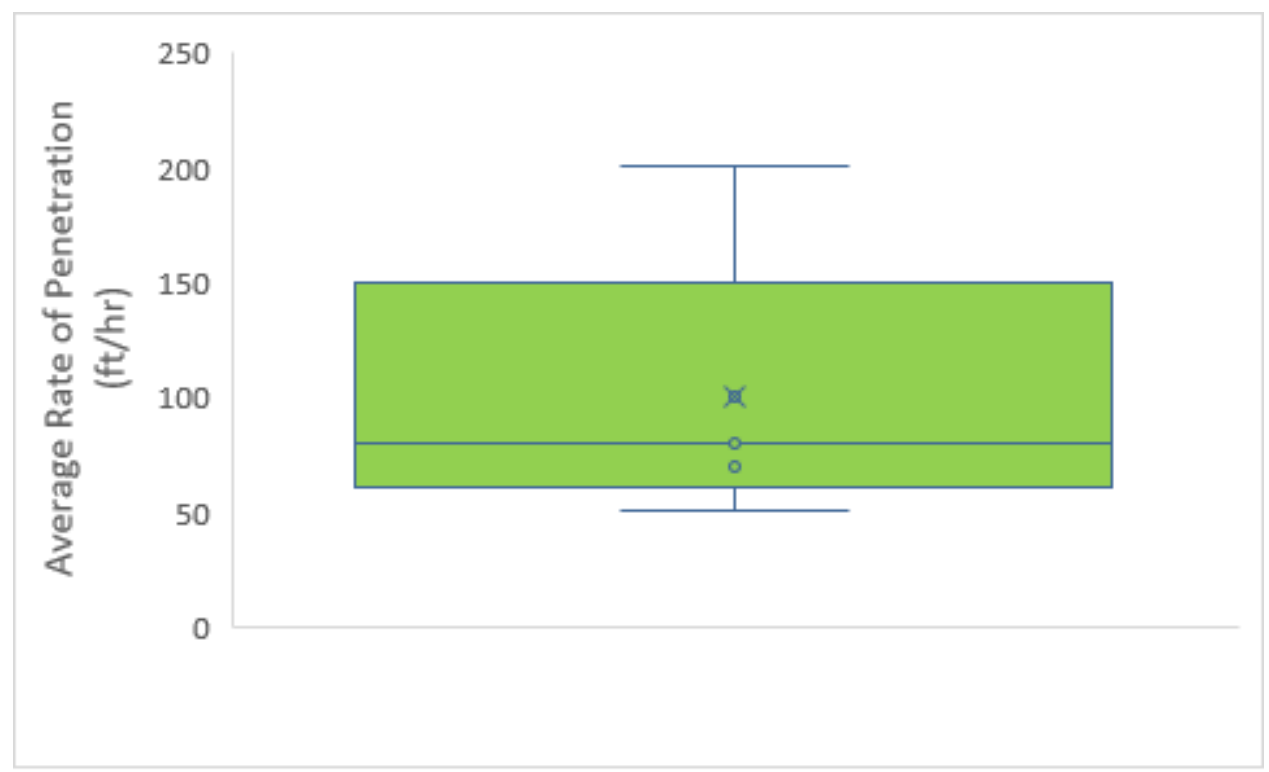

Figure 9. Survey results of the ROP of typical drill rigs used for installing GHXs.

Figure 10 shows the survey results of ROP and the associated drilling cost. The trend line (dotted line) of the available data indicates that the drilling cost decreases with the increase of ROP. The outlier $(\$ 16 / \mathrm{ft}$ drilling cost at $70 \mathrm{ft} / \mathrm{h} \mathrm{ROP}$ ) is from a survey respondent who drills at various geological conditions, 
including sandstone, shale, coal, limestone, igneous to metamorphic to unconsolidated alluvium. Two survey respondents provided information of the lifespan of drilling bits, which varies from 2,000 to $6,000 \mathrm{~h}$.

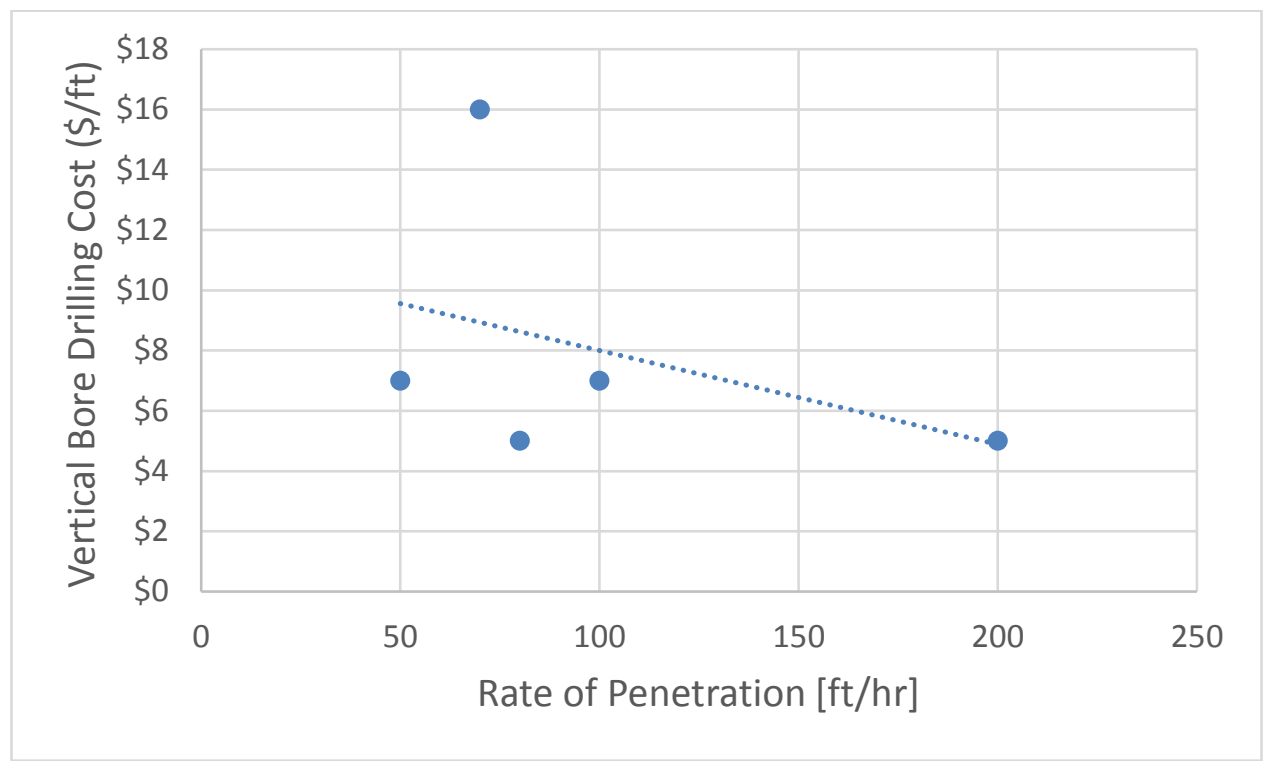

Figure 10. Survey results of vertical bore drilling costs and ROP.

\subsection{SUMMARY}

Based on the previous survey results, the following conclusions are drawn:

- Despite the fact that VBGHXs are more expensive than other types of GHXs, they are the most commonly used GHXs. This is because of their moderate land requirement and small environmental effects.

- Typical design of VBGHXs uses a single U-tube loop, which is made with HDPE pipe. Typical depth of the vertical bore is $200-400 \mathrm{ft}$ and the typical bore diameter is $4.75-5.75 \mathrm{in}$. Various grouting materials are used in practice to fill the annulus between the outer surface of HDPE pipe and the borehole wall.

- The costs of drilling vertical bores vary widely $(\$ 5.0-\$ 15.5 / \mathrm{ft})$ and geological formations encountered during drilling is one of the factors that determines the costs of drilling.

- Mud rotary, air rotary, and downhole hammer are commonly used drilling rigs. Typical ROP of vertical bore drilling is $60-150 \mathrm{ft} / \mathrm{h}$. Increasing ROP tends to reduce the drilling cost.

Therefore, the focus of this study is the VBGHXs. The previously described typical design of a VBGHX is used as a baseline, and the cost reduction potential resulting from various improvements in the design and installation of VBGHX is presented in the following sections.

\section{COST MODEL OF VERTICAL BORE GROUND HEAT EXCHANGERS}

Finger et al. (1997) developed a cost model for VBGHX installation based on information collected from eight site visits. Figure 11 shows the structure of the cost model. This model can output a detailed breakdown of labor, material, and equipment cost of installing an individual BHE and the overall cost for 
implementing a bore field, which includes multiple BHEs. The overall bore field cost includes the cost for installing each individual BHE and all the related distributed costs.

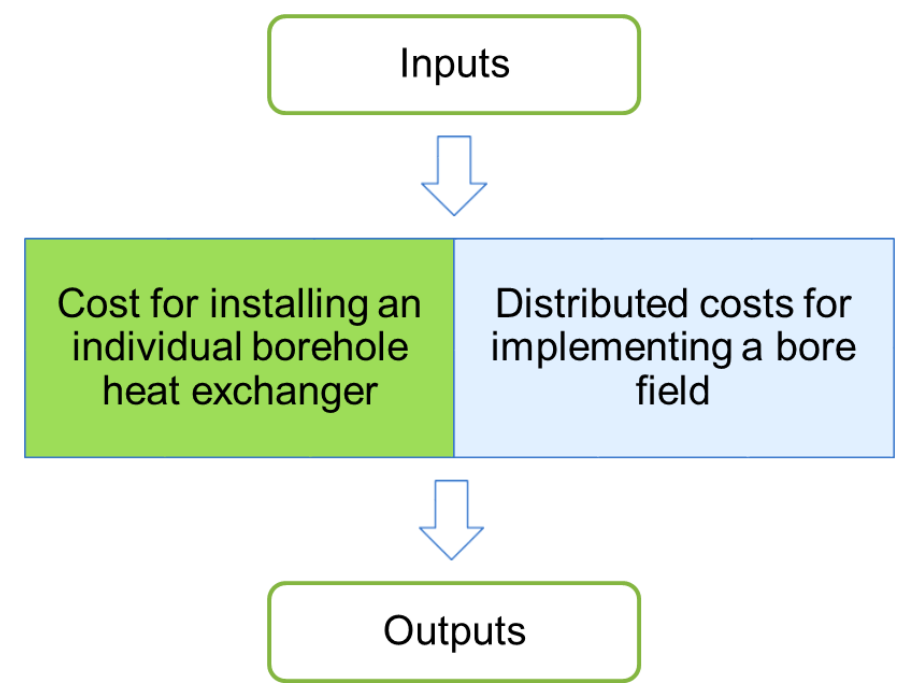

Figure 11. Cost model structure for VBGHXs.

The original model is updated in this project with information collected from the survey (Section 2) and other resources. In addition, the cost model is further improved to (1) account for the cost of casing; (2) estimate drilling performance (i.e., ROP) based on user-specified geological conditions and user-selected drilling technology; and (3) automatically update material costs based on user-specified BHE design, including heat exchanger loop configuration and materials of pipe, grout, and heat transfer fluids.

Required user inputs of the updated cost model are listed below. The items in bold are newly added and were not required in the original model.

- $\quad$ BHE design

○ Borehole depth

- Borehole diameter

- Heat exchanger loop configuration (single U-tube, double U-tube, or coaxial)

- Materials of grout, pipe, and heat transfer fluid

$\circ$ Casing information (cost, depth, time)

- Drill rig to be used (rotary or percussive)

- Geological conditions (thickness and type of various soil/rock layers along the depth of a borehole)

- Total number of boreholes

Based on these user inputs, the updated cost model calculates the costs of labor, material, and equipment associated with each step of a VBGHX installation. In addition, it outputs other results, including the installed cost of individual BHE (dollars), the normalized BHE cost (dollars/foot of bore depth), total cost of the borehole field (dollars), and the normalized total bore field cost (dollars/foot of bore depth).

Table 1 lists all the items of the installed cost breakdown for an individual BHE. Brief descriptions of the major tasks of the installation process are given in Appendix B. These descriptions are adopted from related industry standards (ANSI 2016), the National Certification Standard for Ground Source Heat Pump Personnel (GHPC 2013), and a guideline of site assessment for large-scale geothermal heat pump 
systems (NGWA 2015). The method and data used to calculate the breakdown costs of labor, material, and equipment are presented in the following subsections.

Table 1. Items for calculating the installed cost of individual VBGHXs

\begin{tabular}{|c|c|c|c|}
\hline Task & Labor cost & Material cost & Equipment cost \\
\hline $\begin{array}{l}\text { Prepare heat } \\
\text { exchanger loop (e.g., } \\
\text { single U-tube) }\end{array}$ & $\begin{array}{l}\text { Based on needed time ( } 0.5 \mathrm{~h} \\
\text { by default) and hourly rate }\end{array}$ & $\begin{array}{l}\text { Based on calculated loop } \\
\text { length and pipe cost }\end{array}$ & $\mathrm{NA}^{a}$ \\
\hline Reposition drill rig & $\begin{array}{l}\text { Based on needed time }(0.15 \mathrm{~h} \\
\text { by default) and hourly rate }\end{array}$ & NA & $\begin{array}{l}\text { Based on needed time and } \\
\text { hourly rate }\end{array}$ \\
\hline $\begin{array}{l}\text { Set cellar box and } \\
\text { mix mud }\end{array}$ & $\begin{array}{l}\text { Based on needed time }(0.25 \mathrm{~h} \\
\text { by default) and hourly rate }\end{array}$ & $\begin{array}{l}\text { Based on fixed amount of } \\
\text { bentonite and cost }\end{array}$ & $\begin{array}{l}\text { Based on needed time and } \\
\text { hourly rate }\end{array}$ \\
\hline Drill bore & $\begin{array}{l}\text { Based on bore depth, } \\
\text { geological condition, drilling } \\
\text { rig, and hourly rate }\end{array}$ & $\begin{array}{l}\text { Based on bore depth and } \\
\text { cost for water and drill bit }\end{array}$ & $\begin{array}{l}\text { Based on calculated time } \\
\text { and hourly rate }\end{array}$ \\
\hline Install casing $^{b}$ & $\begin{array}{l}\text { Based on needed time }(0.2 \mathrm{~h} \\
\text { by default) and hourly rate }\end{array}$ & $\begin{array}{l}\text { Based on user inputs and } \\
\text { material cost }\end{array}$ & $\begin{array}{l}\text { Based on calculated time } \\
\text { and hourly cost }\end{array}$ \\
\hline $\begin{array}{l}\text { Pull drill strings out } \\
\text { of bore hole }\end{array}$ & $\begin{array}{l}\text { Based on needed time }(0.1 \mathrm{~h} \\
\text { by default) }\end{array}$ & NA & $\begin{array}{l}\text { Based on needed time and } \\
\text { hourly rate }\end{array}$ \\
\hline $\begin{array}{l}\text { Install heat } \\
\text { exchanger loop }\end{array}$ & $\begin{array}{l}\text { Based on needed time }(0.1 \mathrm{~h} \\
\text { by default) }\end{array}$ & $\begin{array}{l}\text { Based on water cost and } \\
\text { calculated volume to fill } \\
\text { the loop }\end{array}$ & $\begin{array}{l}\text { Based on needed time and } \\
\text { hourly rate }\end{array}$ \\
\hline Pull weight bar & $\begin{array}{l}\text { Based on needed time }(0.1 \mathrm{~h} \\
\text { by default) }\end{array}$ & NA & $\begin{array}{l}\text { Based on needed time and } \\
\text { hourly rate }\end{array}$ \\
\hline $\begin{array}{l}\text { Anchor heat } \\
\text { exchanger loop }\end{array}$ & $\begin{array}{l}\text { Based on needed time }(0.1 \mathrm{~h} \\
\text { by default) }\end{array}$ & $\begin{array}{l}\text { Based on fixed amount } \\
\text { and rebar cost }\end{array}$ & $\begin{array}{l}\text { Based on needed time and } \\
\text { hourly rate }\end{array}$ \\
\hline Grout bore & $\begin{array}{l}\text { Based on needed time }(0.4 \mathrm{~h} \\
\text { by default) }\end{array}$ & $\begin{array}{l}\text { Based on grout material } \\
\text { cost and calculated } \\
\text { amount of grout }\end{array}$ & $\begin{array}{l}\text { Based on needed time and } \\
\text { hourly rate }\end{array}$ \\
\hline $\begin{array}{l}\text { Charge heat transfer } \\
\text { fluid }\end{array}$ & $\begin{array}{l}\text { Based on needed time }(0.1 \mathrm{~h} \\
\text { by default })\end{array}$ & $\begin{array}{l}\text { Based on fluid cost and } \\
\text { calculated volume to fill } \\
\text { the loop }\end{array}$ & $\begin{array}{l}\text { Based on needed time and } \\
\text { hourly rate }\end{array}$ \\
\hline $\begin{array}{l}\text { Pump excess mud } \\
\text { into tank/vacuum } \\
\text { truck }\end{array}$ & $\begin{array}{l}\text { Based on needed time }(0.15 \mathrm{~h} \\
\text { by default) }\end{array}$ & NA & $\begin{array}{l}\text { Based on needed time and } \\
\text { hourly rate }\end{array}$ \\
\hline $\begin{array}{l}\text { Clean and pick up } \\
\text { cellar box }\end{array}$ & $\begin{array}{l}\text { Based on needed time }(0.1 \mathrm{~h} \\
\text { by default })\end{array}$ & NA & $\begin{array}{l}\text { Based on needed time and } \\
\text { hourly rate }\end{array}$ \\
\hline
\end{tabular}

${ }^{a}$ Not applicable. 
${ }^{b}$ Casing is needed in certain areas where the overburden (soil) is soft. In this case, a vertical bore is cased with steel pipe from the ground surface until reaching the bedrock.

\subsection{LABOR COST}

Labor cost is calculated based on the hourly rate of a driller and helpers (usually two) and the estimated time for them to perform specific tasks. The hourly rate is calculated based on the average wage of drillers and helpers and the rates of other indirect costs paid by their employer (e.g., medical insurance, social security, and Medicare). Table 2 lists the wage range of drillers and helpers, as well as the rate of other indirect costs. The regional mean hourly wages of drillers and helpers, which are retrieved from the May 2016 National Occupational Employment and Wage Estimates published by the Bureau of Labor Statistics ${ }^{2}$, are used to calculate labor cost at a given location. The rates of indirect costs are estimated based on available information of similar jobs.

Table 2. Wages and rates of other costs for a driller and helper(s)

\begin{tabular}{cc}
\hline \multicolumn{2}{c}{ Wages } \\
\hline Driller & $\$ 25 / \mathrm{h}$ \\
Helper & $\$ 20 / \mathrm{h}$ \\
Rates of other indirect costs & $18 \%$ \\
Workmen's comp $^{a}$ & $\$ .4 \%$ \\
Medical insurance $^{b}$ & $6.1 \%$ \\
FUTA/SUTA $^{c}$ & $1.45 \%$ \\
FICA $^{d}$ & $6 \%$ \\
Medicare $^{\text {Holidays }}{ }^{e}$ & $5 \%$ \\
Vacation $^{e}$ &
\end{tabular}

\footnotetext{
${ }^{a}$ Workmen's compensation is the amount given to a worker, which is determined as a percentage of the hourly wage, if that worker is injured while working.

${ }^{b}$ Medical insurance is the amount of money set aside to pay for medical insurance for workers.

${ }^{c}$ FUTA/SUTA is the federal/state unemployment tax, which is charged as a percentage of the first $\$ 7,000$ of a worker's wages.

${ }^{d}$ FICA is a tax to pay for items such as social security and Medicare, which is charged as a percentage of a worker's wages.

${ }^{e}$ Holidays and vacation represent time paid to employees as part of their benefit compensation, which is accounted for as a percentage of the worker's wages.
}

As listed in Table 1, the time needed to perform each task has a default value, which is from the original cost model of Finger et al. (1997) except for the time needed to drill a borehole. The needed time to drill a borehole $\left(t_{\text {drill }}\right)$ is calculated based on needed bore depth $\left(L_{\text {bore }}\right)$ and the ROP of the drill rig at the given geological condition, as expressed in Eq. (1).

\footnotetext{
${ }^{2}$ https://www.bls.gov/oes/current/oes_nat.htm.
} 


$$
t_{d r i l l}=\frac{L_{\text {bore }}}{R O P(\text { geological condition,drill rig })} .
$$

The ROPs ${ }^{3}$ listed in Table 3 are implemented in the cost model to calculate the ROP for a given drill rig at a given geological condition (i.e., the different ground formations encountered during drilling). For a given drill rig, the ROP depends on the mechanical characteristics of the encountered ground formations. Available literature (Kahraman et al. 2003, Kivade et al. 2015, and Kahraman 2003) indicates that increasing the modulus ratios of the ground formation leads to a lower ROP for the rotary drilling but to a higher ROP for percussive drilling; increasing the compressive strength of the ground formation leads to lower ROPs for the percussive drilling. The ROP of a drill rig is also dependent on the power (i.e., pressure and thrust) imposed to the drill bit.

Users need to provide the percentages of various ground formations encountered during drilling and the type of a drill rig to be used. These inputs are used along with the ROP data listed in Table 3 to calculate an average ROP of the selected drill rig, which is weighted with the user-specified percentages of various ground formations encountered during drilling. This average ROP is used to calculate the time needed for drilling a borehole to a given depth.

Table 3. ROP of different drill rigs at various geologies

\begin{tabular}{|c|c|c|c|c|}
\hline Geology & Rotary & $\begin{array}{c}\text { Down hole } \\
\text { hammer }\end{array}$ & Auger & Cable tool \\
\hline Soil (till, sand, gravel) & $148 \mathrm{ft} / \mathrm{h}^{a}$ & NA & $80-133 \mathrm{ft} / \mathrm{h}^{c}$ & $20-40 \mathrm{ft} / \mathrm{h}^{c}$ \\
\hline Shale (limestone/clay) & $83^{a} \mathrm{ft} / \mathrm{h}^{a}$ & $117.1 \mathrm{ft} / \mathrm{h}^{b}$ & NA & NA \\
\hline Rock (granite/basalt) & $24 \mathrm{ft} / \mathrm{h}^{a}$ & $37.5 \mathrm{ft} / \mathrm{h}^{b}$ & NA & NA \\
\hline
\end{tabular}

According to Marbun et al. (2013), casing usually takes about 3\% of the time needed for drilling a deep borehole (more than $900 \mathrm{ft}$ ). Since the vertical bores of VBGHXs are shallower than $900 \mathrm{ft}$, the percentage of time needed for casing would be higher than $3 \%$. It is assumed that the default time for casing is $0.2 \mathrm{~h}$.

\subsection{MATERIAL COST}

Material cost is calculated based on the amount of needed materials and the current market price of each material. The needed amounts of materials are calculated based on the BHE design, including bore depth, bore diameter, heat exchanger loop configuration, pipe materials, grout materials, and heat transfer fluid. Table 4 lists the typical price of various materials used in the installation. These prices are obtained from the survey discussed in the previous section and quotes of related material vendors.

\footnotetext{
${ }^{3}$ ROP does not account for the time needed to pull drill strings out of a bore hole, which is accounted for separately in the cost model.
} 
Table 4. Typical prices of materials used for implementing VBGHXs

\begin{tabular}{lcc}
\hline \multicolumn{1}{c}{ Material } & Typical Price (\$) & Unit \\
\hline Bentonite & 0.41 & per pound \\
Water & 0.0003 & per gallon \\
Pipe (HDPE single U-tube) & 0.52 & per foot of bore length \\
0.5 in. rebar & 0.44 & per foot \\
Grout (bentonite-water mix) & 0.33 & per gallon \\
Header & 8.40 & per bore \\
Drill bit & 350 & each \\
Heat transfer fluid (ethanol) & 2.30 & per gallon \\
\hline
\end{tabular}

\subsection{EQUIPMENT COST}

Equipment cost is calculated based on the hourly rate for using equipment (e.g., a drill rig, auxiliary equipment, or an air compressor) and the time needed to perform specific tasks (see Table 1). The hourly equipment rate includes costs for both purchasing and maintaining the equipment.

Typical drill rigs for VBGHX installation are truck-mounted water well rigs or modified geophysical "short hole" rigs. Many drill rigs in service today are 10 to 30 years old (Sachs 2002). Market prices of various used drill rigs were collected from two online databases (SMC 2017 and ND 2007). Table 5 lists the average market prices of used mud rotary and auger drill rigs by the year in which they were manufactured. As shown in the table, the average cost of a 20 -year-old used mud rotary dill rigs is near $\$ 200,000$, which is about 50\% more expensive than auger drill rigs of the same age. A single used sonic drilling rig could cost $\$ 472,500$. A new rotary drill rig can cost up to $\$ 500,000$, and a remanufactured "short hold" rig costs roughly $\$ 100,000$ (Sachs 2002).

Table 5. Market prices of various drill rigs

\begin{tabular}{lccc}
\hline & Mud rotary $\mathbf{( \$ )}$ & Auger $(\$)$ & Cost ratio: rotary/auger \\
\hline 1960's & 62,200 & 18,500 & 3.4 \\
1970's & 89,300 & 46,500 & 1.9 \\
1980's & 111,000 & 89,100 & 1.2 \\
1990's & 130,000 & 87,400 & 1.5 \\
2000's & 198,000 & 135,000 & 1.5 \\
\hline
\end{tabular}

The price of equipment, interest rate of the loan, depreciation period, and effective working time of the equipment are used to calculate a portion of the hourly rate needed to pay back the loan. The other portion of the hourly rate is to recover the maintenance cost. The cost and frequency of maintenance/replacement of the major components of a mud rotary drill rig (engine, mud pumps, tires, and rotary system) were estimated by Finger et al. (1997) and were used to calculate the hourly maintenance cost of the drill rig. The annual maintenance costs of other equipment were assumed to be 5\% of their purchase prices. The hourly fuel cost, which is calculated based on the hourly fuel use for operating the equipment and the fuel price at the time of this study (2017), is also accounted for in the hourly rate of an equipment. 


\subsection{DISTRIBUTED COSTS}

Distributed costs include the costs for pre- and post-drilling activities for implementing a bore field such as locating underground utilities, moving rigs to the job site, connecting heat exchangers in each individual bore, and restoring the drilling site. Some of these costs are fixed and are taken directly from user input (e.g., costs for locating utilities and moving the rig to the location), but other costs are calculated based on the size of the bore field (i.e., the number of vertical bores). The cost for designing a bore field is calculated as a percentage ( $10 \%$ by default) of the bare-bone cost of the bore field installation, which accounts for only the labor, material, and equipment costs for implementing a bore field. In addition, the profit and overhead (including contingency) of the bore field installation is counted as another distributed cost, which is a percentage ( $20 \%$ by default) of the sum of the bare-bone installation cost and the bore field design cost.

\subsection{MAPPING BETWEEN INPUT AND COSTS}

Table 6 shows the mapping between some major user input/parameters of the cost model (shown in the horizontal header) and the main cost items for implementing a bore field (shown in the vertical header). As can be seen from this table, the number of bores affects all the cost items, which indicates that reducing the number of bores might reduce the overall installed cost of a bore field. Given the laborintensive nature of a VBGHX installation, labor time determines the cost of each installation activity. Furthermore, except for preparing the heat exchanger loop (which can be done separately before drilling starts), all the other cost items are affected by both the equipment rate and the labor time. Therefore, automation of the installation process (e.g., connecting and disconnecting drill pipes) and higher ROP drilling that can shorten labor time could reduce not only the labor cost but also the cost for using (renting) the equipment. However, automation could increase the equipment cost associated with borehole drilling. Besides, the mapping shows that bore depth affects not only the time needed for drilling, grouting, and installing the heat exchanger loop but also the amount of materials needed for the heat exchanger loop, grout, and heat transfer fluid. It is thus important to not oversize bore depth. On the other hand, bore diameter affects only the cost of grouting and a smaller bore diameter could reduce the needed grouting material and associated cost.

\subsection{LIMITATIONS}

The current version of the cost model has the following limitations, and further studies and data collections are needed to improve them:

- It is assumed that the ROP of a drill rig does not change with bore depth (i.e., constant penetration speed along the depth of a vertical bore)

- The cost of a coaxial heat exchanger loop is a rough estimate because of currently limited applications.

- Uncertainties are high in the estimated profit and overhead for implementing a bore field. This cost is affected by many factors, including project size and competition of the drilling market. 
Table 6. Mapping between component costs and major input and parameters

\begin{tabular}{|c|c|c|c|c|c|c|c|c|c|c|c|}
\hline Cost items & $\begin{array}{l}\text { Labor } \\
\text { time }\end{array}$ & $\begin{array}{l}\text { Labor } \\
\text { rate }\end{array}$ & $\begin{array}{l}\text { Equip } \\
\text { rate }\end{array}$ & $\begin{array}{l}\text { Bore } \\
\text { depth }\end{array}$ & $\begin{array}{l}\text { Bore } \\
\text { dia. }\end{array}$ & $\begin{array}{l}\text { Number } \\
\text { of bores }\end{array}$ & ROP & $\begin{array}{l}\text { Pipe } \\
\text { cost }\end{array}$ & $\begin{array}{l}\text { Grout } \\
\text { cost }\end{array}$ & $\begin{array}{c}\text { Heat } \\
\text { transfer } \\
\text { fluid } \\
\text { cost } \\
\end{array}$ & $\begin{array}{l}\text { Hea } \\
\text {-der } \\
\text { cost }\end{array}$ \\
\hline $\begin{array}{l}\text { Install } \\
\text { horizontal } \\
\text { piping }\end{array}$ & $\mathrm{x}$ & $\mathrm{x}$ & $\mathrm{x}$ & & & $\mathrm{X}$ & & $\mathrm{x}$ & & & $\mathrm{x}$ \\
\hline Restore site & $\mathrm{x}$ & $\mathrm{x}$ & $\mathrm{x}$ & & & $\mathrm{x}$ & & & & & \\
\hline $\begin{array}{l}\text { Prepare heat } \\
\text { exchanger } \\
\text { loop (e.g., } \\
\text { single U-tube) }\end{array}$ & $\mathrm{x}$ & $\mathrm{x}$ & & $\mathrm{x}$ & & $\mathrm{x}$ & & $\mathrm{x}$ & & & \\
\hline $\begin{array}{l}\text { Reposition } \\
\text { drill rig }\end{array}$ & $\mathrm{x}$ & $\mathrm{x}$ & $\mathrm{x}$ & & & $\mathrm{x}$ & & & & & \\
\hline $\begin{array}{l}\text { Set cellar box } \\
\text { and mix mud }\end{array}$ & $\mathrm{x}$ & $\mathrm{x}$ & $\mathrm{X}$ & & & $\mathrm{x}$ & & & & & \\
\hline Drill bore & $\mathrm{x}$ & $\mathrm{x}$ & $\mathrm{x}$ & $\mathrm{x}$ & & $\mathrm{x}$ & $\mathrm{x}$ & & & & \\
\hline Install casing & $\mathrm{x}$ & $\mathrm{x}$ & $\mathrm{x}$ & & & $\mathrm{x}$ & & $\mathrm{x}$ & & & \\
\hline $\begin{array}{l}\text { Put drill pipes } \\
\text { out of a } \\
\text { borehole }\end{array}$ & $\mathrm{x}$ & $\mathrm{x}$ & $\mathrm{x}$ & & & $\mathrm{x}$ & & & & & \\
\hline $\begin{array}{l}\text { Install heat } \\
\text { exchanger } \\
\text { loop }\end{array}$ & $\mathrm{x}$ & $\mathrm{x}$ & $\mathrm{x}$ & $\mathrm{x}$ & & $\mathrm{x}$ & & & & & \\
\hline $\begin{array}{l}\text { Pull weight } \\
\text { bar }\end{array}$ & $\mathrm{x}$ & $\mathrm{x}$ & $\mathrm{x}$ & & & $\mathrm{x}$ & & & & & \\
\hline $\begin{array}{l}\text { Anchor heat } \\
\text { exchanger } \\
\text { loop }\end{array}$ & $\mathrm{x}$ & $\mathrm{x}$ & $\mathrm{x}$ & & & $\mathrm{x}$ & & & & & \\
\hline Grout bore & $\mathrm{x}$ & $\mathrm{x}$ & $\mathrm{x}$ & $\mathrm{x}$ & $\mathrm{x}$ & $\mathrm{x}$ & & & $\mathrm{x}$ & & \\
\hline $\begin{array}{l}\text { Charge heat } \\
\text { transfer fluid }\end{array}$ & $\mathrm{x}$ & $\mathrm{x}$ & $\mathrm{x}$ & $\mathrm{x}$ & & $\mathrm{x}$ & & & & $\mathrm{x}$ & \\
\hline $\begin{array}{l}\text { Pump excess } \\
\text { mud into tank/ } \\
\text { vacuum truck }\end{array}$ & $\mathrm{x}$ & $\mathrm{x}$ & $\mathrm{x}$ & & & $\mathrm{x}$ & & & & & \\
\hline $\begin{array}{l}\text { Clean and } \\
\text { pick up cellar } \\
\text { box }\end{array}$ & $\mathrm{x}$ & $\mathrm{x}$ & $\mathrm{x}$ & & & $\mathrm{x}$ & & & & & \\
\hline
\end{tabular}

\section{COST ANALYSIS OF TYPICAL VERTICAL BORE GROUND HEAT EXCHANGERS}

To identify the key cost drivers and the areas that have significant potential for cost reduction, detailed breakdowns of time and cost spent in each step of implementing a typical design of an individual BHE (see Table 7) with current practices was calculated with the updated cost model (discussed in Section 3) and is analyzed in this section. This establishes a base case of typical installation scenarios that cover a large fraction of the residential and commercial market. 


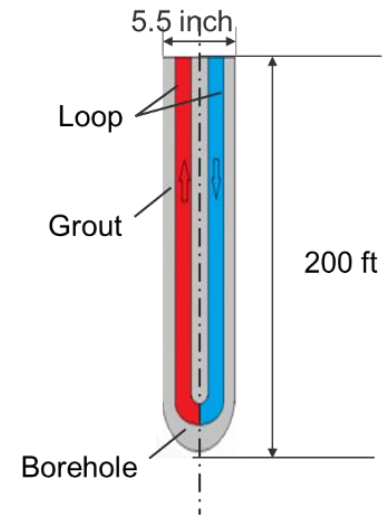

- $200 \mathrm{ft}$ bore depth

- 5.5 in. bore diameter

- Single U-tube heat exchanger loop made with HDPE pipe

- Standard bentonite grouted $\left(\mathrm{K}=0.4 \mathrm{Btu} / \mathrm{h}-\mathrm{ft}-{ }^{\circ} \mathrm{F}\right)$

- $20 \%$ antifreeze solution as heat transfer fluid

- No casing

It is assumed that the ground formation along the depth of the vertical bore includes soil ( $40 \mathrm{ft}$ below the grade), soft rock (41-100 ft), and hard rock (101-200 ft). It is also assumed that a mud rotary drill rig is used to drill the vertical bore and that the weighted average ROP in this ground formation is $66.5 \mathrm{ft} / \mathrm{h}$. Casing is not used in this base case.

\subsection{TIME ANALYSIS OF BASE CASE}

The step-by-step time breakdown for installing the typical BHE is shown in Table 7. The total time for completing the BHE installation is about $5.1 \mathrm{~h}$ in this base case. In this analysis, it is assumed that all time would be spent expeditiously for implementing the BHE without any delay among individual tasks.

As can be seen in Table 7, drilling the bore hole consumes the most time, representing about $60 \%$ of the overall operational time. The other $40 \%$ of the time is spent performing functions not directly related to drilling the bore, including preparing the heat exchanger loop (10\% of the overall time) and grouting ( $8 \%$ of the overall time). There are no other individual nondrilling activities that takes more than $5 \%$ of the overall time. As discussed in Section 3, drilling time is determined by the ROP and can be shortened by increasing the ROP (i.e., with a better drill rig and an automated process for connecting the drill pipes).

Table 7. Time breakdown for each step of implementing an individual BHE

\begin{tabular}{llcc}
\hline Category & \multicolumn{1}{c}{ Activity/step } & Time (h) & $\begin{array}{c}\text { Percentage } \\
(\mathbf{\%})\end{array}$ \\
\hline \multirow{3}{*}{ Preparation } & Prepare heat exchanger loop & 0.5 & 9.9 \\
& Reposition drill rig & 0.2 & 3.0 \\
& Set cellar box and mix mud & 0.3 & 4.9 \\
& Drill bore hole & 3.0 & 59.5 \\
& Install casing & 0.0 & 0.0 \\
& Put drill pipes out of a borehole & 0.1 & 2.0 \\
& Install loop & 0.1 & 2.0 \\
& Put grout in place & 0.4 & 7.9 \\
& Charge heat transfer fluid & 0.1 & 2.0 \\
& Pull weight bar & 0.1 & 2.0 \\
Postprocess & Anchor top of heat exchanger loop & 0.1 & 2.0 \\
& Pump excess mud into tank/vacuum truck & 0.2 & 3.0 \\
\hline Total time & Clean and pick up cellar box & 0.1 & 2.0 \\
\hline
\end{tabular}




\subsection{COST ANALYSIS OF BASE CASE}

The cost associated with each task for implementing an individual BHE was calculated with the cost model and is shown in Table 8. Each cost breakdown includes all the costs of labor, material, and equipment associated with each task. The total bare-bone installed cost for implementing the BHE (excluding any profit and overhead as well as the cost for sizing the BHE) is about $\$ 950$ in the presented base case. This is equivalent to $\$ 4.75$ per linear foot of the vertical bore. As can be seen in Table 8 , while drilling the bore hole contributes the most to the total cost, it represents only about $52 \%$ of the total cost. There are considerable costs associated with other nondrilling activities, particularly preparing the heat exchanger loop ( $\$ 124$ or $13 \%$ ), grouting the bore hole ( $\$ 112$ or $12 \%)$, and charging the heat transfer fluid $(\$ 43$ or $5 \%)$.

Table 8. Cost breakdown for each step of implementing an individual BHE

\begin{tabular}{llrr}
\hline Category & \multicolumn{1}{c}{ Activity/Step } & Cost $\mathbf{( \$ )}$ & $\begin{array}{r}\text { Percentage } \\
(\mathbf{\%})\end{array}$ \\
\hline \multirow{3}{*}{ Preparation } & Prepare heat exchanger loop & 123.63 & 13.0 \\
& Reposition drill rig & 23.52 & 2.5 \\
& Set cellar box and mix mud & 49.45 & 5.2 \\
& Drill bore hole & 495.05 & 52.1 \\
& Install casing & 0.00 & 0.0 \\
& Put drill pipes out of a borehole & 15.68 & 1.7 \\
Installation & Install loop & 15.68 & 1.7 \\
& Put grout in place & 111.58 & 11.7 \\
& Charge heat transfer fluid & 43.38 & 4.6 \\
& Pull weight bar & 15.68 & 1.7 \\
& Anchor top of heat exchanger loop & 17.00 & 1.8 \\
Postprocess & Pump excess mud into tank/vacuum truck & 23.52 & 2.5 \\
& Clean and pick up cellar box & 15.68 & 1.7 \\
\hline Total cost & & $\mathbf{9 4 9 . 8 6}$ & $\mathbf{1 0 0}$ \\
\hline
\end{tabular}

Figure 12 shows the costs of labor, material, and equipment associated with each task. It indicates that labor contributes the most ( $\$ 440$ or $46 \%$ ) to the overall cost followed by equipment ( $\$ 289$ or $30 \%$ ) and material (\$220 24\%). 


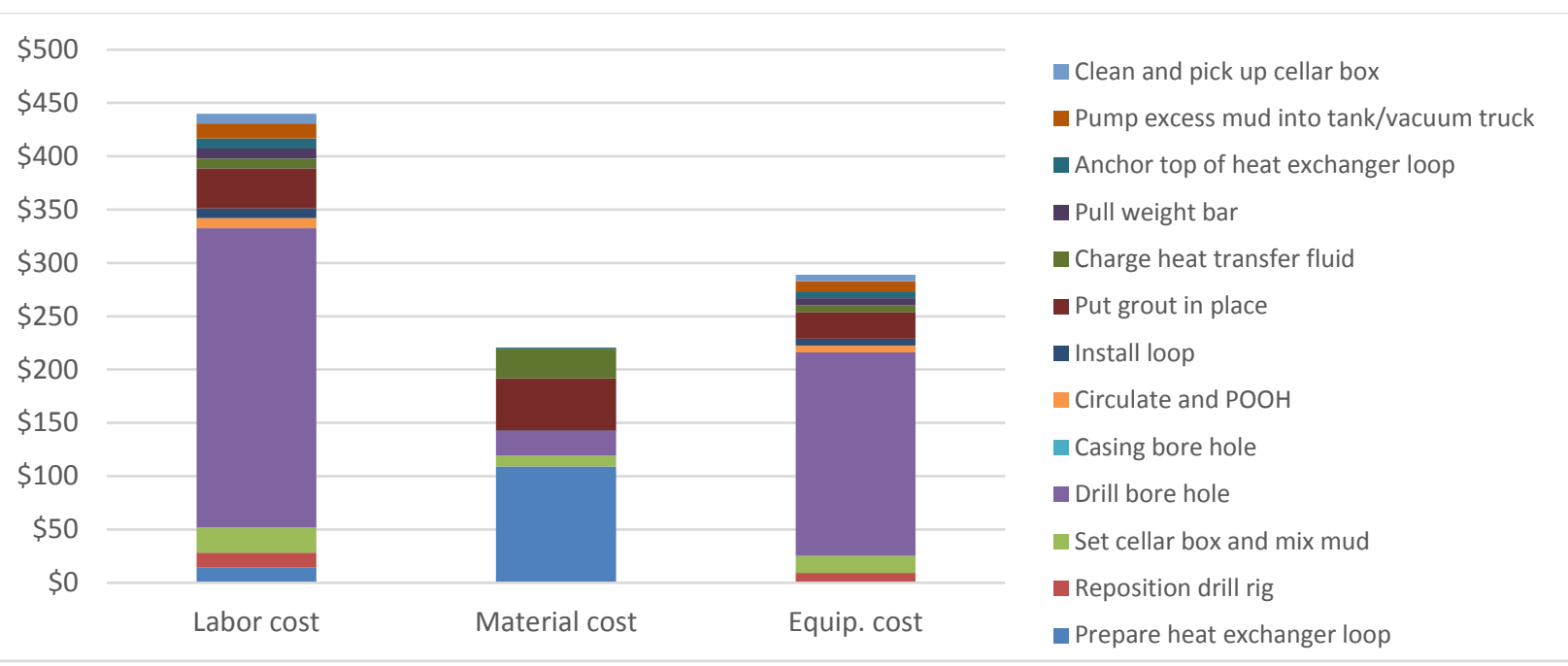

Figure 12. Costs of labor, material, and equipment associated with each task.

Figure 13 shows the percentage of each task in the overall costs of labor, material, and equipment. In the presented base case, it is assumed that all of the equipment is kept at the construction site when implementing the BHE and thus the cost of using the equipment is charged based on the time needed to perform each task. As shown in Figure 13, drilling contributes most (64-66\%) to the total labor and equipment costs. However, if the equipment can be used more effectively (e.g., move the drill rig to another job when other nondrilling tasks are performed), the equipment use/rental time could be reduced as well as the associated cost, especially for bore fields involving multiple BHEs. The heat exchanger loop, grout, and heat transfer fluid contribute most to the material cost $(50 \%, 22 \%$, and $13 \%$, respectively). Some advanced materials might be more expensive but they can help reduce the required size of the BHE by improving its heat transfer performance (e.g., reducing borehole thermal resistance). These materials thus have potential to reduce the cost of needed BHEs. An analysis of advanced materials on the cost of BHEs is discussed in Section 6.

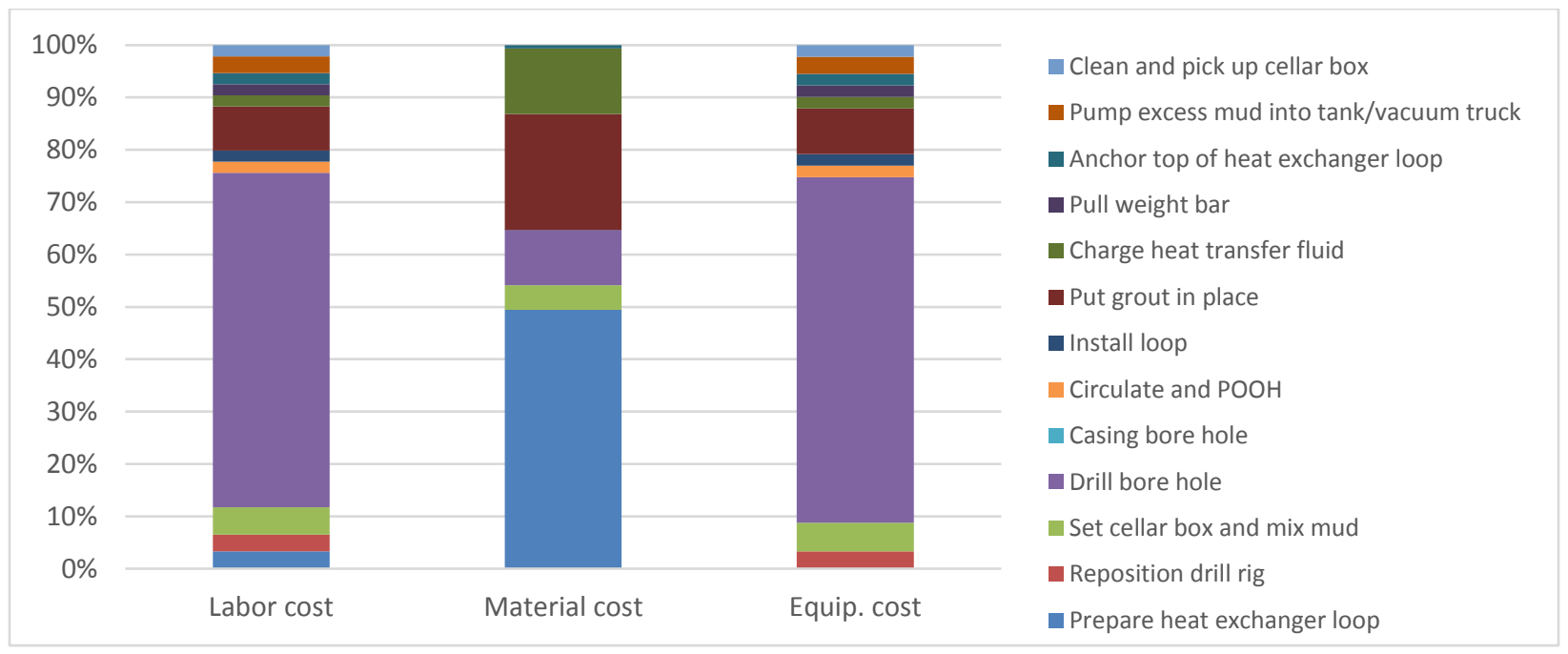

Figure 13. Percentage of each task in the overall costs of labor, material, and equipment. 
Figure 14 shows a comparison of the installed cost resulting from three different ground formations (including the base case) while all other parameters of the installation are identical. As shown in this figure, the cost of implementing an individual BHE is significantly affected by the ground formation. The cost of drilling vertical bores in a relatively soft formation (e.g., clay) is less than half that in hard rock (e.g., granite) because a mud rotary rig can drill much faster in clay than in granite (Table 3 ). This indicates that the location (i.e., local ground formation) is a determining factor for the cost of installing a BHE. Detailed high-resolution data for the ground formation at shallow subsurfaces is desirable to identify better locations for installing VBGHXs.

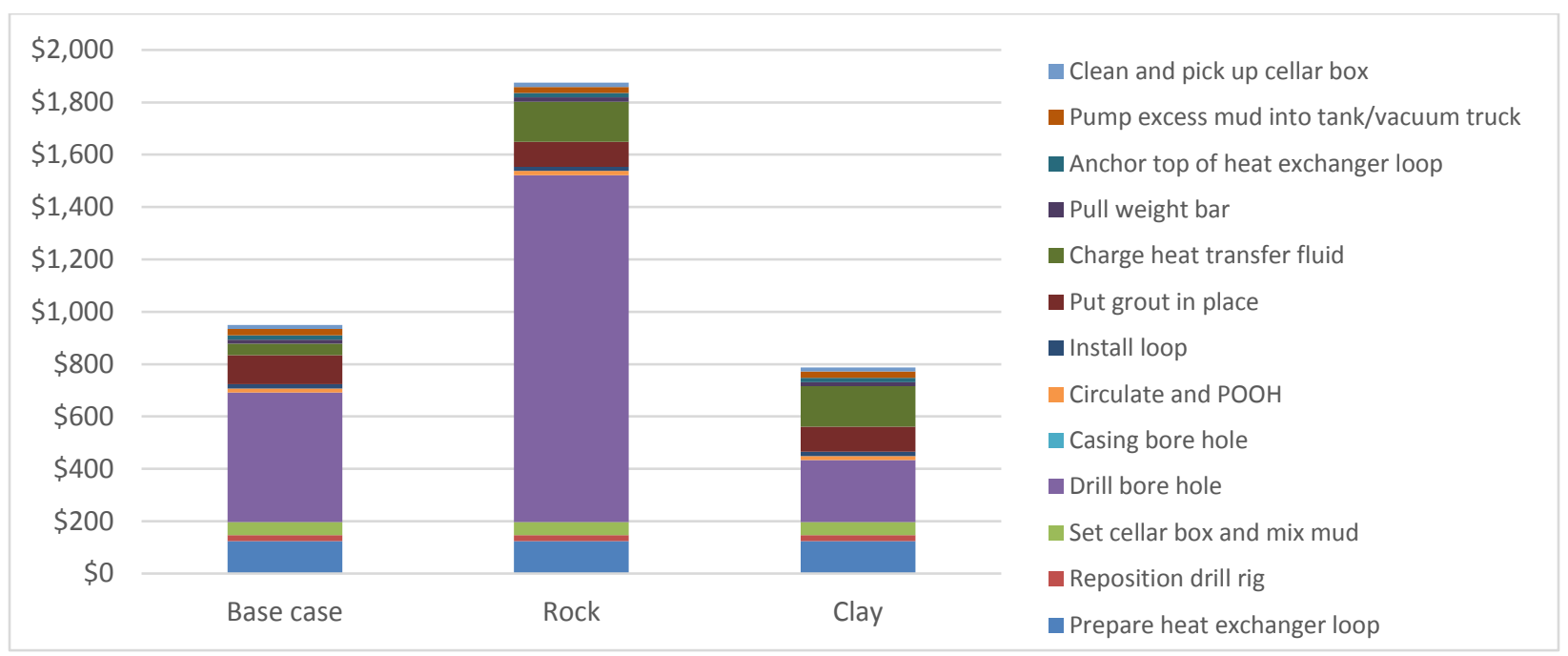

Figure 14. Task costs resulting from different ground formations.

\subsection{VALIDATION OF COST MODEL}

Battocletti and Glassley (2013) reported survey results of the normalized costs of VBGHXs (dollars per linear foot of vertical bore) by census regions and dominant geologies (see Appendix C). The normalized total installed costs of VBGHXs, including both the cost of implementing all the individual BHEs and the distributed costs for a typical residential application (with a 4-ton capacity) at different ground formations were calculated with the updated cost model and compared with the survey results from Battocletti and Glassley (2013), as shown in Figure 15. This comparison shows that the predicted costs match well with the survey results - about $8 \%$ higher for rock and 3\% higher for clay. This comparison indicates that the updated cost model can predict the installed cost of a VBGHX with reasonable accuracy. It thus is used along with a sizing program for VBGHX to evaluate the cost reduction potential of possible improvements in drilling, BHE design, and bore field configuration (see Sections 5 and 6). 


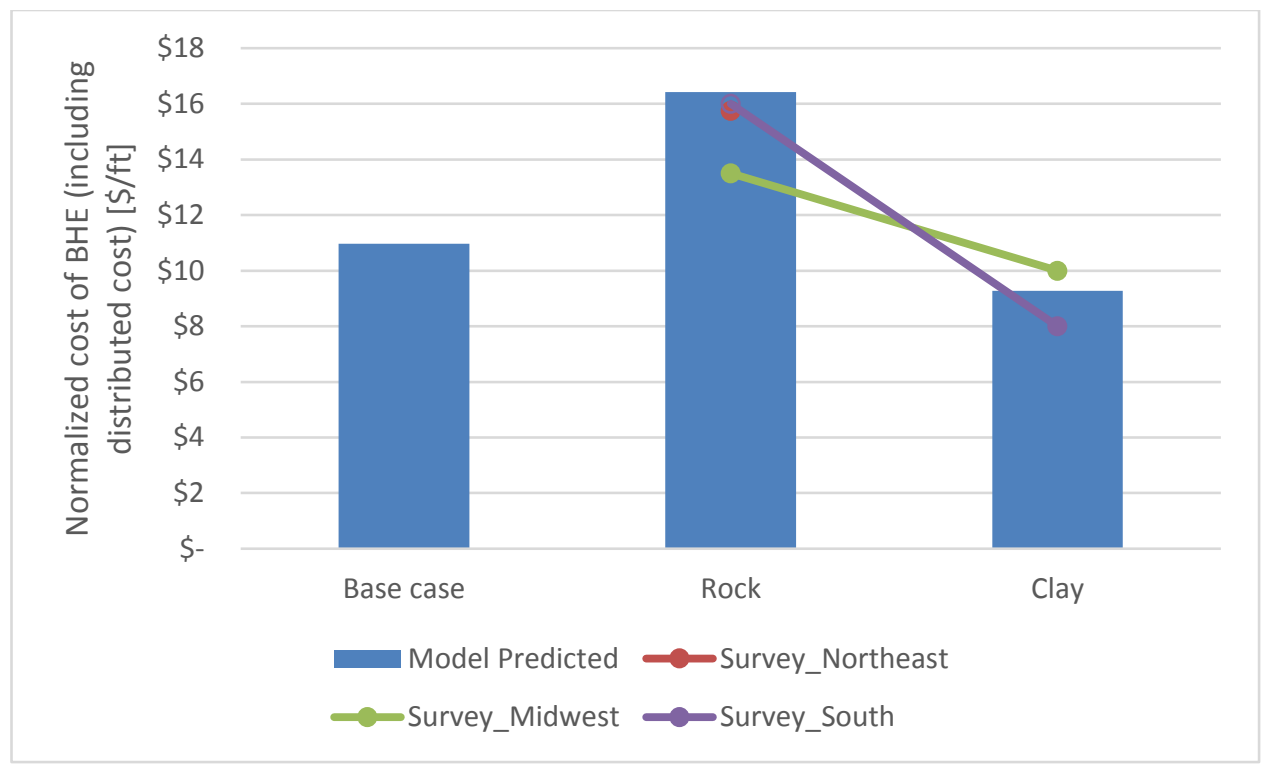

Figure 15. A comparison of VBGHX costs at different ground formations: model predicted vs. survey results.

\subsection{DISCUSSIONS}

- Drilling contributes the most to both the time and cost of implementing a BHE in the presented base case. Reducing drilling time by increasing ROP and the efficacy of using drill rigs can reduce drilling time, especially for projects with multiple BHEs. However, there is a tradeoff between increased ROP and the cost of a drill rig. An analysis for the impacts of drill rig ROP and cost on the overall cost of a BHE are discussed in Section 6.

- Advanced materials that can reduce the cost of heat exchanger loop and grout, or reduce the needed size of a BHE while retaining performance, have potential to reduce the cost of BHEs.

\section{POTENTIAL SOLUTIONS TO REDUCE THE COST OF VBGHXS}

Through an extensive literature review and interviews with industry experts, a collection of potential solutions for reducing the cost of VBGHXs has been identified and is presented in this section. The identified solutions include various emerging technologies to improve drilling, BHE design (e.g., using better and cheaper materials), and borehole field layout. The effectiveness of each individual solution or a combination of several solutions is discussed in Section 6.

\subsection{IMPROVEMENTS IN DRILLING PROCESS}

\subsubsection{Overview of Conventional Drilling Technologies for VBGHX Installation}

Conventional drilling technologies use a rotary torque, a percussion action, or a combination to drill vertical bores. Several drilling technologies are currently used for VBGHX installation, including mud rotary, air rotary, air hammer, sonic, and auger. Each of these drilling technologies has its limitations in applicability, advantages, and disadvantages, as summarized in Table 9. This information is obtained from interviews with experts and from various literature (Sachs 2002, TCEPA 2013, Cushman and Tartakovsky 2017, Zacchei 2016, and other related information from the drilling industry). 
Table 9. Comparison of various drilling methods used for installing VBGHXs

\begin{tabular}{|c|c|c|c|c|c|}
\hline & Mud rotary & Air rotary & Air hammer & Sonic & Auger \\
\hline \multicolumn{6}{|c|}{ Applicability } \\
\hline $\begin{array}{r}\text { Unconsolidated, } \\
\text { soft rock }\end{array}$ & Perferred & $\begin{array}{l}\text { May have hole } \\
\text { stability issue }\end{array}$ & $\begin{array}{l}\text { May have hole } \\
\text { stability issue }\end{array}$ & Perferred & Perferred \\
\hline $\begin{array}{r}\text { Competent } \\
\text { rock, hard rock }\end{array}$ & $\begin{array}{l}\text { Slower than air } \\
\text { methods }\end{array}$ & Perferred & Perferred & $\begin{array}{c}\text { Applicable (all } \\
\text { types of soil and } \\
\text { rock) }\end{array}$ & Not Applicable \\
\hline $\begin{array}{r}\text { Bore diameter } \\
\text { (in) }\end{array}$ & $<36$ & $<36$ & $<8$ & $<12$ & $<36$ \\
\hline $\begin{array}{r}\text { Max. bore } \\
\text { depth } \\
(f t)\end{array}$ & $>1000$ & $>1500$ & $>1500$ & $<600$ & $<150$ \\
\hline \multicolumn{6}{|c|}{ Strengths and Weaknesses } \\
\hline Speed & $\begin{array}{l}\text { Fast in weak } \\
\text { rock }\end{array}$ & $\begin{array}{c}\text { Fast in weak } \\
\text { rock }\end{array}$ & $\begin{array}{c}\text { Fast in weak } \\
\text { rock }\end{array}$ & $\begin{array}{l}\text { Fast in weak } \\
\text { rock }\end{array}$ & Slow \\
\hline Reliability & $\begin{array}{l}\text { Might need } \\
\text { casing in poor } \\
\text { conditions } \\
\text { (unstable hole, } \\
\text { voids) }\end{array}$ & $\begin{array}{c}\text { Resists } \\
\text { circulation loss } \\
\text { but not work } \\
\text { well with more } \\
\text { than } 50 \mathrm{ft} \text { water } \\
\text { column above } \\
\text { bit }\end{array}$ & $\begin{array}{c}\text { Resists } \\
\text { circulation loss } \\
\text { but cannot be } \\
\text { used with more } \\
\text { than a } 50 \mathrm{ft} \\
\text { water column } \\
\text { above bit }\end{array}$ & $\begin{array}{c}\text { Resists } \\
\text { circulation loss }\end{array}$ & $\begin{array}{l}\text { Good in right } \\
\text { conditions } \\
\text { (shallow depth } \\
\text { usually with } \\
\text { casing) }\end{array}$ \\
\hline Drilling fluid & $\begin{array}{l}\text { Mud (water and } \\
\text { bentonite) }\end{array}$ & $\begin{array}{c}\text { Air with } \\
\text { foaming agent }\end{array}$ & Air & No & No \\
\hline $\begin{array}{r}\text { Operator's } \\
\text { working } \\
\text { condition }\end{array}$ & $\begin{array}{l}\text { Water \& mud } \\
\text { management }\end{array}$ & $\begin{array}{l}\text { High pressure } \\
\text { air and dust }\end{array}$ & $\begin{array}{l}\text { High pressure } \\
\text { air and dust }\end{array}$ & $\begin{array}{l}\text { High frequence } \\
\text { vibration }\end{array}$ & Relatively better \\
\hline Cost & Moderate & Moderate & Moderate & High & Low \\
\hline Maintenance & Moderate & Moderate & Moderate & High & Low \\
\hline Noise & Moderate & Moderate & High & Moderate & Low \\
\hline Energy use & Moderate & Moderate & High & Moderate & Low \\
\hline
\end{tabular}

\subsubsection{New Development in Drilling Technologies}

Recent developments in drilling technologies focus on improvement of production capacity, operator safety, operating conditions, and environmental impacts. It is believed that the following improvements have potential to shorten the drilling process and reduce the related labor and equipment costs

(GEOTeCH 2016):

- Automated drill pipe manipulator to eliminate the need of manually handling drill pipes.

- New drill rigs customized for VBGHX installation to improve mobility and cost effectiveness.

- Advanced measuring and monitoring systems to enable more effective drilling.

- Improved power output control to reduce fuel consumption of drill rigs. 
There are many other drilling technologies that have not been commonly used for VBGHX installations or that are still under development. The following is a brief introduction to a few drilling technologies that could be applied for VBGHX installations.

Coil tubing drilling uses a long steel tube wound around a reel instead of the sectional drill strings used in rotary drill rigs. This allows for faster tripping, with the ability to pump drilling fluid throughout the process, which can also help increase stability of a borehole. One large disadvantage of coil tubing drilling rigs is their inability to rotate, requiring downhole hydraulic motors, which are expensive. In addition, a relatively sophisticated system is required to separate solids from the returned drilling fluid if it is to be reused by the hydraulic motor. Once hydraulic motors become inexpensive, coil tubing drilling would allow for faster drilling at an affordable cost.

Casing drilling incorporates casing in the drilling process by replacing the drill pipes with the casing (Gaurina-Medimurec 2005). Casing drilling can reduce operation time by eliminating the need for pulling out drill strings from the borehole and improving the stability of the borehole by casing its full length. It could be combined with augur drilling to drill large diameter shallow holes in soil or unconsolidated, soft rock.

Jet-assisted drilling uses water jets to help increase the penetration rate by weakening the rock or cleaning the borehole. The jet requires high water pressures to operate and will consume a large amount of clean water.

Electrohydraulic drilling uses electric spark discharges created at the bottom of a borehole to form a pressure pulse to break the rock. It can be used as an independent means of drilling or in combination with a more conventional drilling method. This drilling method allows for faster penetration, but the borehole needs to be filled with water and electric energy needs to be transmitted to the needed depth (Kussaiynov et al. 2014).

Thermal-assisted drilling uses various means (e.g., microwave or laser) to weaken or melt rocks with heat and thus increase the penetration rate. These technologies will consume a large amount of energy to generate the needed heat. Other challenges include protecting drillers from the elevated temperatures, strong microwaves, or laser beams, and delivering a large amount of energy to a given depth in a borehole (Pierce et al. 1996 and Rossi 2017).

\subsection{IMPROVEMENTS IN BOREHOLE HEAT TRANSFER}

\subsubsection{Emerging Heat Exchanger Designs}

Recent studies have focused on development of improved BHEs that offer lower borehole thermal resistance, can be quickly installed, and do not have significant pumping power penalties.

- Deep borehole. Deep boreholes are of interest for applications where available land is limited. In addition, under some geological conditions drilling a deep borehole can be less expensive than drilling a few shallower boreholes for the same heat transfer capacity. There are several issues that complicate BHE designs, including grouting procedures for avoiding pipe collapse/burst, maintaining satisfactorily low pressure drop along the deep borehole, limiting short-circuiting effects, and the advantages vs. the disadvantages of warmer ground temperatures at deeper depths (Acuña 2016, Gehlin et al. 2015).

- Alternative heat exchanger loop designs. As indicated in the survey results presented in Section 2, the single U-tube loop is most commonly used in the BHEs in the United States. However, there are 
many alternative designs for the heat exchanger loop inside a vertical bore, including the double Utube loop; coaxial loop; TWISTER (four U-tube loops twisted together); GeoColum; and helical loops, also referred to as "conic basket heat exchangers" (Boughhanmi et al. 2015), which can be installed in boreholes as shallow as $50 \mathrm{ft}$ below the grade (Cheap GSHPs 2015). Figure 16 shows a few new designs of heat exchanger loops, including (a) TWISTER (Jensen 2014), (b) basket heat exchanger (Boughanni et al. 2015), and (c) GeoColum (Cordts 2011).

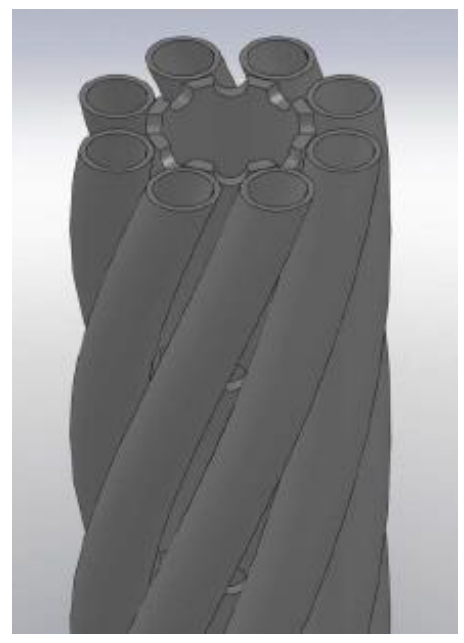

(a) TWISTER

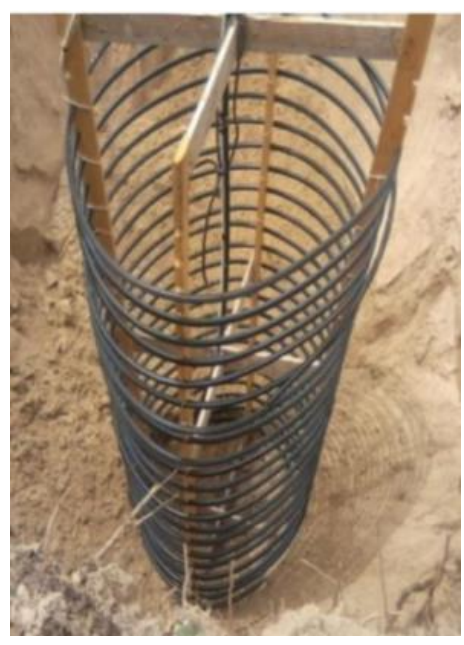

(b) Basket heat exchanger

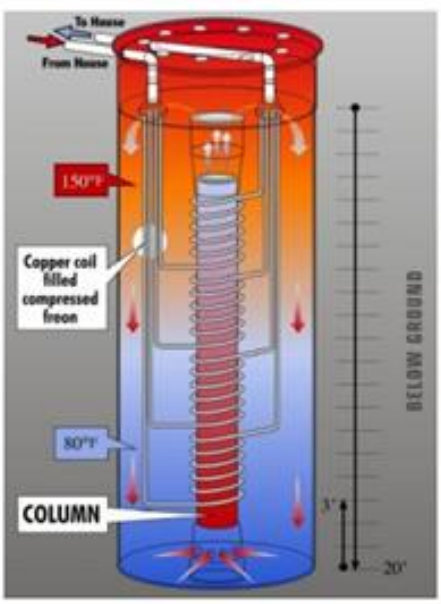

(c) GeoColumn

Figure 16. Alternative designs for VBGHXs.

Performance BHEs that use single U-tube, double U-tube, and coaxial heat exchanger loops have been experimentally studied (Liu et al. 2013) and can also be reliably modeled with commercial software, such as GLHEPro (Spitler 2000). However, the performance data of other alternative heat exchanger loops are still limited, and available commercial software cannot currently model these heat exchanger loops. Therefore, unfortunately, the more recent heat exchanger loops are not included in this study. It is highly desirable to develop a standard testing method for evaluating the performance of the new heat exchanger loops and to develop reliable computer models for sizing and predicting their performance.

- Integration with phase change materials (PCMs). A few approaches for incorporating PCMs with BHEs have been investigated recently. Computational Fluid Dynamic (CFD) simulations conducted in previous studies (Bottarelli et al. 2013 and Qi et al. 2016) indicate that by adding PCMs in the grout (in vertical bores) or backfill (in horizontal trench) the working fluid temperature supplied to the heat pump becomes more stable and favorable for more energy-efficient operation. In addition, the thermal effect radius (i.e., the minimum spacing between boreholes for avoiding thermal interactions) of an individual BHE decreases, which means more BHEs can be placed in a given area without sacrificing performance caused by thermal interactions among them.

\subsubsection{Advanced Materials}

\subsubsection{Heat exchanger pipe}

As indicated by the survey results in Section 2, HDPE pipe is most commonly used for the heat exchanger loop of VBGHXs. Although HDPE pipes are very durable, their thermal conductivity is low $(0.23 \mathrm{Btu} / \mathrm{h}-$ 
ft- ${ }^{\circ} \mathrm{F}$ ). A recent study (Gonthier 2012) indicates that the thermal conductivity can be increased by $75 \%$ to $0.4 \mathrm{Btu} / \mathrm{h}-\mathrm{ft}-{ }^{\circ} \mathrm{F}$ by mixing thermally conductive fillers (e.g., thermoplastic elastomer and zinc oxide) with HDPE materials.

\subsubsection{Heat transfer fluid}

Palm and Ignatowicz (2016) studied the effects of corrosion inhibitors and other additives on the fluid and thermal properties of antifreeze mixtures. They are also investigating possible alternative additives such as nanoparticles and possible alternative water-antifreeze mixtures. It is estimated that the thermally enhanced heat transfer fluid can increase the convective heat transfer inside the heat exchanger loop by $35 \%$.

\subsubsection{Grouting material}

Grouting is the placement of a low permeability material into the annular space between the borehole wall and the heat exchanger loop in the borehole. The primary purpose of grouting is to prevent the movement of surface and/or subsurface groundwater along the borehole depth. Grouting material with a high thermal conductivity can reduce the resistance for transferring heat through the grout-filled annual space in the borehole. Bentonite-based grouting materials are generally considered the best grouting choice when conditions permit and are allowed by local and regional regulations. Cement-based grout is another option. However, cement-based grouts do not form a good lasting bond with plastic pipes, especially during heat extraction from the ground, which results in reduced heat transfer capability (IGSHPA 2000). The thermal conductivity of both bentonite- and cement-based grouts can be increased by mixing with thermally conductive additives, such as silica sands, quartzite sand, and carbon graphite (Tiedje and Guo 2013). Table 10 lists the thermal conductivities of various grouting materials. Several commercially available thermally enhanced grouts have thermal conductivities up to $1.6 \mathrm{Btu} / \mathrm{h}-\mathrm{ft}-{ }^{\circ} \mathrm{F}$.

Table 10. Thermal conductivities of various grouting materials

\begin{tabular}{lcc}
\hline \multicolumn{1}{c}{ Grouts } & $\begin{array}{c}\text { Thermal conductivity } \\
\left(\mathbf{B t u} / \mathbf{h}-\mathbf{f t}-{ }^{\circ} \mathbf{F}\right)\end{array}$ & Note \\
\hline Bentonite-water mixtures & $0.38-0.45$ & With $15.3 \%-30 \%$ bentonite solids \\
Bentonite-additive mixtures & $0.8-1.6^{a, b, c}$ & With sand or graphite \\
Cement-water mixtures & $0.5-0.56$ & Water/cement ratio: $0.46-0.62$ \\
Cement-additive mixtures & $0.71-1.54$ & With sand \\
\hline${ }^{a}$ A mix of bentonite and graphite (e.g., Barotherm Max) has a thermal conductivity of $1.6 \mathrm{Btu} / \mathrm{h} \cdot \mathrm{ft} \cdot{ }^{\circ} \mathrm{F}$. \\
${ }^{b}$ A mix of bentonite and silica sand (e.g., Barotherm Gold) has a thermal conductivity of $1.0 \mathrm{Btu} / \mathrm{h} \cdot \mathrm{ft} \cdot{ }^{\circ} \mathrm{F}$. \\
${ }^{c}$ A mix of bentonite and an engineered alternative to silica sand (e.g., PowerTECx) can achieve thermal conductivities ranging \\
from $0.79-1.60 \mathrm{Btu} / \mathrm{h} \cdot \mathrm{ft} \cdot{ }^{\circ} \mathrm{F}$.
\end{tabular}

\subsection{OPTIMIZATION OF BORE FIELD DESIGN}

Conventional bore field designs usually layout boreholes in regular grids and fix the spacing and depth of boreholes. The total number of boreholes are then determined to maintain the supply water temperature within a specific range for given thermal loads over a long period (e.g., 20 years). However, many design parameters can affect the required total number of boreholes (and the total length of drilling), including bore spacing, bore depth, layout of bores, and thermal loads allocated to each borehole. Bayer et al. (2014) reported that the total number of boreholes and the cost of a bore field can be reduced by strategically optimizing the layout and thermal load in each borehole. This strategy enforces uniform heat transfer within a bore field by removing less effective boreholes, which are usually located centrally in 
the field. This strategy is particularly effective when the heat extraction and heat rejection imposed to a bore field are not balanced on an annual basis, meaning more heat is rejected to the ground than that being extracted during a year, or vice versa. Chuck et al. (2017) demonstrated a unique circular configuration of a bore field in which boreholes are placed in three coaxial rings and the three boreholes in the same radial direction are connected in series. This configuration allows more heat to be transferred at the perimeter of the bore field where the spacing between boreholes is larger than in the core area.

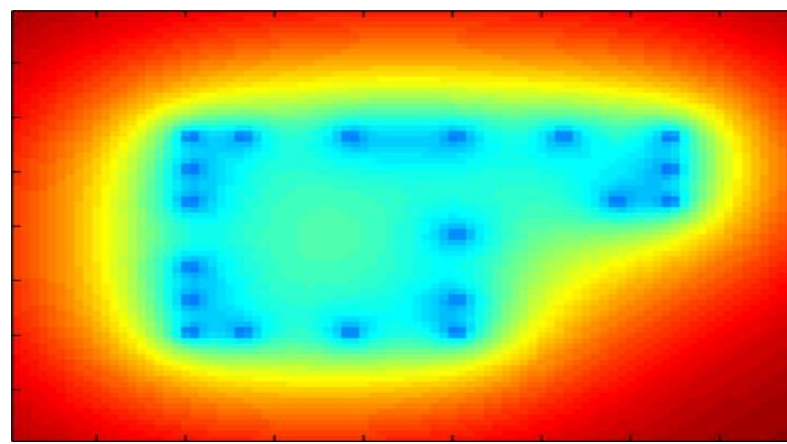

(a) Temperature distribution of a strategically optimized bore field by Bayer et al. (2014).

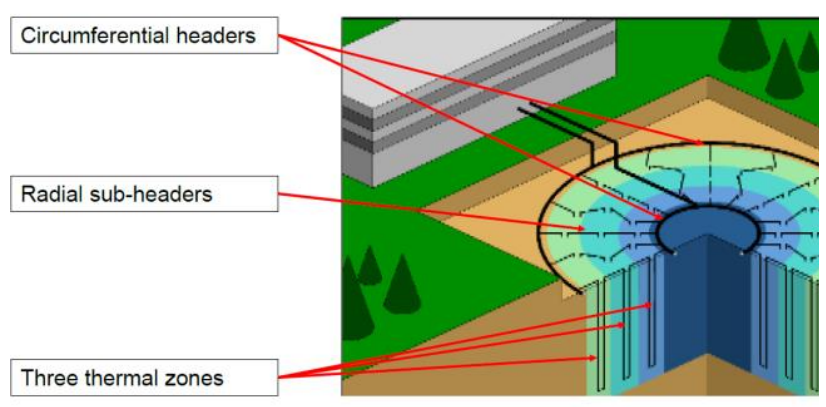

(b) Bore field layout and connection demonstrated by Chuck et al. (2017).

Figure 17. Examples of optimized bore field.

\section{ANALYSIS OF COST REDUCTION POTENTIAL OF VBGHXS}

A parametric study was conducted using the updated cost model and a widely used sizing tool for VBGHX to evaluate the effectiveness of various possible cost reduction solutions at various conditions, including different ground formations and thermal loads.

\subsection{METHODOLOGY}

This study focused on VBGHXs used for commercial GHP systems so that impacts of improvements in both individual BHEs and a bore field could be evaluated. A three-step procedure, depicted in Figure 18, was used to evaluate the cost reduction resulting from a given improvement. The first step is to determine the needed total bore length and associated cost of a baseline VBGHX for satisfying a given thermal load. The baseline VBGHX represents the typical design practice. The second step is to make an improvement in one of three aspects, including drilling, BHE design, and bore field configuration, then determine the needed total bore length and associated cost of the improved VBGHX for satisfying the same thermal load. The third step is to evaluate the resulting changes in the total bore length and the cost resulting from the improvement. 


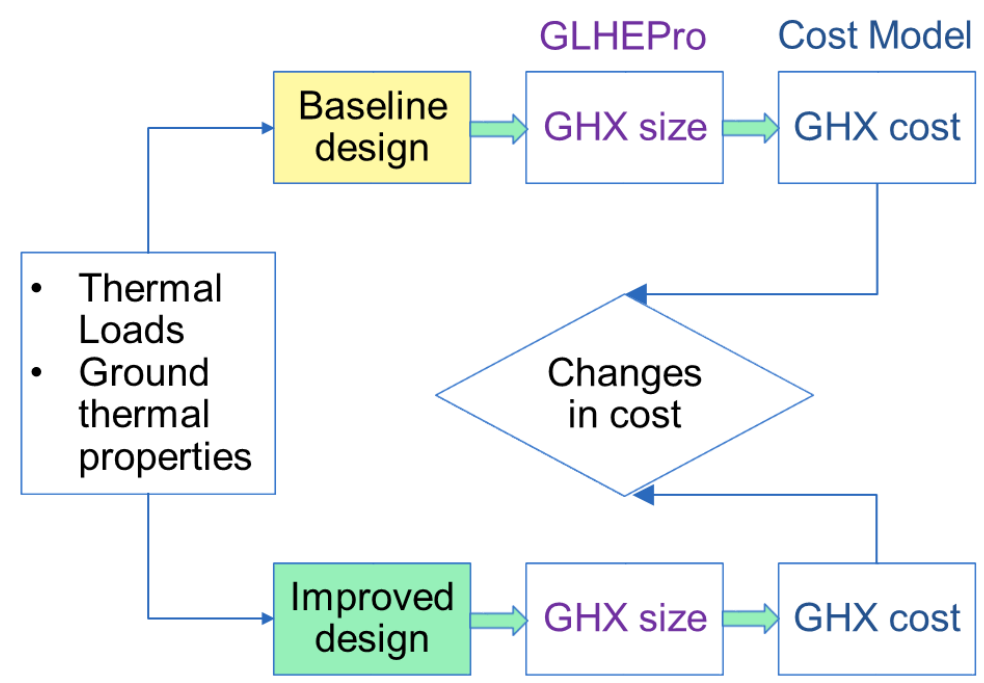

Figure 18. Procedure for evaluating cost reduction of improvements in VBGHXs.

The thermal loads are computed using building energy simulations for a GHP system serving a reference building at various climate zones. The reference building and the baseline design of the VBGHX are discussed in Subsection 6.1.1. The total bore length needed to satisfy the thermal load is determined with GLHEPro (Spitler et al. 2017). GLHEPro is a commercial software for sizing VBGHXs based on the widely used g-function method developed by Eskilson (1987).

\subsubsection{Reference Building and Baseline VBGHX Design}

For this study, the US Department of Energy (DOE) commercial reference building model (NREL 2011) for a medium-sized office was adopted to determine the thermal load of the VBGHX. The modeled office building has a floor space of 53,620 $\mathrm{ft}^{2}$. A distributed GHP system was modeled to provide space heating and cooling to the reference building. The distributed GHP system conditions each zone of the building with an individual water-to-air heat pump (WAHP). Multiple WAHPs are connected to the VBGHX through a common water loop. Four different ground formations were selected to represent the typical range of various ground formations. Thermal properties of the four ground formations are listed in Table 11 .

Table 11. Thermal properties of four different ground formations

\begin{tabular}{lcccc}
\hline & $\begin{array}{c}\text { Thermal conductivity } \\
\left(\mathrm{Btu} /\left[\mathrm{h}-\mathrm{ft}-{ }^{\circ} \mathrm{F}\right]\right)\end{array}$ & $\begin{array}{c}\text { Density } \\
\left(\mathrm{lb} / \mathrm{ft}^{3}\right)\end{array}$ & $\begin{array}{c}\text { Specific heat } \\
\left(\mathrm{Btu} /\left[\mathrm{lb}-{ }^{\circ} \mathrm{F}\right]\right)\end{array}$ & $\begin{array}{c}\text { Volumetric heat } \\
\left(\mathrm{Btu} /\left[{ }^{\circ} \mathrm{F}-\mathrm{ft}^{3}\right]\right)\end{array}$ \\
\hline Dense rock & 2 & 200 & 0.1997 & 39.93 \\
Average rock & 1.4 & 175 & 0.1997 & 34.94 \\
Heavy soil (damped) & 0.75 & 131 & 0.2298 & 30.1 \\
Heavy soil (dry) & 0.5174 & 100 & 0.2498 & 24.98 \\
\hline
\end{tabular}

Three different locations (Atlanta, Georgia; Seattle, Washington; and Helena, Montana) were selected to represent different thermal load profiles - significantly imbalanced, moderately imbalanced, and nearly balanced - as shown in Figure 19. 


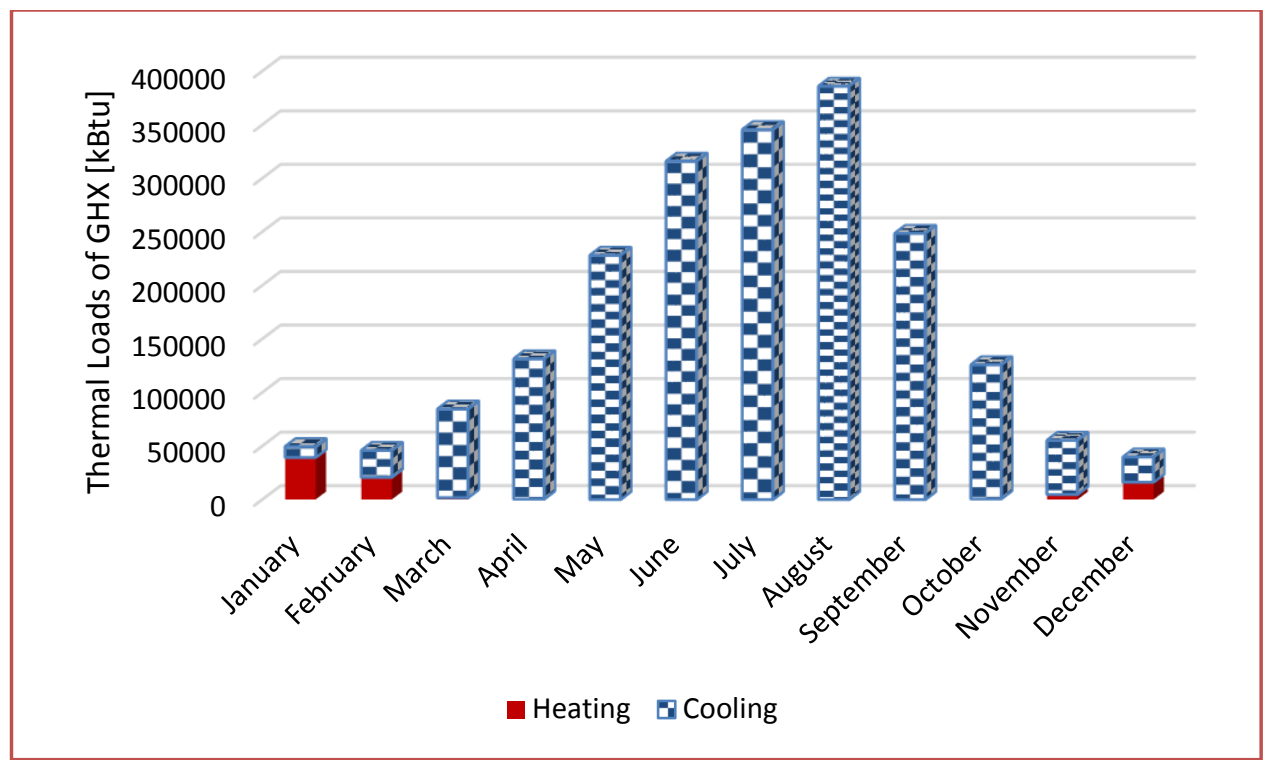

(a) Atlanta, Georgia (significantly cooling-dominated load profile)

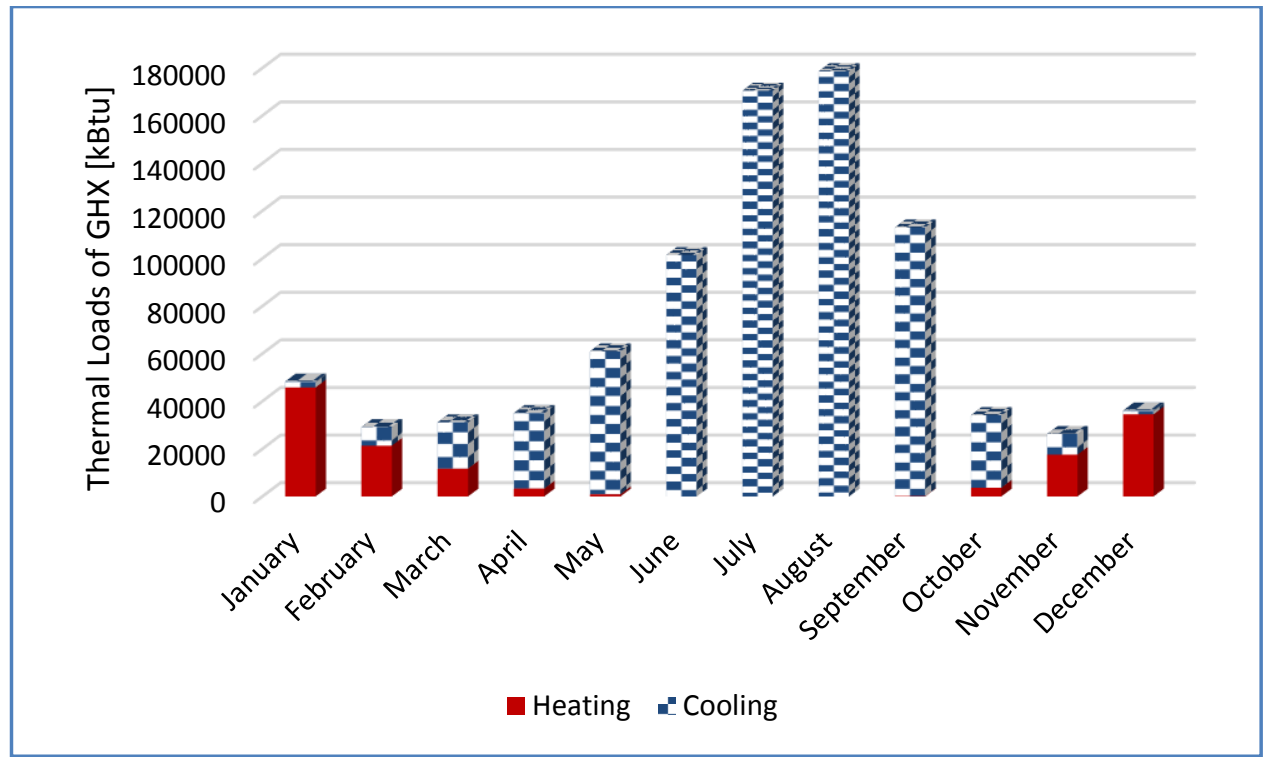

(b) Seattle, Washington (moderately cooling-dominated load profile) 


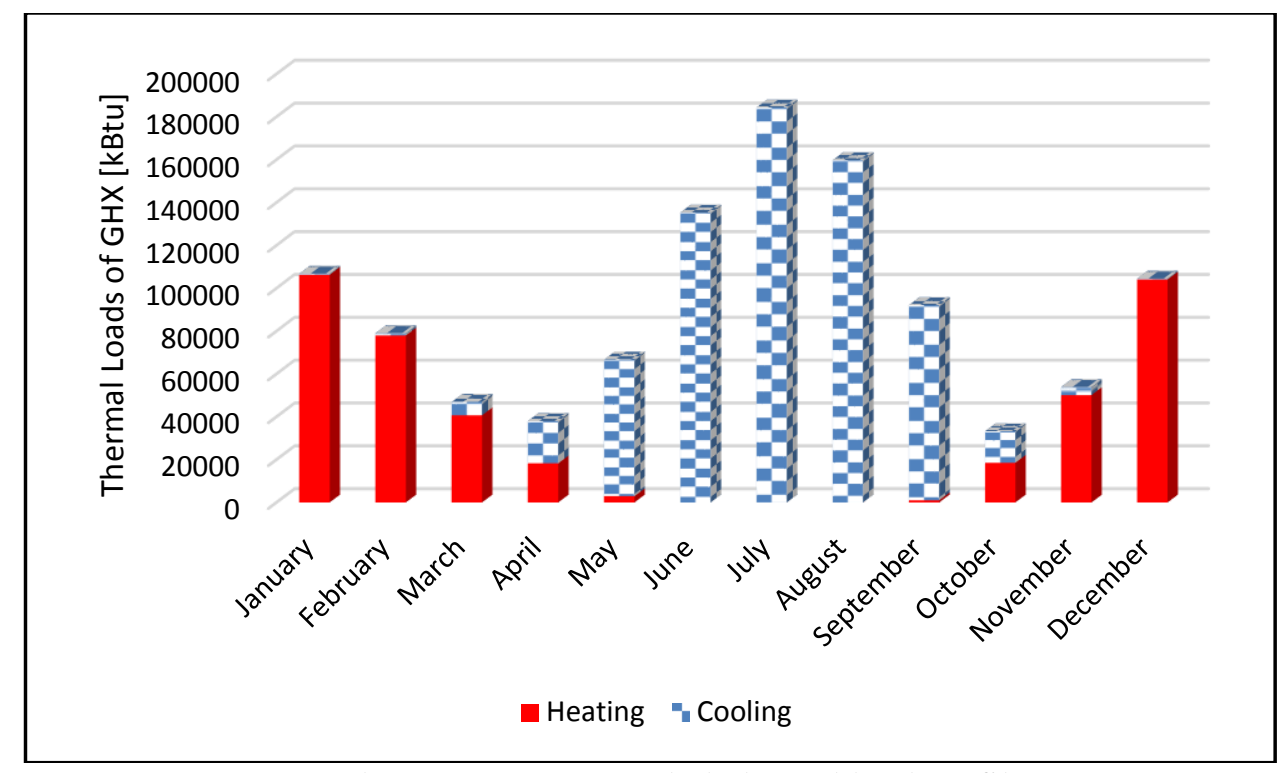

(c) Helena, Montana (nearly balanced load profile)

Figure 19. Mothly thermal loads at three locations.

Design of the baseline VBGHX is described subsequently, and it is assumed that a used 20-year-old mud rotary drill rig (priced at $\$ 200,000$ ) was used for drilling vertical bores:

- Boreholes with a 5.5 in. diameter are laid out in a square array with $20 \mathrm{ft}$ center-to-center spacing.

- The total number of boreholes and the depth of each bore are sized with GLHEPro to maintain the supply fluid temperature from the VBGHX within a desired range-from $12.5^{\circ} \mathrm{F}$ below to $27.5^{\circ} \mathrm{F}$ above the undisturbed ground temperature at a given location. The depth of the individual vertical bore in the base case will not exceed $400 \mathrm{ft}$.

- A single U-tube heat exchanger loop is made with HDPE pipe.

- Standard bentonite grouting is used $\left(\mathrm{K}=0.4 \mathrm{Btu} / \mathrm{h}-\mathrm{ft}-{ }^{\circ} \mathrm{F}\right)$.

- The heat transfer fluid is a $20 \%$ aqueous solution of ethanol.

- A $50 \mathrm{ft}$ steel casing from the ground surface is included.

\subsubsection{Investigated Improvements}

Improvements in three categories were investigated, including (1) borehole heat transfer, (2) bore field design, and (3) drilling. Table 12 lists the key BHE design parameters of the baseline VBGHX and 11 improved cases, each with one or several of the following borehole heat transfer improvements:

- Thermally enhanced (TE) pipe with $0.43 \mathrm{Btu} /\left(\mathrm{h}-\mathrm{ft}-{ }^{\circ} \mathrm{F}\right)$ thermal conductivity

- TE grouts with 1.6 or $1.0 \mathrm{Btu} /\left(\mathrm{h}-\mathrm{ft}-{ }^{\circ} \mathrm{F}\right)$ thermal conductivity

- TE fluid, which increases heat transfer inside the heat exchanger loop by $35 \%$

- Small boreholes with 4.5-in. bore diameter (BD)

- Alternative heat exchanger loops, including double U-tube and coaxial loops 
Table 12. Borehole heat exchanger designs of baseline and improved cases

\begin{tabular}{|c|c|c|c|c|c|c|c|}
\hline \multirow{3}{*}{ No. } & \multirow{3}{*}{$\begin{array}{c}\text { Case name } \\
\text { Baseline }\end{array}$} & \multirow{3}{*}{$\begin{array}{c}\begin{array}{c}\text { Borehole } \\
\text { thermal } \\
\text { resistance } \\
\left({ }^{\circ} \mathbf{F} / \mathbf{B t u} /[\mathbf{h}-\mathbf{f t}]\right)\end{array} \\
0.4205 \\
\end{array}$} & \multicolumn{3}{|c|}{ Materials } & \multicolumn{2}{|c|}{ Borehole design } \\
\hline & & & \multicolumn{2}{|c|}{$\begin{array}{l}\text { Grout Pipe } \\
\left.\left(\text { Btu/[h-ft- }{ }^{\circ} \text { F }\right]\right)\end{array}$} & \multirow{2}{*}{$\begin{array}{c}\begin{array}{c}\text { Fluid } \\
\text { type }\end{array} \\
\text { Water }\end{array}$} & \multirow{2}{*}{$\begin{array}{c}\begin{array}{c}\text { Loop } \\
\text { type }\end{array} \\
\text { Single } \\
\text { U-tube }\end{array}$} & \multirow{2}{*}{$\begin{array}{c}\begin{array}{c}\text { Bore diam } \\
\text { (in.) }\end{array} \\
5.5\end{array}$} \\
\hline & & & 0.43 & 0.225 & & & \\
\hline 1 & Grout_1.6 & 0.1736 & 1.6 & 0.225 & Water & $\begin{array}{l}\text { Single } \\
\text { U-tube }\end{array}$ & 5.5 \\
\hline 2 & Grout_1.0 & 0.2287 & 1 & 0.225 & Water & $\begin{array}{l}\text { Single } \\
\text { U-tube }\end{array}$ & 5.5 \\
\hline 3 & TE pipe ${ }^{a}$ & 0.3873 & 0.43 & 0.4 & Water & $\begin{array}{l}\text { Single } \\
\text { U-tube }\end{array}$ & 5.5 \\
\hline 4 & TE fluid & 0.4124 & 1 & 0.225 & TE fluid & $\begin{array}{l}\text { Single } \\
\text { U-tube }\end{array}$ & 5.5 \\
\hline 5 & D-U-Tube ${ }^{a}$ & 0.2313 & 1 & 0.225 & Water & $\begin{array}{l}\text { Double } \\
\text { U-tube }\end{array}$ & 5.5 \\
\hline 6 & BD_4.5 & 0.3416 & 1 & 0.225 & Water & $\begin{array}{l}\text { Single } \\
\text { U-tube }\end{array}$ & 4.5 \\
\hline 7 & D-U-Tube ${ }^{a}$ and BD_4.5 & 0.1542 & 1 & 0.225 & Water & $\begin{array}{l}\text { Double } \\
\text { U-tube }\end{array}$ & 4.5 \\
\hline 8 & Coaxial $^{b}$ with BD_4.5 & 0.3921 & 1 & 0.225 & Water & Coaxial & 4.5 \\
\hline 9 & $\begin{array}{c}\text { Coaxial }^{b} \text { with BD_5.5 } \\
\text { and Grout_1.0 }\end{array}$ & 0.3959 & 1 & 0.225 & Water & Coaxial & 5.5 \\
\hline 10 & $\begin{array}{c}\text { Coaxiall }^{b} \text { with BD_4.5 } \\
\text { and Grout_1.0 }\end{array}$ & 0.3639 & 1 & 0.225 & Water & Coaxial & 4.5 \\
\hline 11 & Bundle case & 0.0596 & 1.6 & 0.4 & TE fluid & $\begin{array}{l}\text { Double } \\
\text { U-tube }\end{array}$ & 4.5 \\
\hline
\end{tabular}

${ }^{a}$ Made with HDPE pipe (0.75 in. diameter and SDR-11 pressure rating).

${ }^{b}$ Made with HDPE pipes: 1 in. diameter inner pipe and 4 in. diameter outer pipe.

Table 12 also lists the calculated borehole thermal resistance (BTR) in each case. As shown in the table, applying TE grout reduces BTR significantly-59\% and $46 \%$ reduction in cases \#1 and \#2, respectively, compared with the baseline. TE pipe results in a small reduction (8\%) in BTR as shown in case \#3. TE fluid has little impact on BTR - only $2 \%$ reduction in case \#4. Double U-tube loop alone (case \#5) results in $45 \%$ reduction in BTR, which is very close to the reduction resulting from applying TE grout.

Downsizing the bore diameter alone (cases \#6) results in a 19\% reduction in BTR, which is larger than the reduction from applying TE pipe or TE fluid. Combining downsized bore diameter with a double Utube (case 7) results in 63\% reduction in BTR, which is larger than applying the best grout. On the other hand, the reduction in BTR is not significant (less than 15\%) by applying the coaxial exchangers even when combined with downsized bore diameter or TE grout (cases \#8 through \#10). A combination of TE grout (with $1.6 \mathrm{Btu} /\left(\mathrm{h}-\mathrm{ft}-{ }^{\circ} \mathrm{F}\right.$ thermal conductivity), double U-tube pipe, TE pipe, and TE fluid results in $86 \%$ reduction in BTR, which is the largest among all the investigated cases.

Table 13 lists prices of the improved materials and alternative heat exchanger loops used in this study. The prices of more commonly used materials are given in Table 4. Because of currently limited applications of coaxial loop and TE pipe, their market prices are not available to authors of this report. As a result, they are estimated based on the market prices of standard HDPE pipe (with $0.75 \mathrm{in}$. diameter and SDR-11 pressure rating). It is assumed that the TE pipe has the same price as the standard HDPE pipe and that the TE fluid has the same price as standard propylene glycol. 
Table 13. Prices of improved materials and loops used for borehole heat exchangers

\begin{tabular}{ll}
\hline \multicolumn{1}{c}{ Item } & \multicolumn{1}{c}{ Price $(\$)$} \\
\hline Double U-tube loop & 1.04 per linear foot of borehole \\
Coaxial loop & $1.0^{a}$ per linear foot of loop \\
TE pipe & $0.26^{b}$ per linear foot of pipe \\
TE fluid & $14.6^{c}$ per gallon \\
TE grout with $1.0 \mathrm{Btu} /\left(\mathrm{h}-\mathrm{ft}-{ }^{\circ} \mathrm{F}\right)$ thermal conductivity & 1.0 per gallon \\
TE grout with $1.6 \mathrm{Btu} /\left(\mathrm{h}-\mathrm{ft}-{ }^{\circ} \mathrm{F}\right)$ thermal conductivity & 1.5 per gallon \\
\hline
\end{tabular}

${ }^{a}$ Include both the inner (1 in. diameter) and outer (4 in. diameter) pipes.

${ }^{b}$ Assuming at the same price of the standard HDPE pipe (0.75 in. diameter and SDR-11 pressure rating).

${ }^{c}$ Assuming at the same price of propylene glycol (\$800/55 gal).

The impact of bore field design on the cost of a VBGHX was also investigated through a parametric study. In this study, it was assumed that the available land area for installing the bore field was fixed, but bore spacing and bore depth could be adjusted to satisfy the design criterion as discussed before.

Figure 20 shows that as the spacing between boreholes (indicated by the blue dots) increases the bore number is reduced. Therefore, to satisfy the given thermal load, bore depth must be increased. The upper limit of the bore depth was set to $1,000 \mathrm{ft}$ in this study.
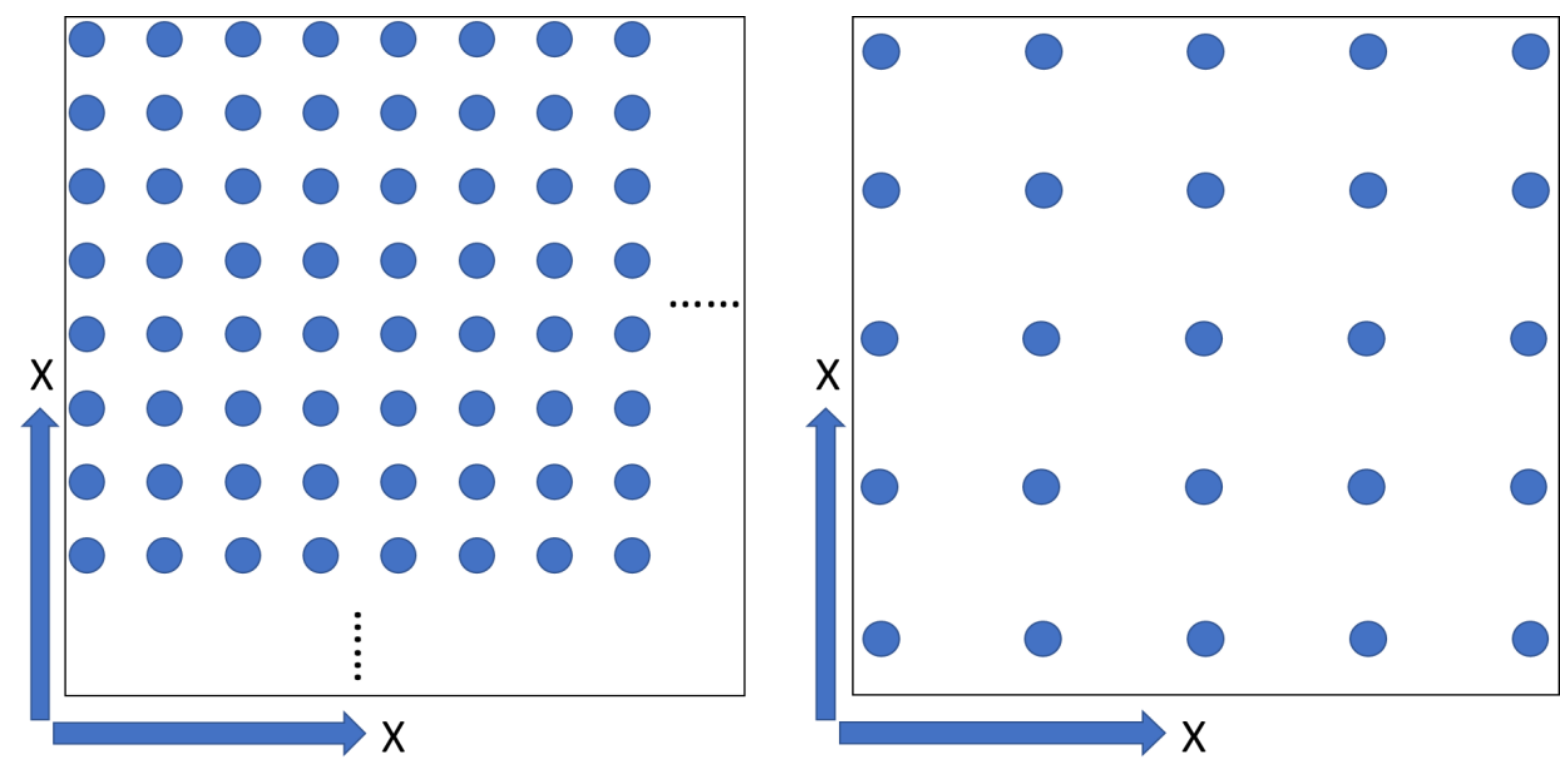

Figure 20. Bore field configuration with increased bore spacing within a fixed land area.

Improvements in drill rigs, such as advanced drill bits, improved power control, and automated drill pipe manipulation, could increase the drilling ROP. A drill rig with a higher ROP might be more expensive than conventional drill rigs. However, if the drill rig is customized for VBGHX installation, its cost might be lower than the multipurpose drill rigs currently used. The impacts of increased ROP on the installed cost of a VBGHX at various ground formations were investigated under three scenarios of different prices for the drill rigs. 


\subsection{RESULTS}

\subsubsection{Effectiveness of Improving Borehole Heat Transfer}

Figures 21 (a) and (b) show percentages of total bore depth reduction in the 11 improved cases listed in Table 12 at the three different locations. Figure 21 (a) shows results with a high ground thermal conductivity (GTC) value, while Figure 21 (b) shows results with a low GTC value.

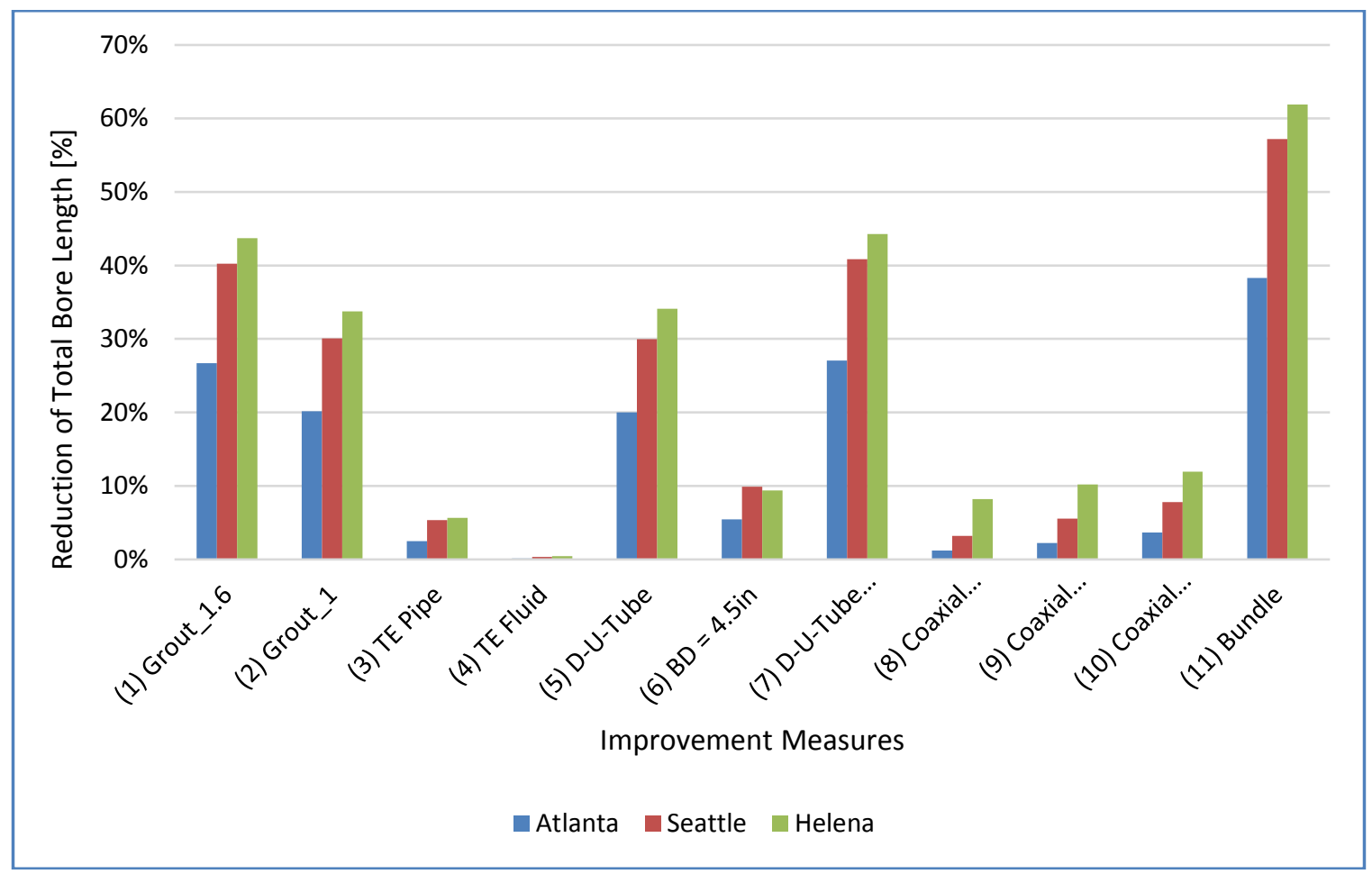

(a) With high GTC (2 Btu/h-ft- $\left.{ }^{\circ} \mathrm{F}\right)$ 


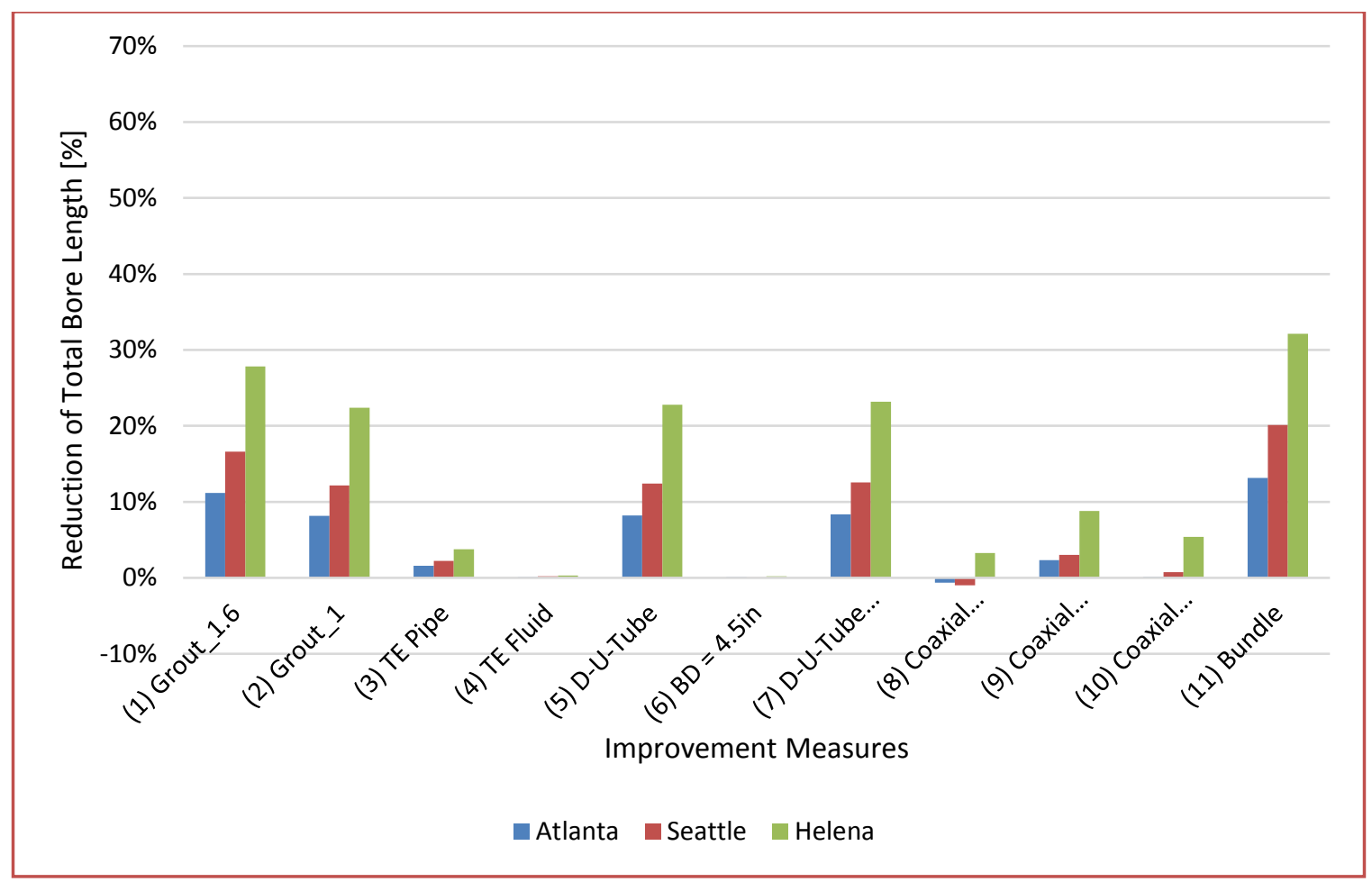

(b) With low GTC $\left(0.52 \mathrm{Btu} / \mathrm{h}-\mathrm{ft}-{ }^{\circ} \mathrm{F}\right)$

Figure 21. Percentages of total bore length reduction resulting from improvements in borehole heat transfer.

The following trends can be observed from these figures:

- GTC affects the bore length reduction potential resulting from borehole heat transfer improvement - more reduction occurs at places with higher GTC.

- The thermal load profile also plays a key role in bore length reduction. For a given improvement, more bore length reduction can be expected if the thermal loads (heat extraction and heat rejection) are more balanced on an annual basis.

- TE grout and double U-tube loops can most effectively reduce bore length compared with other individual improvements. Applying coaxial heat exchangers can reduce the required bore length, but the reduction was less than $12 \%$ in all the investigated cases. Downsizing borehole diameter results in a moderate bore length reduction (5-9\%) at places with a higher GTC, but it is not effective where GTC is low. TE pipe and TE fluid have a very small impact on the bore length since the heat transfer resistance of the pipe wall and inside the heat exchanger loop is much smaller than other components of the BTR if the flow inside the loop is turbulent.

- Combining all the individual improvements, the required bore length for satisfying a given thermal load can be reduced by $38-62 \%$ when GTC is $2 \mathrm{Btu} /\left(\mathrm{h}-\mathrm{ft}-{ }^{\circ} \mathrm{F}\right)$, but the percentages become smaller (13-32\%) when GTC is only $0.52 \mathrm{Btu} /\left(\mathrm{h}-\mathrm{ft}-{ }^{\circ} \mathrm{F}\right)$.

Figures 22 (a), (b), and (c) show the cost reduction percentages of individual BHE resulting from the 11 different improvements. The numerical number in the horizontal axes of these figures is the index number of each improvement as listed in Table 12. Each figure shows cost reduction percentages at one of the three locations (with different thermal load profiles), and bars with assorted colors indicate different ground formations. The following trends can be observed from these figures: 
- Although applying all the investigated improvements can reduce the required total bore length, the impacts of the improvements on the cost of implementing a BHE are different and they are strongly dependent on the cost for applying an improvement and the GTC where the BHE is installed. Moderate cost reductions (the negative percentages shown in Figure 22) are realized by applying TE grout, double U-tube, or both (cases 1, 2, 5, 7, and 11) at locations with relatively high GTC values (e.g., dense rock). However, the installed cost of a BHE could increase because of applying the same improvements at a ground formation with low GTC value (e.g., dry soil), which indicates that the cost reduction due to the shortened bore length is less than the cost premium of the TE grout or the double U-tube loop.

- Applying the coaxial heat exchangers results in increased cost in all investigated cases. This is because while using coaxial heat exchangers can shorten the required bore length (Figure 21), their cost is much higher than that of the conventional single U-tube loop.

- Applying TE pipe and TE fluid, or downsizing borehole diameter (cases 3, 4, and 6) can slightly reduce the installed cost of a BHE (less than $6 \%$ cost reduction) in all the investigated cases because these improvements can shorten the required bore length and associated labor and equipment cost without any cost premium. As discussed earlier, it is assumed that the prices of the improved materials are the same as those of the conventional materials (Table 13). This result indicates that it is not worth the cost to use more expensive pipe and heat transfer fluid for BHEs.

- Applying all the individual improvements together, the installed cost of a BHE can be reduced by up to 33\% (e.g., at Helena, Montana, and with dense rock), but this will also increase the installed cost by up to $24 \%$ in other applications (e.g., at Atlanta, Georgia, and with dry soil). This result indicates that improving borehole heat transfer by applying expensive materials and heat exchangers can reduce the installed cost of BHEs if the ground formation has high GTC and the thermal loads are nearly balanced. However, these improvements are not recommended as a cost reduction measure in areas with low GTC and imbalanced thermal loads. This is because the thermal resistance of the ground formation and the thermal interactions among BHEs are the dominant factors affecting the performance of a VBGHX so that improving borehole heat transfer is not cost effective.

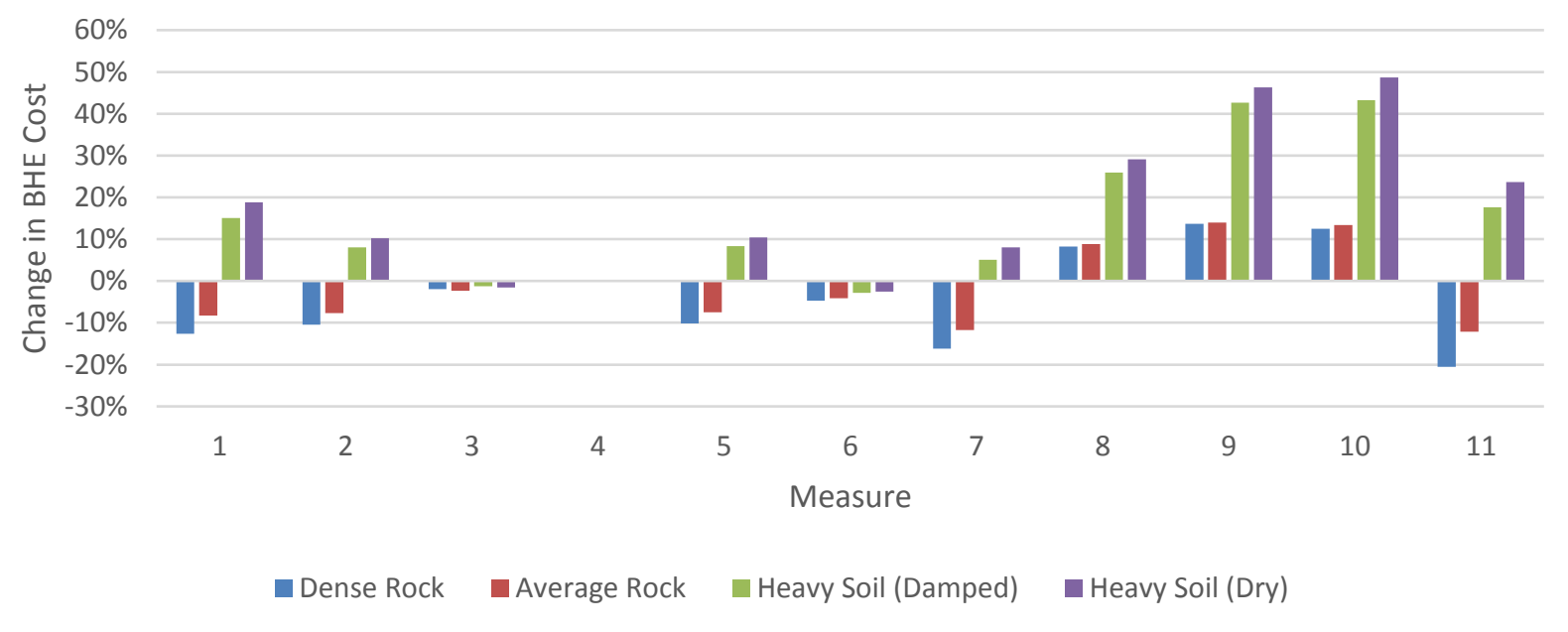

(a) Atlanta, Georgia (with significantly cooling-dominated load profile) 


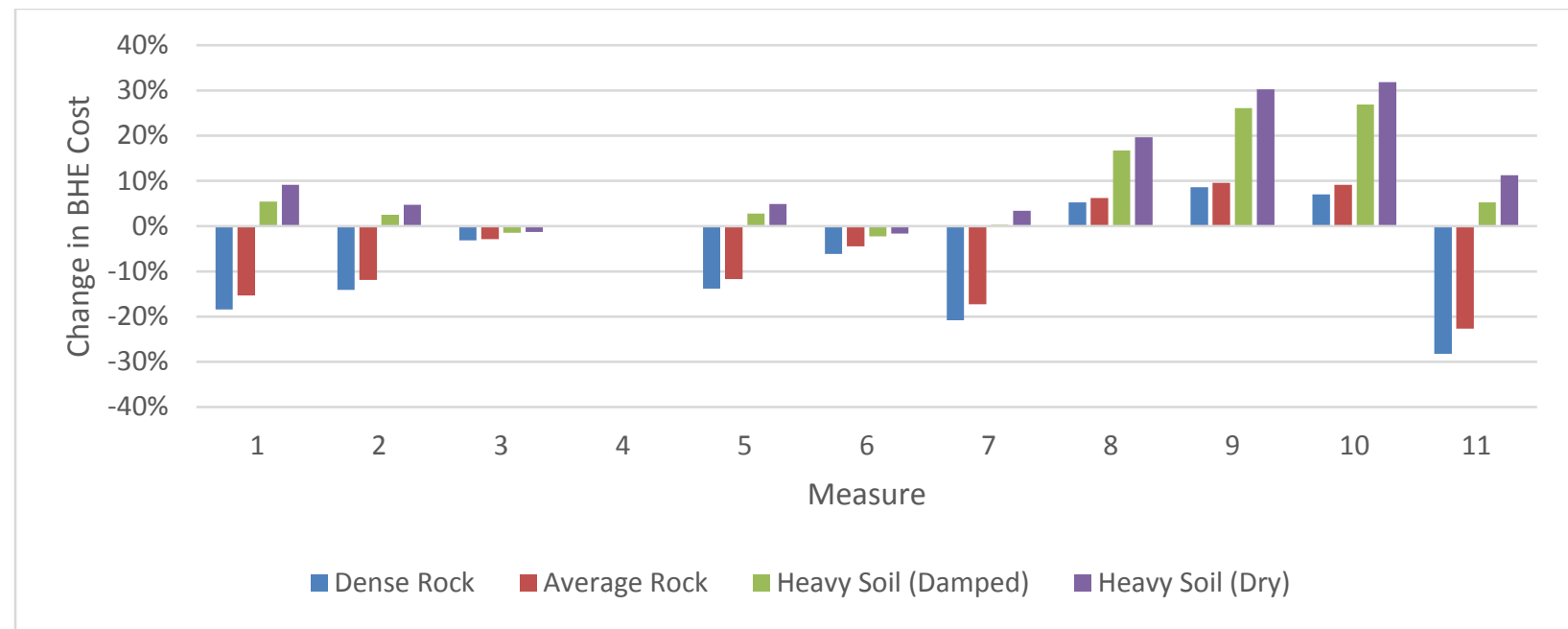

(b) Seattle, Washington (with moderately cooling-dominated load profile)

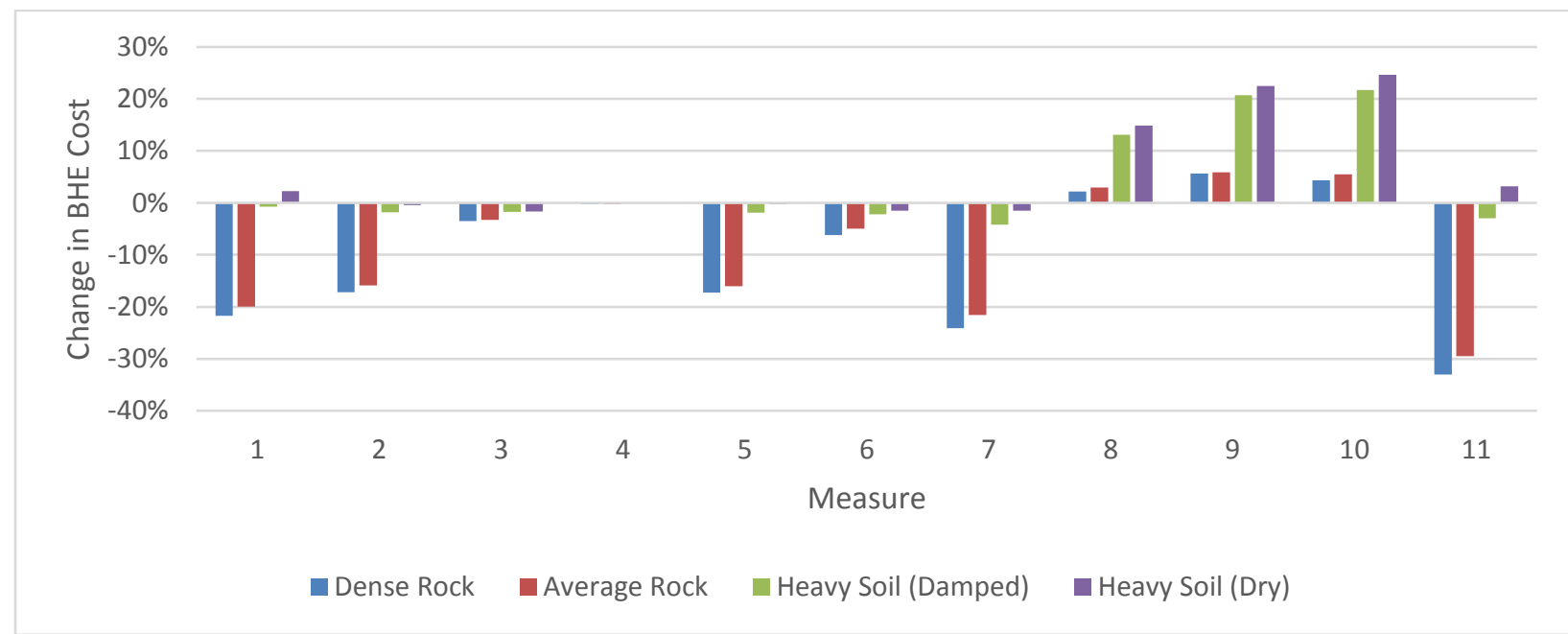

(c) Helena, Montana (with nearly balanced load profile)

Figure 22. Changes of borehole heat exchanger cost resulting from improvements in borehole heat transfer.

\subsubsection{Effectiveness of Improving Bore Field Design}

In addition to borehole heat transfer improvement, the impacts of increasing bore spacing within a fixed land area (described in Section 6.1.2) were investigated through a parametric study. In this study, all the BHEs in a bore field used single U-tube loops but they were improved by using the thermally enhanced materials (grout, pipe, and fluid) and smaller (4.5 in) bore diameter. After each change in the bore spacing, the resulting borehole numbers and the needed depth of each borehole were calculated with GLHEPro. Figures 23 and 24 show (a) the reduction of the total bore length of the entire bore field and (b) the needed depth of each individual BHE in ground formations with high and low GTC values, respectively. The data series in these figures represent various locations (i.e., thermal load profiles). 


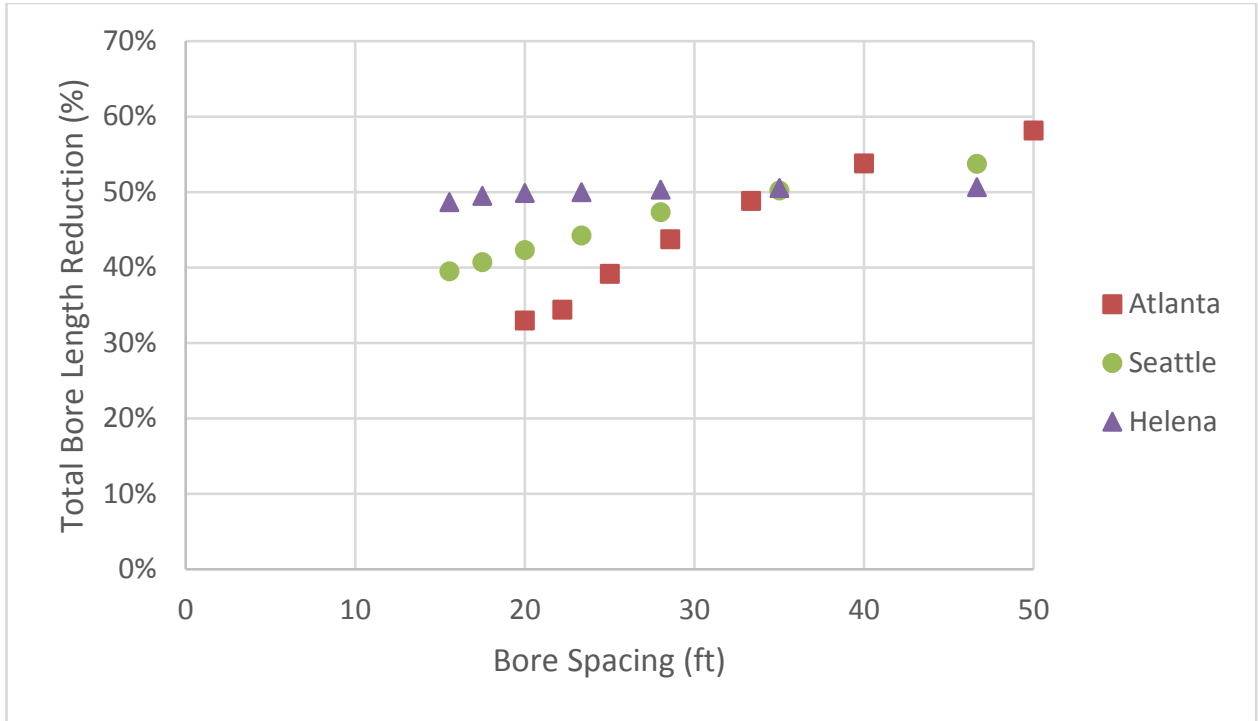

(a) Reduction in total bore length

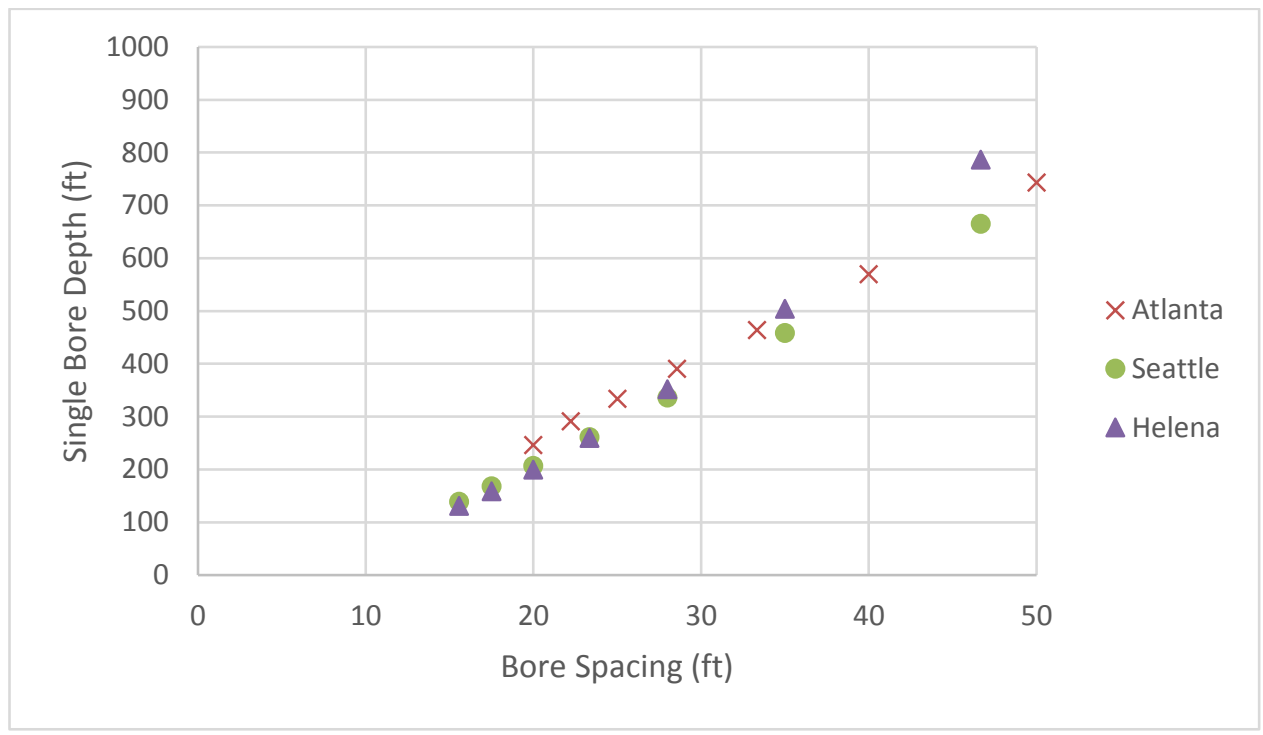

(b) Increase in individual bore depth

Figure 23. Changes in (a) total bore depth of a bore field and (b) depth of individual borehole resulting from increasing bore spacing (with high GTC $-2 \mathrm{Btu} /\left[\mathrm{h}-\mathrm{ft}-{ }^{-} \mathrm{F}\right]$ ). 


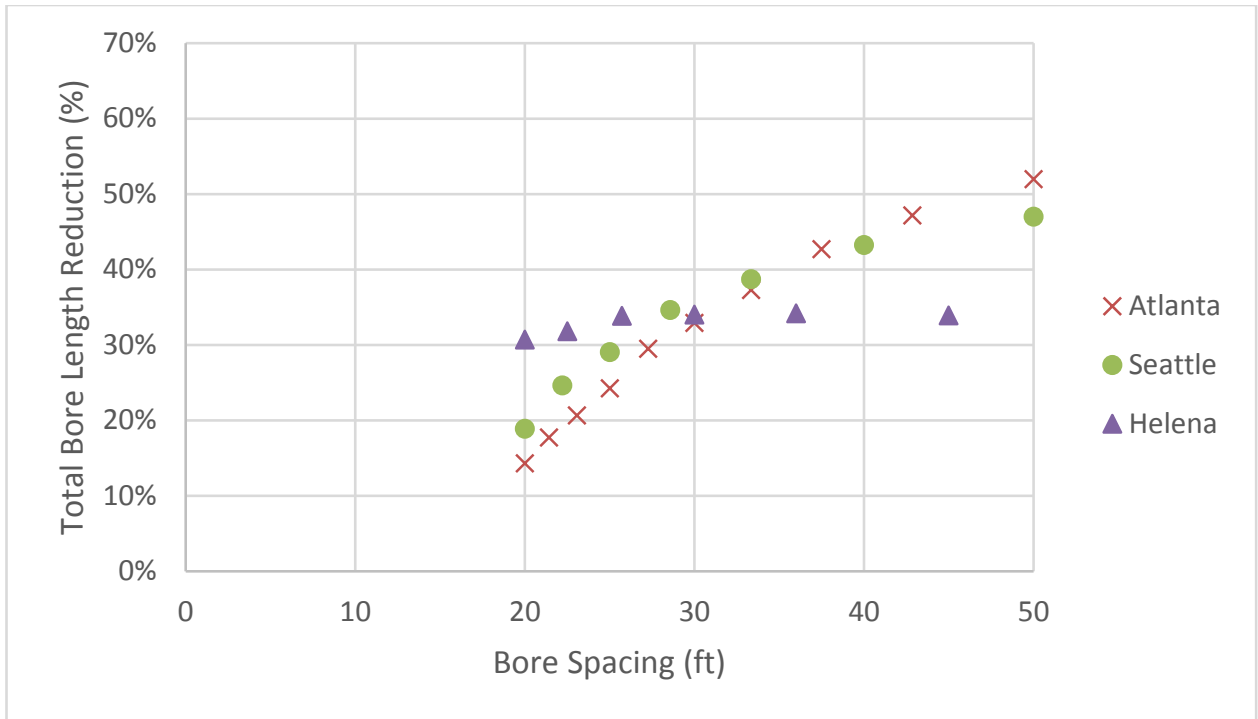

(a) Reduction in total bore length

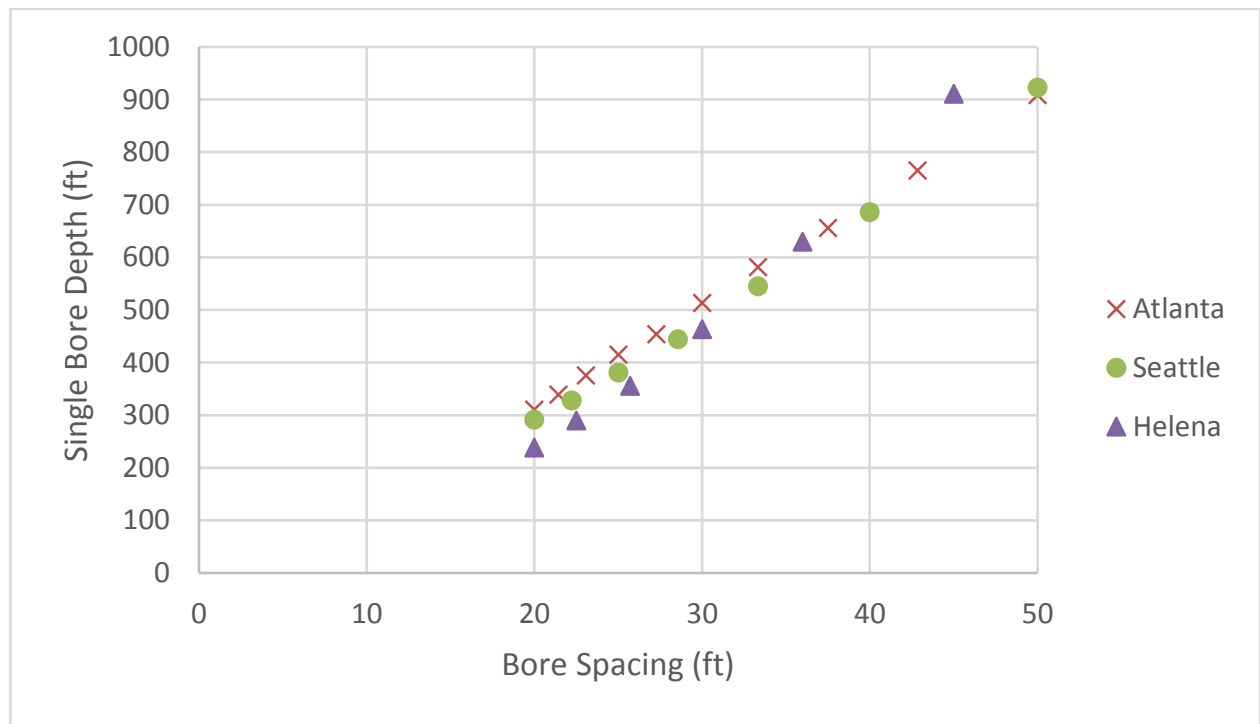

(b) Increase in individual bore depth

Figure 24. Changes in (a) total bore depth of a bore field and (b) depth of individual borehole resulting from increasing bore spacing (with high GTC $-0.52 \mathrm{Btu} /\left[\mathrm{h}-\mathrm{ft}-{ }^{\circ} \mathrm{F}\right]$ ).

The following trends can be observed from Figures 23 and 24:

- Increasing bore spacing can further reduce the required total bore length of an entire bore field if the thermal loads are not balanced. For cases with balanced thermal loads (e.g., at Helena, Montana), increasing bore spacing beyond $15 \mathrm{ft}$ at a ground formation with a high GTC (or $30 \mathrm{ft}$ at a ground formation with a low GTC) does not further reduce the total bore length. On the other hand, increasing bore space from 20 to $30 \mathrm{ft}$ in Atlanta, Georgia (with significantly imbalanced thermal loads) would reduce the total bore length by about $45 \%$ compared with the baseline when GTC is high (34\% reduction when GTC is low). This is about $12-20$ percentage points more reduction, depending on GTC value, than that resulting from just improving borehole heat transfer alone (indicated by data points with $20 \mathrm{ft}$ spacing). The impact of bore spacing on the 
total bore length reduction is smaller (about 8-16 percentage points more reduction) for a bore field with moderately imbalanced thermal loads (e.g., at Seattle, Washington).

- The depth of individual boreholes increases linearly with the increasing of bore spacing. At places with a high GTC $\left[2 \mathrm{Btu} /\left(\mathrm{h}-\mathrm{ft}-{ }^{\circ} \mathrm{F}\right)\right]$, the needed individual bore depth is less than $400 \mathrm{ft}$ after increasing bore spacing to $30 \mathrm{ft}$ (and thus reducing the total borehole numbers quadratically). In contrast, the needed individual bore depth must be increased to more than $450 \mathrm{ft}$ for a $30 \mathrm{ft}$ bore spacing when GTC is low $\left(0.52 \mathrm{Btu} /\left[\mathrm{h}-\mathrm{ft}-{ }^{\circ} \mathrm{F}\right]\right)$.

Figures 25 (a), (b), and (c) show the reduction in bore field cost, which includes both the costs for implementing each individual BHE and the distributed costs, as discussed in Section 3.4, resulting from improving both the borehole heat transfer and the bore field layout. Each figure shows cost reduction percentages at various locations (i.e., thermal load profiles); data points with assorted colors indicate different ground formations.

These figures indicate that the total bore field cost can be reduced by up to $50 \%$ by improving borehole heat transfer and increasing bore spacing to $30 \mathrm{ft}$. Increasing bore spacing will not only reduce the total bore length and the related drilling cost but will also reduce some distributed costs because of the reduced bore numbers (e.g., the costs of horizontal piping and relocation of drill rigs). Figure 25 also indicates that the cost reduction resulting from improving the bore field layout is more effective at places with high GTC and imbalanced thermal loads. However, the slope of cost reduction decreases after increasing bore spacing beyond $30 \mathrm{ft}$.

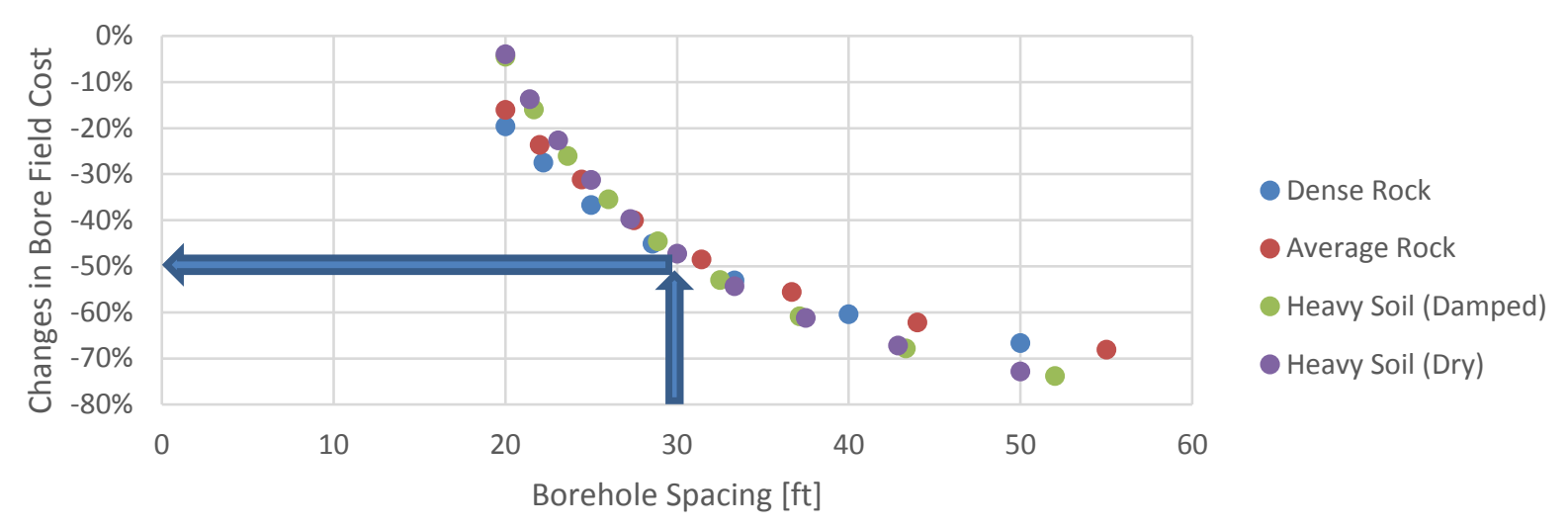

(a) Atlanta, Georgia (with significantly cooling-dominated load profile)

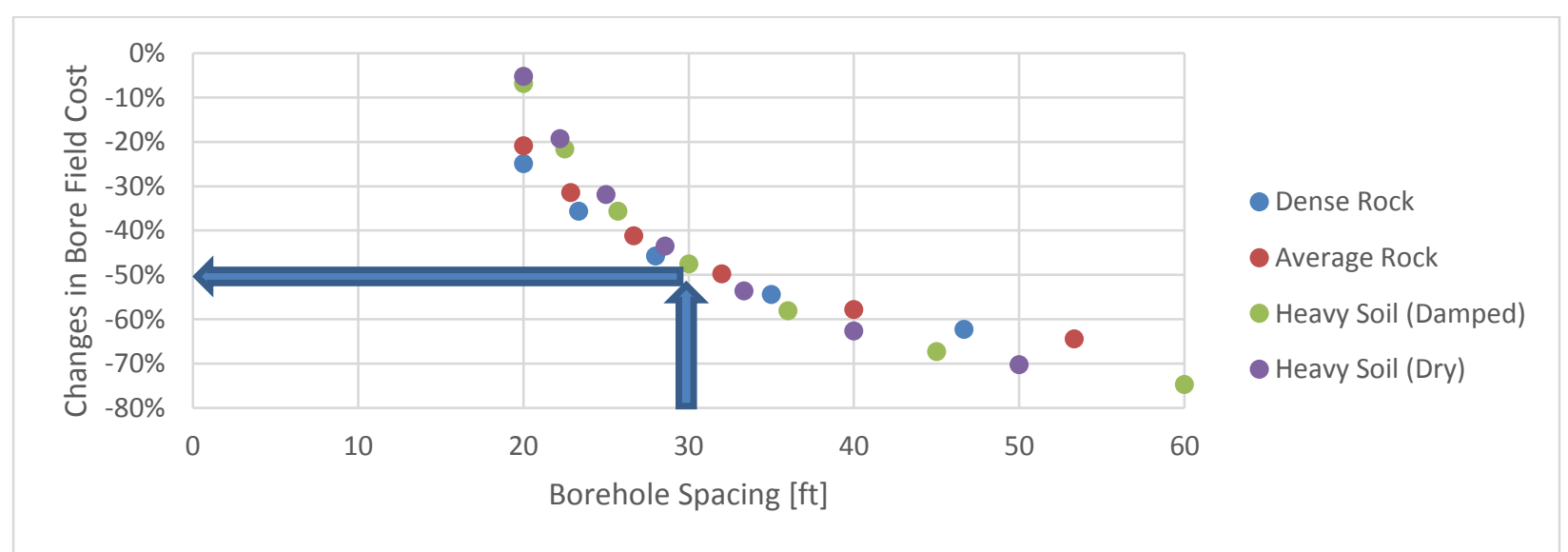

(b) Seattle, Washington (with moderately cooling-dominated load profile) 


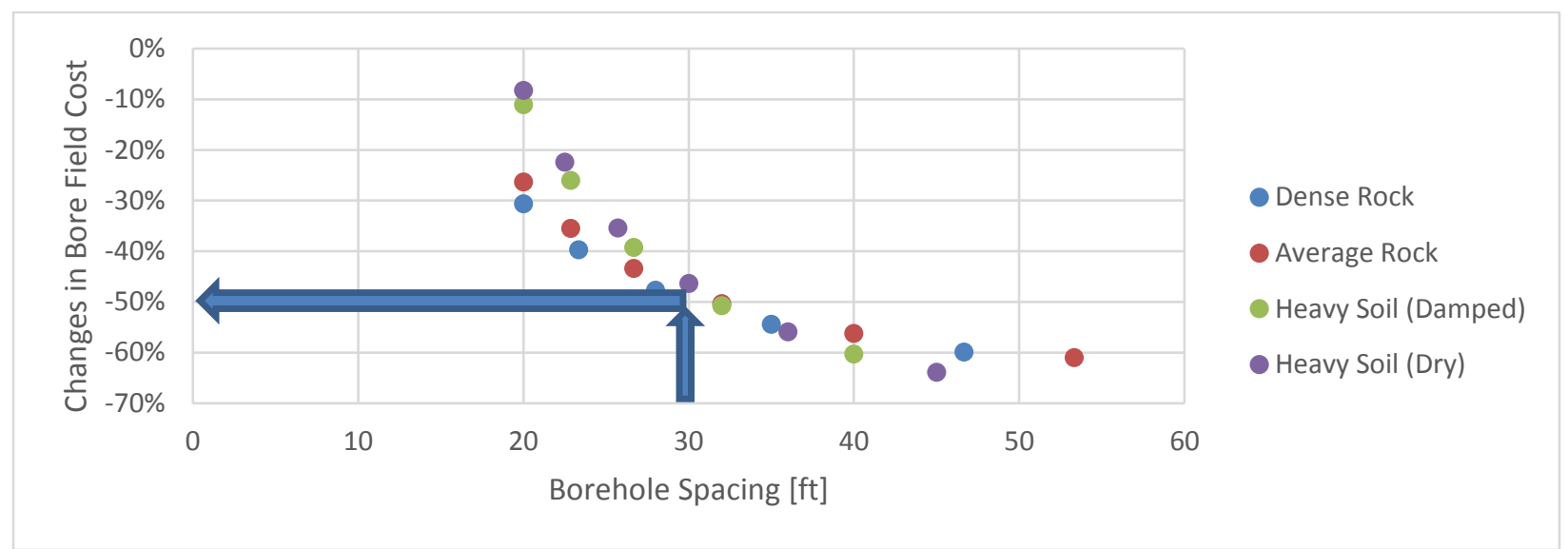

(c) Helena, Montana (with nearly balanced load profile)

Figure 25. Changes in total bore field cost resulting from improving borehole heat transfer and bore field layout.

\subsubsection{Effectiveness of Improving Drill Rigs}

Figure 26 shows the reduction percentages of the normalized cost of individual BHE resulting from increased ROPs, assuming the price of the drill rig is fixed $(\$ 200,000)$ and does not vary with the ROPs. As can be seen in this figure, the reduction of the normalized cost of individual BHE increases with the increase of ROP, but the relationship is not linear - the cost reduction percentages become smaller after increasing ROP by $25 \%$ from the current average value (listed in Table 3 ). This is because the contribution of drilling-related costs in the overall BHE cost becomes smaller with the increase of ROP. With a $25 \%$ increase in ROP, the normalized cost can be reduced by $16 \%$ when drilling at rock and without casing. If casing is used, the cost would be reduced by only $12 \%$. With the same increase in ROP, the cost reduction is smaller when drilling at shale (easier for drilling) $-10 \%$ without casing and $6 \%$ with casing. The cost can be reduced by $15 \%$ (at shale with casing) to 39\% (at rock without casing) if ROP is increased by $100 \%$. As shown in Table 3, the average ROP of rotary drilling at shale is about three times that at rock; therefore, the drilling cost contributes much less to the overall cost when drilling in shale than in rock. This explains the smaller cost reduction when drilling at shale than at rock resulting from the same increase of ROP. The extra cost for casing increases the overall cost of the BHE and thus leads to a smaller share of drilling cost. As a result, drilling with casing showed smaller cost reduction percentages resulting from increased ROP when compared with drilling without casing. 


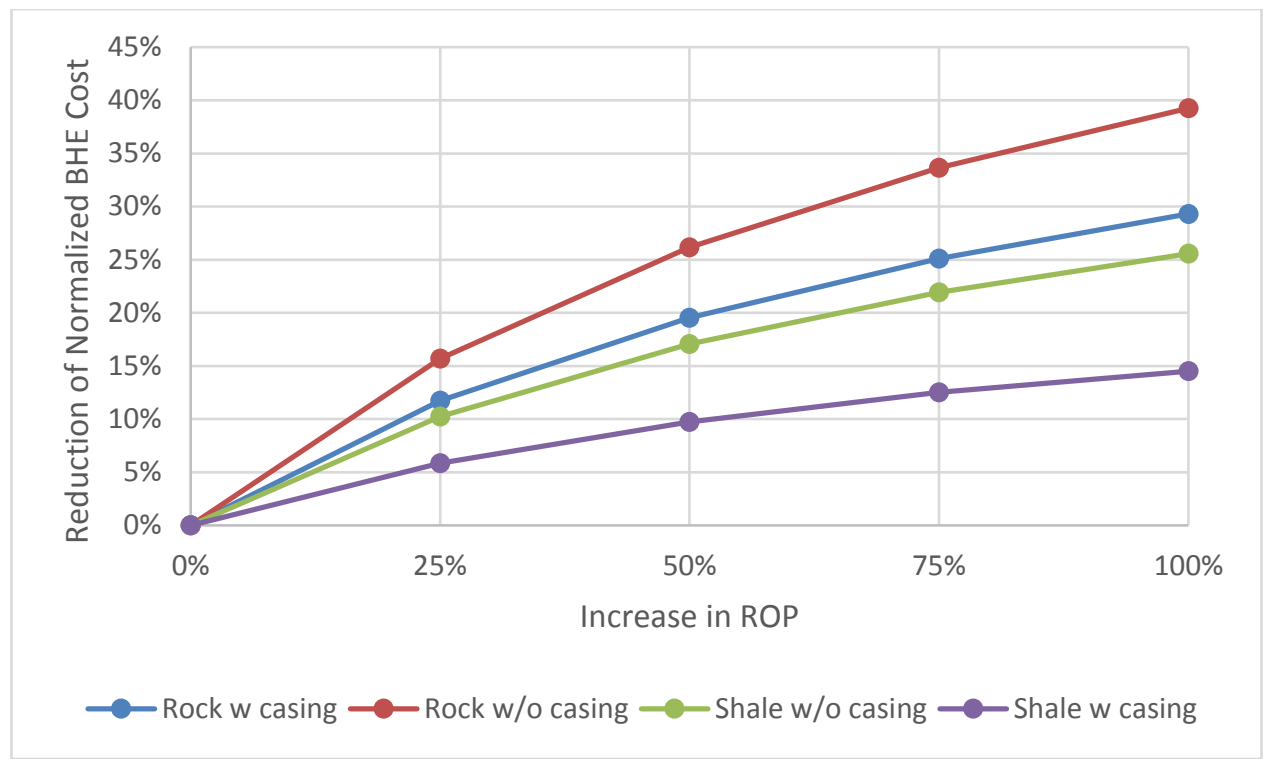

Figure 26. Reduction in normalized borehole heat exchanger cost resulting from increased rate of penetration at various drilling conditions.

To account for changes of drill rig price on the BHE cost reduction, further analysis was conducted. Figure 27 shows the reduction in the normalized cost of individual BHE resulting from a $25 \%$ increase in ROP at four different drilling conditions. Three scenarios of price changes were studied-no change, $25 \%$ decrease, and $25 \%$ increase - in each drilling condition. Between the $25 \%$ increase and $25 \%$ decrease of the drill rig prices, the cost reduction varies from $9 \%$ to $12 \%$ when drilling at rock with casing and from $12 \%$ to $20 \%$ without casing. The cost reduction is only $4 \%-8 \%$ when drilling at shale with casing, and it is slightly higher $(7 \%-14 \%)$ without casing.

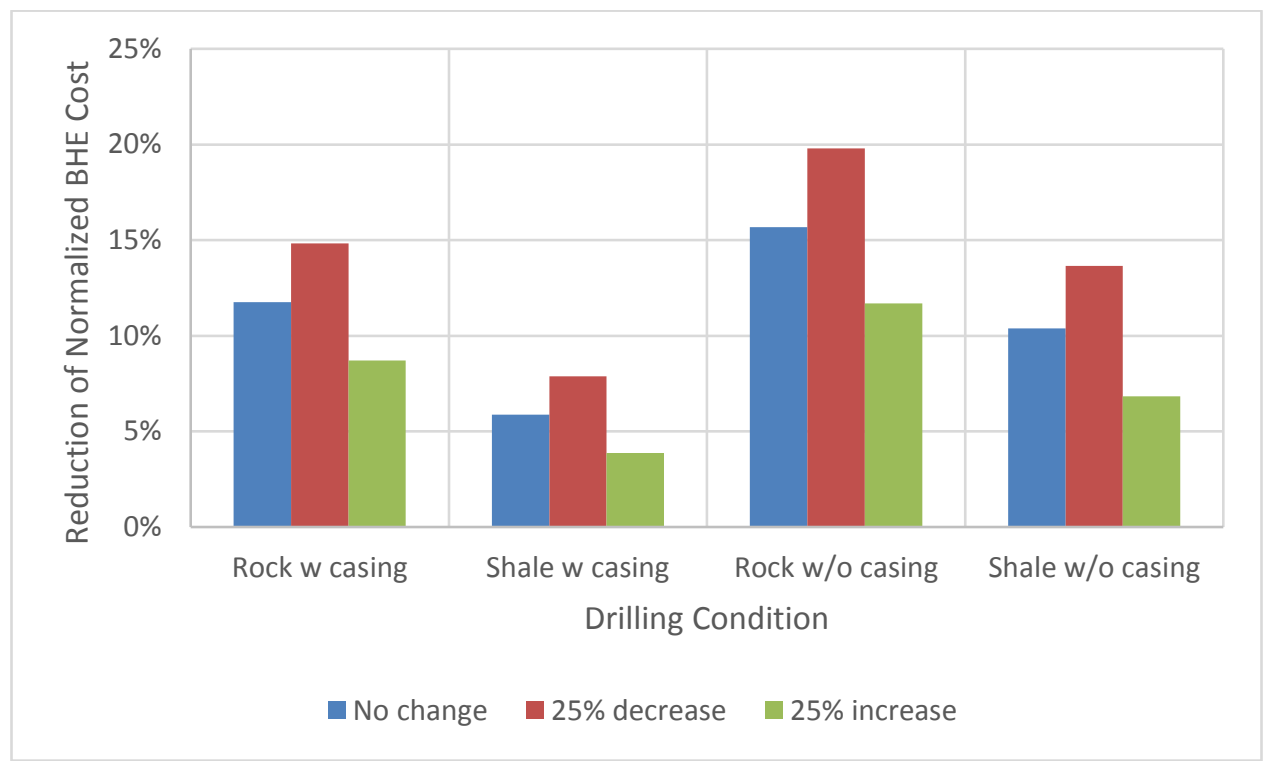

Figure 27. Reduction in normalized borehole heat exchanger cost redulting from a $25 \%$ increase in the rate of penetration at various drilling conditions under three price change scenarios. 


\section{CONCLUSIONS AND RECOMMENDATIONS}

This study systematically analyzed the installation processes and associated costs of VBGHXs to identify the following key factors that affect the time and cost of a VBGHX installation:

- Drilling contributes the most to both the time and the overall cost of a VBGHX installation in the presented base case. Reducing drilling time by increasing ROP and more time effectively using drill rigs can reduce the drilling time and the associated cost. There is a tradeoff between increased ROP and the price of drill rigs.

- Other nondrilling activities also contributed significantly to the time and cost, particularly the activities associated with preparing heat exchanger loop and grouting. Advanced materials that can reduce the price of pipe and grout, or reduce the needed size of VBGHXs, while retaining performance have the potential to reduce costs.

The cost reduction potential of various improvements was evaluated through a parametric study using an updated cost model for VBGHX installation and coupled with a well-established sizing program for VBGHX. The updated cost model can predict detailed cost breakdown for each task of the installation process. Baseline specifications were developed to represent typical VBGHX installation that covers a large fraction of the residential and commercial market. This baseline scenario was then altered to assess the impacts of improvements in borehole heat transfer design, bore field layout, and drilling technologies on the installed cost of VBGHXs under various geological and thermal loading conditions.

This analysis was based on following assumptions:

- The ROP of a drill rig does not change with the bore depth (i.e., constant penetration speed along the depth of a vertical bore).

- A coaxial heat exchanger is about the same price as that of a double U-tube loop.

- TE pipe is the same price as the standard HDPE pipe, and the TE fluid is the same price as standard propylene glycol.

- The cost for designing a bore field was calculated as $10 \%$ of the bare-bone cost of a bore field, which accounts for only the labor, material, and equipment costs for implementing a bore field. In addition, the profit and overhead (including contingency) of the bore field installation were accounted for as $20 \%$ of the sum of the bare-bone installation cost and the bore field design cost.

The following are the main findings from the cost reduction potential analysis:

- Among the investigated improvements in borehole heat transfer, TE grout and double U-tube loop are the most effective measures for reducing the required bore length for satisfying a given thermal load.

- GTC at a given location determines the magnitude of bore length reduction resulting from a given improvement in VBGHX design. At places with high GTC, more than $60 \%$ reduction in total bore length can be achieved.

- Borehole heat transfer improvement results in moderate (less than 30\%) cost reduction at ground formations with high GTC (e.g., higher than $1.4 \mathrm{Btu} / \mathrm{h}-\mathrm{ft}-{ }^{\circ} \mathrm{F}$ ); however, it might result in an increase in VBGHX cost at ground formations with low GTC (e.g., less than $0.75 \mathrm{Btu} / \mathrm{h}-\mathrm{ft}-{ }^{\circ} \mathrm{F}$ ).

- For VBGHXs having multiple vertical bores, increasing bore spacing (up to $30 \mathrm{ft}$ ) and bore depth can reduce bore numbers and the required total bore length. It can, therefore, reduce the overall bore field cost by up to $50 \%$. 
- Higher ROP of drilling can shorten drilling time, which reduces the associated labor and equipment cost for installing a BHE. Assuming the price of a drill rig is unchanged, a 25\% increase in ROP can result in 6\%-16\% reduction in the installed cost of BHE depending on the ground formation and whether casing is used. However, the cost reduction might become smaller if the higher ROP is achieved with more expensive drill rigs.

Because the best solution for reducing the cost of a VBGHX depends on many factors, further study is recommended to develop guidelines on how to best use different technologies to effectively reduce the cost of VBGHXs and result in minimized cost of GHP systems.

The following research and development is recommended to reduce the cost of VBGHXs: (1) improve mobility and automation of drilling machines to reduce the time and labor needed for drilling vertical boreholes; (2) develop new GHXs that require less drilling of vertical bores or that can be implemented with low drilling costs; (3) develop a standard testing method for evaluating the performance of new heat exchanger loops, and (4) expand the capabilities of a sizing and simulation program to optimize borehole field design so that the required total bore length of a bore field can be reduced while satisfying thermal demands.

\section{REFERENCES}

Acuña, J. 2016. “Deep Borehole Heat Exchangers for Ground-Source Heat Pumps.” Retrieved 7/15/2016, from http://effsysexpand.se/p19-djupa-borrhalsvarmevaxlare-for-bergvarmepumpar/.

ANSI (American National Standards Institute). 2016. Design and installation of ground source heat pump systems for commercial and residential buildings. ANSI/CSA C448 Series-16.

Battocletti, E. C., and W. E. Glassley. 2013. Measuring the Costs and Benefits of Nationwide Geothermal Heat Pump Deployment. United States. doi:10.2172/1186828. Database available online at https://gdr.openei.org/submissions/180.

Bayer P., M. de Paly, M. Beck 2014. Strategic optimization of borehole heat exchanger field for seasonal geothermal heating and cooling, Applied Energy 136 (2014) 445-453

Bottarelli, M., et al. 2013. "Ground-source heat pumps: benefits of using phase change materials." Sustainable Energy Storage in Buildings Conference, 29-33. Trinity College, Dublin, Ireland.

Boughhanmi, H., et al. 2015. "Thermal Performance of a Conic Basket Heat Exchanger Coupled to a Geothermal Heat Pump for Greenhouse Cooling Under Tunisian Climate." Energy and Building 104: 8796.

Cordts, D. 2011. "The GeoColumn ${ }^{\mathrm{TM}}$ Geothermal Heat Pump Company." Geothermal Energy Workshop. April 13, 2011.

Hammock, C and S. Sullens. 2017. Coupling Geothermal Heat Pumps with Underground Seasonal Thermal Energy Storage (Final Report). ESTCP Project EW-201135, March 2017

Cushman, H. and D. Tartakovsky. 2017. The Handbook of Groundwater Engineering. Boca Raton, FL: CRC Press, Taylor \& Francis Group. 
Eskilson, P. 1987. Thermal analysis of heat extraction boreholes. Doctoral thesis, University of Lund, Sweden.

Finger, J., et al. 1997. Systems study of drilling for installation of geothermal heat pumps. SAND97-2132. Albuquerque, New Mexico: Sandia National Laboratories.

Foremost Industries, LP. 2003. Benefits of Dual Rotary Drilling in Unstable Overburden Formations. http://www.drillingspareskenya.com/images/dr_benefits.pdf.

Gehlin, S. 2016. "Borehole Thermal Energy Storage." In Advances in Ground-Source Heat Pump Systems. Amsterdam: Woodhead Publishing: 295-327.

Jensen, R. 2014. "TWISTER High Efficiency Geothermal Heat Exchanger.” 2014 Annual Conference of International Ground Source Heat Pump Association. Baltimore, Maryland.

IGSHPA. 2000. Grouting for Vertical Geothermal Heat Pump Systems Engineering Design and Field Procedures Manual. ISBN: 0-929974-06-9.

Gaurina-Medimurec, N. 2005. “Casing Drilling Technology.” Rud.-geol.-naft. zb., Vol. 17.

Geothermal Heat Pump Consortium (GHPC). 2013. National Certification Standard for Ground Source Heat Pump Personnel. 1050 Connecticut Avenue NW Suite 1000, Washington, DC 20036.

Gonthier, S. 2012. "GEOPERFORMX Thermally Enhanced Pipe for Geothermal Applications.” 2012 Annual Conference of International Ground Source Heat Pump Association. October 4th, 2012.

Kahraman, S., N. Bilgin, C. Feridunoglu. 2003. "Dominant rock properties affecting the penetration rate of percussive drills.” International Journal of Rock Mechanics \& Mining Sciences 40: 711-723.

Kahraman, S. 2003. "Performance analysis of drilling machines using rock modulus ratio." The Journal of The South African Institute of Mining and Metallurgy, 515-522.

Kivade, S., C. S. Murthy, and H. Vardhan. 2015. "Experimental Investigations on Penetration Rate of Percussive Drill." Procedia Earth and Planetary Science 11: 89-99.

Kussaiynov, K., N. Shuyushbayeva, G. Shaimerdenova, and G. Bulkairova, and D. Ospanova. 2014. Electro-hydraulic pulse technology of drilling wells for installation of heat exchange elements of heat pumps. Life Science Journal 2014; 11(11s), pp 469-472

Liu, X., and J. Munk. 2013. Field Test and Evaluation of Residential Ground Source Heat Pump Systems Using Emerging Ground Coupling Technologies. ORNL/TM-2013/39. Oak Ridge, Tennessee: Oak Ridge National Laboratory.

Liu, X., P. Hughes, K. McCabe, J. Spitler, and L. Southard. 2018. GeoVision Analysis: Thermal Applications Task Force Report-Geothermal Heat Pumps. ORNL/TM-2017/502. Oak Ridge, Tennessee: Oak Ridge National Laboratory.

Lund, J. W. 2001. "Geothermal heat pumps-An overview." Geo-Heat Center Quarterly Bulletin 22(1): $1-2$.

National Ground Water Association (NGWA). 2015. "Understanding Hydrogeology and Its Impact on Large-Scale Geothermal Heat Pump Systems.” NGWA Press. 
National Driller (ND). 2017. Online database of used drilling rigs for sale.

https://www.nationaldriller.com/classifieds/category/2758-all-rigs.

NREL (National Renewable Energy Laboratory). 2011. US Department of Energy Commercial Reference Building Models of the National Building Stock. NREL/TP-5500-46861. Golden: Colorado: National Renewable Energy Laboratory.

New York State Energy Research and Development Authority (NYSERDA). 2017. Renewable Heating and Cooling Policy Framework: Options to Advance Industry Growth and Markets in New York. February, 7, 2017 (available at https://www.nyserda.ny.gov/-/media/Files/.../PPSER/NYSERDA/RHCFramework.pdf accessed on 8/31/2018)

Palm, B., and M. Ignatowicz. 2016. "Adsorption Corrosion Inhibitors, Green Corrosion Inhibitors and Alternative Secondary Fluids for Indirect Systems.” Retrieved 7/15/2016, from http://effsysexpand.se/p03-adsorberande-korrosionsinhibitorer/.

Pierce, K. G., B. J. Livesay, and J. T. Finger. 1996. Advanced Drilling Systems Study. SAND95-0331. Albuquerque, New Mexico: Sandia National Laboratories.

Qi, D., et al. 2016. "Numerical investigation on thermal performance of ground heat exchangers using phase change materials as grout for ground source heat pump system." Applied Thermal Engineering 106, $1023-1032$.

Rossi. E., 2017. "Exploration of deep geothermal resources: Towards a new drilling technology." Institute of Geophysics, ETH, Zürich.

Sachs, H. 2002. Geology and drilling methods for ground-source heat pump installations. ASHRAE, Atlanta.

Sun Machinery Corp. (SMC). 2017. Online database of used drilling rigs for sale.

http://www.sunmachinery.com/.

Spitler, J. 2000. "GLHEPRO-A design tool for commercial building ground loop heat exchangers."

Proceedings of the fourth international heat pumps in cold climates conference.

The California Environmental Protection Agency (TCEPA). 2013. Drilling, Logging, and Sampling at Contaminated Sites. The California Environmental Protection Agency, Department of Toxic Substances Control.

Tiedje, E., and P. Guo. 2014. "Thermal Conductivity of Bentonite Grout Containing Graphite or Chopped Carbon Fibers." Journal of Materials in Civil Engineering 26(7), https://doi.org/10.1061/(ASCE)MT.1943-5533.0000977.

Zacchei, M., 2016. GEOthermal Technology for Economic Cooling and Heating. D7.1 Market Assessment. GEOTeCH. 


\section{APPENDIX A. SURVEY QUESTIONNAIRES}

\section{A Survey for Ground Heat Exchanger Installation $(4 / 6 / 2017)$}

Oak Ridge National Lab (ORNL) is working on a research project to understand the current state-of-theart of ground heat exchanger installation, including methods, installation technologies, and needed equipment and materials. The goal of this study is to identify technology improvements needed to facilitate wider adoption of ground source heat pump systems in both the commercial and residential sectors. This survey is a part of the project and it is to collect information of the typical installation process and associated cost. We will keep your answers to this survey confidential and only report general information (such as the average cost breakdown of a ground heat exchanger in a region) in our study. Please take a few moments to complete and return this survey. Your input is vital to the success of this project and will be greatly appreciated.

\section{Section 1. Information about you and your company}

1. How many years have you been involved with Ground Source Heat Pumps?

2 years or less. 3-5 years. 6 to 10 years. Over 10 years.

2. Which of the following best describes your company type: Electric Cooperative. Electric G\&T. HVAC Contractor. Loop Contractor. Loop and HVAC Contractor. Other (Specify)

3. What is your title and/or job description?

4. How many ground source heat pumps (in cooling tons) has your company installed during the last two years?

\section{Section 2. Information about ground loop}

5. Please indicate the percentage of loop systems you typically install:
a. Straight horizontal?
Less than $10 \%$
$10-25 \%$
26-50\%
b. Horizontal-slinky?
_ Less than $10 \%$
$10-25 \%$
$26-50 \%$
$51-75 \%-76-100 \%$
c. Vertical? _ Less than $10 \%$ $10-25 \%$
$51-75 \%-76-100 \%$
d. Other? Less than $10 \%$ $-10-25 \%-26-50 \%$ $26-50 \%-51-75 \%-76-100 \%$

6. What is the average cost per ton for each type of ground loop (direct cost only)?

\section{Cost to Install Loop (per ton)}

Straight horizontal
Horizontal - Slinky
Vertical
Other

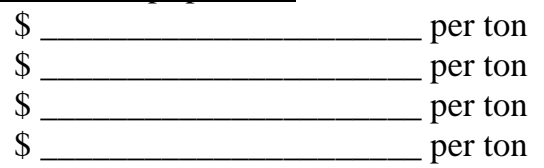

7. Please indicate the percentage of following ground loop piping materials you have installed within the last two years: None

a. High Density Polyethylene (HDPE)?

_ Less than 25\% _ $25-50 \%$ _ $50-75 \%$ _ $75-100 \%$ None

b. Crosslinked polyethylene (PEX)?

_ Less than $25 \%$ _ _ $25-50 \%$ _ _ 50-75\% _ $75-100 \%$

c. Polybutylene (PB)?

_ Less than $25 \%$ _ _ $25-50 \%$ _ $50-75 \%$ _ $75-100 \%$ None 


\begin{tabular}{|c|c|c|c|c|c|}
\hline None & Copper? & __ Less than $25 \%$. & $-25-50 \%$ & $-50-75 \%$ & $-75-100 \%$ \\
\hline None & PVC? & _- Less than $25 \%$. & $-25-50 \%$ & $-50-75 \%$ & $-75-100 \%$ \\
\hline None & Other $\_?$ & _- Less than $25 \%$. & $-25-50 \%$ & $-50-75 \%$ & $-75-100 \%$ \\
\hline
\end{tabular}

8. Please indicate the percentage of following types of ground loop you have installed within the last two years:

\begin{tabular}{|c|c|c|c|c|c|c|}
\hline None & Single U-tube? & Less than $10 \%$. & $-10-25 \%$ & $-25-50 \%$ & $-50-75 \%$ & $-75-100 \%$ \\
\hline None & Double U-tube? & __ Less than $10 \%$. & $-10-25 \%$ & $-25-50 \%$ & $-50-75 \%$ & $-75-100 \%$ \\
\hline None & Co-axial? & _ Less than $10 \%$ & $-10-25 \%$ & $-25-50 \%$ & $-50-75 \%$ & $-75-100 \%$ \\
\hline None & DX? & $\ldots$ Less than $10 \%$ & $-10-25 \%$ & $-25-50 \%$ & $-50-75 \%$ & $-75-100 \%$ \\
\hline None & Other ___ ? & _- Less than $10 \%$. & $-10-25 \%$ & $-25-50 \%$ & $-50-75 \%$ & $-75-100 \%$ \\
\hline
\end{tabular}

9. What is the approximate cost per foot of ground loop piping material? Please indicate the piping material in your answers.
$3 / 4 " ? \quad \$$
$1 " ? \quad \$$
$\$$
$1-1 / 4 " ? \$$
$1-1 / 2 " ? \$$

10. What is the average length per vertical borehole or horizontal trench? ft.

12. What is the approximate cost per foot of horizontal header piping?
$1 "$ ? \$ $\quad \$$
$1-1 / 4 " ? \$$
$1-1 / 2 " ?$
$\$$
2"?
$\$$

13. Please detail the following information for boreholes and trenches:

How many feet trenches do you dig in a working day on average?

What is the approximate price of digging a trench per foot?

$\$$

How many feet vertical boreholes do you drill in a working day on average?

What is the average borehole depth?

What is the average borehole diameter?

$\mathrm{ft} . / \mathrm{hr}$.

What is the average rate of penetration?

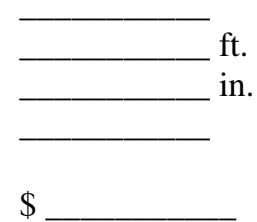

\section{Section 3. Information about drilling and grouting}

14. Please indicate the percentage of drilling rigs used for the past two years:

A. Cable Tool

__ Less than $10 \%$ of the time.

$10-25 \%$ of the time. - $50-75 \%$ of the time. _ $75-100 \%$ of the time. _ $\quad$ None of the time. — $50-75 \%$ of the time. _ $75-100 \%$ of the time. _ None of the time.

$25-50 \%$ of the time.

B. Mud Rotary
C. Reverse Rotary
__ Less than $10 \%$ of the time. _ $10-25 \%$ of the time. _ _ $25-50 \%$ of the time. D. Air Rotary _ $50-75 \%$ of the time. _ $75-100 \%$ of the time. __ None of the time.

__ Less than $10 \%$ of the time. __ $10-25 \%$ of the time. __ $25-50 \%$ of the time. $50-75 \%$ of the time. _ $75-100 \%$ of the time. _ None of the time. 
E. Downhole Hammer

Less than $10 \%$ of the time.

Less than $10 \%$ of the time. $50-75 \%$ of the time.
$10-25 \%$ of the time.

$75-100 \%$ of the time.
$25-50 \%$ of the time.

None of the time.

15. What type of drill bits has your company typically used to drill boreholes?

16. What are the sizes and approximate cost of the drill bits most commonly used?

\begin{tabular}{ll}
$\underline{\text { Size }}$ in & $\$$ \\
\hline in & $\$$ \\
\hline in & $\$$
\end{tabular}

17. Do you own or rent the equipment needed? __ Own _ Rent.

(IF Own) What are the approximate costs for the equipment?

$\begin{array}{ll}\text { Labor } & \$ \\ \text { Rig } & \$ \\ \text { Water Truck } & \$ \\ \text { Grout Machine } & \$ \\ \text { Backhoe } & \$ \\ \text { Other } & \$ \\ \text { Storage } & \$ \\ \text { Maintenance } & \end{array}$

(IF Rent) What are the approximate rental costs per hour for the equipment?

$\begin{array}{ll}\text { Rig } & \$ \\ \text { Water Truck } & \$ \\ \text { Grout Machine } & \$ \\ \text { Backhoe } & \$ \\ \text { Other } & \$\end{array}$

18. What is the approximate cost to move the equipment? \$

20. What is the approximate cost for fuel? \$

20. What is the approximate cost for labor? \$

21. How many people, on average, are onsite to help with installation?

22. What are the approximate costs for the drill mud and grouting?

Drill Mud

Drill Mud Additives

Grout

Tremie Pipe for Grouting Borehole

Water

$\$$
$\$$
$\$$

23. What type of grout do you use on average?

24. What type of mud do you use on average?

25. Please detail the types of geological formations you encounter during drilling (sand, limestone, shale, etc.)

26. Do you charge varying rates for drilling boreholes in different geological formations? __ Yes. __ No. (IF YES) Please indicate two or three of the most common geological formations and the cost of drilling: 


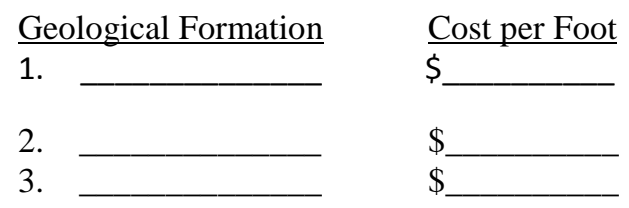

\section{Section 4. Information about other costs}

27. What is the approximate percentage of fitting (e.g., fusion) cost to total horizontal piping cost? Less than $10 \%$. $10-25 \%$. $26-50 \%$. $51-75 \%$ $76-100 \%$

28. What is the approximate cost for a site survey? \$

29. What is the approximate cost for flushing?

$\$$

30. What is the approximate cost for the hydrostatic test (leakage detection) of the ground loop? \$

31. What is the approximate cost for restoring a site after installing a vertical loop?

32. What is the approximate cost for restoring a site after installing a horizontal loop?

33. How long does it take to restore a site on average? hr.

34. What are the approximate administrative costs for the following items?

Company Shared Cost
Bid Plans
Inspection Fees
Permits
Fines and Penalties
Ownership
Repairs

$\$$

35. What kind of Warranty does your company offer?

36. What is the average total ground loop cost per installed cooling ton (including both direct and indirect cost)? $\$$

\section{Section 5. Your comments}

37. Do you have any suggestions you would like to make on how to reduce ground source heat pump costs? 


\section{List of received comments:}

1. Train, use, and promote well water systems - less cost/greater efficiencies

2. Automatic Slinky

3. $25 \%$ of all federal work cost is insurance/bond/Davis Bacon Wag and the biggest retainage which can last for years. Find ways to reduce these and the cost could go down $30 \%$

4. Better load calculations, improve outside air strategies \& control sequence of operation, which results in lower GSHP \& GHX costs, not to mention lower operating costs. More engineers need to understand how to pre-design a GHX first before assuming parameters for a TC test, to optimize GHX parameters to best fit site, mechanical basis of design and controls. More engineers need to understand GHX contractor assets and capabilities to optimize loop design, \& also be more involved with site quality control during loop installation. Doing so will help with better more cost effective GHX design.

5. Boreholes 300' or less are the most cost-effective depth. The cost increases over these depths.

6. The drilling rigs are very expensive, access to job sites and landscape is expensive. All of the little things add up. I would like to talk to someone in more detail. I am passionate about geothermal and would like to help.

7. Perhaps CT wasn't a good choice for your survey. We have a verity of bedrock and glacial till containing large boulders. In addition to that, our bedrock contains large sources of water that further complicate the drill process and we have a moral obligation to protect ground water. In CT, we mud rotor to bedrock, hammer to $500 \mathrm{ft}$. It's the only way, no other drills work in CT. 



\section{APPENDIX B. A BRIEF DESCRIPTION OF MAJOR TASKS FOR INSTALLING GROUND HEAT EXCHANGERS}

Site survey is for evaluating the potential and suitable ground heat exchangers for a GHP system on a particular site and to develop critical site data for design purposes. It proceeds with progressive assessment against a pre-approved set of decision-making criteria. It relies on professional judgment as well as field observations, testing, analysis, and comparative evaluation for the thermal and hydrogeological properties of the site based on local drilling logs (or in-situ test for ground thermal properties) and other published data.

Vertical bore drilling is for construction of loop wells for vertical ground heat exchangers, providing a closed-loop system for heat exchange with the earth while protecting surrounding groundwater resources from contamination. This task includes planning, execution and management of all phases of any vertical loop installation. This task should comply with applicable regulations governing the drilling process, as well as avoid damage with buried utilities and other underground structures.

Horizontal directional drilling is for construction of horizontally bored ground heat exchangers, providing a closed-loop system for heat exchange with the earth while protecting surrounding groundwater resources from contamination. It involves planning, execution and management of all phases of horizontally bored ground heat exchanger installation. This task should comply with applicable regulations governing the drilling process, as well as avoid damage with buried utilities and other underground structures.

Grouting is for mixing and placement of grout through a tremie pipe to surround the loop assembly in a borehole, which comprises a ground heat exchanger. This task includes mixing grout, in accordance with the manufacturer's instructions, in an appropriate mechanical mixer in accordance with the grout manufacturer's instructions, and ensures the proper placement of the grout from the bottom to the top of the borehole. It also includes checking the grouted boreholes for subsidence of the grout and adding additional grout to the bore hole if the grout level is not within specified limits of the top of the hole. This task is essential to protect the public safety of drinking water supplies and to ensure the proper performance of the ground heat exchanger.

Casing is a procedure to aid in the drilling process by stabilizing the borehole when drilling in unstable geologies, or making a given borehole more stable than it would have been otherwise. The way in which casing is typically implemented is that, after a certain depth is reached when drilling, the drill pipes are pulled out, so the casing pipe can be inserted into the borehole, with the gap between the casing pipe and the borehole wall being sealed with grout. Casing pipe is typically made with steel or PVC, depending on factors like local geology type and presence of groundwater.

Horizontal piping is for the connection between the ground heat exchanger and mechanical equipment. This task includes the installation of a horizontal trenched ground loop heat exchanger or the connecting (looping or headering) of a vertically drilled or horizontally bored ground loop heat exchanger. The primary focus of this task is the process of joining of approved loop assembly materials (for example, heat fusion of high density polyethylene pipe (HDPE)) and performing required tests to ensure the integrity of the final product.

Flushing/purging and charging is for removing air and debris from the closed-loop piping of a ground heat exchanger after it is installed under the ground and connected to the heat pump. It also includes filling in the closed-loop piping with heat transfer fluid (e.g., water or aqueous solution of antifreeze) specified in the design. 
Hydrostatic testing is to pressurize the closed-loop piping of a ground heat exchanger and its associated piping to check any leak on it.

Site restoration involves landscaping and contouring the property as closely as possible to predrilling conditions. 


\section{APPENDIX C. SUMMARY OF SURVEY RESULTS OF NORMALIZED COST OF VBGHX ${ }^{a}$}

\begin{tabular}{|c|c|c|c|}
\hline Loop Type & Census Region & Dominant Geology & Price $(\$ / f t)$ \\
\hline \multirow{14}{*}{ Vertical Drilled } & National & Unknown & 14.00 \\
\hline & \multirow{4}{*}{ Northeast } & Hard rock & 16.50 \\
\hline & & Soft rock & 15.00 \\
\hline & & Sand & 23.00 \\
\hline & & Other or unknown & 17.00 \\
\hline & \multirow{4}{*}{ Midwest } & Hard rock & 13.00 \\
\hline & & Soft rock & 14.00 \\
\hline & & Clay & 10.00 \\
\hline & & Other or unknown & 12.00 \\
\hline & \multirow{4}{*}{ South } & Hard rock & 16.00 \\
\hline & & Clay & 8.00 \\
\hline & & Sand & 7.00 \\
\hline & & Other or unknown & 14.50 \\
\hline & West & Any & 14.00 \\
\hline
\end{tabular}

